\title{
Chemically Modified Metal Oxide Nanostructures Electrodes for Sensing and Energy Conversion
}

\author{
Sami Abdelfatah Ibrahim Elhag
}

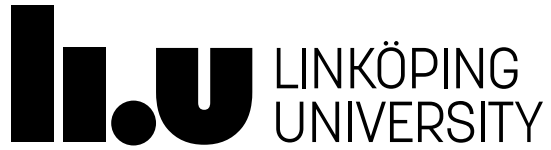

Physical Electronics and Nanotechnology Division Department of Science and Technology (ITN) Campus Norrköping, Linköping University SE-60174 Norrköping Sweden 
Copyright @ 2017 by Sami Elhag samielhaj_60@hotmail.com samielhaj@60gmail.com sami.elhag@liu.se Institution: ITN : Fysik och Elektroteknik ISBN: 978-91-7685-590-4

ISSN 0345-7524 
To My Family and the Soul of My Father 


\title{
Chemically Modified Metal Oxide Nanostructures Electrodes for Sensing and Energy Conversion
}

\author{
Sami Elhag
}

\begin{abstract}
The goal of this thesis is the development of scalable, low cost synthesis of metal oxide nanostructures based electrodes and to correlate the chemical modifications with their energy conversion performance. Methods in energy conversion in this thesis have focused on two aspects; a potentiometric chemical sensor was used to determine the analytical concentration of some components of the analyte solution such as dopamine, glucose and glutamate molecules. The second aspect is to fabricate a photoelectrochemical (PEC) cell. The biocompatibility, excellent electro-catalytic activities and fast electron transfer kinetics accompanied with a high surface area to volume ratio; are properties of some metal oxide nanostructures that of a potential for their use in energy conversion. Furthermore, metal oxide nanostructures based electrode can effectively be improved by the physical or a chemical modification of electrode surface. Among these metal oxide nanostructures are cobalt oxide $\left(\mathrm{Co}_{3} \mathrm{O}_{4}\right)$, zinc oxide $(\mathrm{ZnO})$ and bismuth zinc vanadate $\left(\mathrm{BiZn}_{2} \mathrm{VO}_{6}\right)$ have all been studied in this thesis. Metal oxide nanostructures based electrodes are fabricated on gold-coated glass substrate by low temperature $\left(<100{ }^{\circ} \mathrm{C}\right)$ wetchemical approach. X-ray diffraction, $\mathrm{x}$-ray photoelectron spectroscopy and scanning electron microscopy were used to characterize the electrodes while ultraviolet-visible absorption and photoluminescence were used to investigate the optical properties of the nanostructures. The resultant modified electrodes were tested for their performance as chemical sensors and for their efficiency in PEC activities. Efficient chemically modified electrodes were demonstrated through doping with organic additives like surfactants. The organic additives are showing a crucial role in the growth process of metal oxide nanocrystals and hence can be used to control the morphology. These organic additives act also as impurities that would significantly change the conductivity of the electrodes. However, no organic additives dependence was observed to modify the crystallographic structure. The findings in this thesis indicate the importance of the use of controlled nanostructures morphology for developing efficient functional materials.
\end{abstract}

Key words: Metal oxide nanostructures, mixed metal oxide nano-compound, low temperature wet-chemical growth, chemically modified electrode, doping, surfactant, chemical sensor, potentiometric sensor and photo-electrochemical activity. 


\title{
List of included papers
}

\author{
Paper I \\ Incorporating beta-cyclodextrin with ZnO nanorods: a potentiometric strategy for \\ selectivity and detection of dopamine \\ Sami Elhag, Zafar H. Ibupoto, Omer Nur and Magnus Willander, Sensors, 2014, 14, 1654.
}

My contribution: All experimental work. Wrote a large part of the first draft of the manuscript.

\section{Paper II}

Habit-modifying additives and their morphological consequences on photoluminescence and glucose sensing properties of $\mathrm{ZnO}$ nanostructures, grown via aqueous chemical synthesis

Sami Elhag, Zafar H. Ibupoto, Volodymyr Khranovskyy, Magnus Willander and Omer Nur, Vacuum, 2015, 116, 21.

My contribution: Design of the growth experiments. I performed all measurements except the PL measurement. I analyzed the data and wrote the first draft of the manuscript.

\section{Paper III}

Effect of urea on the morphology of $\mathrm{Co}_{3} \mathrm{O}_{4}$ nanostructures and their application for potentiometric glucose biosensor

Zafar H. Ibupoto, Sami Elhag, Omer Nur, and Magnus Willander, Electroanalysis, 2014, 26, 1773.

My contribution: Partial contribution to growth design, measurements and analysis of the data, and I wrote the first draft of the manuscript.

\section{Paper IV}

Dopamine wide range detection sensor based on modified $\mathrm{Co}_{3} \mathrm{O}_{4}$ nanowires electrode

Sami Elhag, Zafar H. Ibupoto, Xianjie Liu, Omer Nur and Magnus Willander, Sensors and Actuators B, 2014, 203, 543.

My contribution: Design of the growth and all experimental measurements except the XPS measurement. I analyzed the data and wrote the first draft of the manuscript.

\section{Paper V}

Efficient donor impurities in ZnO nanorods by polyethylene glycol for enhanced optical and glutamate sensing properties

Sami Elhag, Kimleang Khun, Volodymyr Khranovskyy, Xianjie Liu, Magnus Willander and Omer Nur, Sensors, 2016, 16, 222.

My contribution: I designed all growth experiments and performed all the experimental measurements except the XPS and PL measurements. I analyzed the data and wrote the first draft of the manuscript. 


\section{Paper VI}

Low-temperature growth of polyethylene glycol-doped $\mathrm{BiZn}_{2} \mathrm{VO}_{6}$ nanocompounds with enhanced photoelectrochemical properties

Sami Elhag, Daniel Tordera, Tymèle Deydier, Jun Lu, Xianjie Liu, Volodymyr Khranovskyy, Lars Hultman, Magnus Willander, Magnus P. Jonsson and Omer Nur, J. Mater. Chem. A, 2017, 5, 1112.

My contribution: I designed all growth experiments and performed all the experimental measurements except the TEM, XPS and PL measurements. I analyzed the data and wrote the first draft of the manuscript.

\section{Related work but not included in the thesis:}

Synthesis of $\mathrm{Co}_{3} \mathrm{O}_{4}$ cotton-like nanostructures for cholesterol biosensor

Sami Elhag, Zafar H. Ibupoto, Omer Nur, and Magnus Willander, Materials, 2015, 8, 149.

Photocatalytic properties of different morphologies of $\mathrm{CuO}$ for the degradation of Congo red organic dye

Azar S, Khani, Zafar H. Ibupoto, Sami Elhag, Omer Nur and Magnus Willander, Ceramics International, 2014 40, 11311.

Fabrication of sensitive potentiometric cholesterol biosensor based on $\mathrm{Co}_{3} \mathrm{O}_{4}$ interconnected nanowires

Zafar H. Ibupoto, Sami Elhag, Omer Nur, and Magnus Willander, Electroanalysis, 2014, 26, 1928.

Supramolecules-assisted ZnO nanostructures growth and their UV photodetector application

Kimleang Khun, Sami Elhag, Zafar H. Ibupoto, Volodymyr Khranovskyy, Omer Nur and Magnus Willander, Solid State Sciences, 2015, 41, 14.

\section{Conference articles}

Comparison between different metal oxide nanostructures and nanocomposites for sensing, energy generation and energy harvesting Magnus Willander, Hatim Alnoor, Sami Elhag, Zafar H. Ibupotob, Eman S. Nour, and Omer Nur, Proceedings of SPIE, Oxide-based materials and devices, 2016, Volume 9749.

Zinc oxide nanostructures and its nano-compounds for efficient visible light photocatalytic processes

Rania E. Adam, Hatim Alnoor, Sami Elhag, Omer Nur and Magnus Willander Proceedings of SPIE, Oxide-based materials and devices, submitted, 2017. 


\section{Acknowledgment}

First, I want to express my gratitude to Professor Dr Magnus Willander and Associate Professor Omer Nour for giving me the opportunity to perform my PhD study at the Physical Electronics and Nanotechnology group. I would like to thank my supervisor Associate Professor Omer Nour, you have been a tremendous mentor for me. I would like to thank you for encouraging me and for allowing me to grow as a scientist and a researcher. Your advice on both research as well as on my career have been priceless. My warmest gratitude to his wife Amel who always strengthened my morale by standing by me in all situations. I would like to express my gratitude to my co-supervisor Professor $\mathrm{Dr}$ Magnus Willander. Under your guidance and encouragement, I successfully surpassed many difficulties and learned a lot from you since I came to know you in 2006. Thank you very much for giving me this opportunity.

I express my deepest gratitude to all my co-authors who shared with me the stressful times and supported me with their knowledge. I am also thankful to our research administrator Ann-Christin Norén for her kind administrative help and cooperation. I am also thankful to our research engineer Lars Gustavsson for his technical support and friendly cooperation. I am thankful to the present and previous group member's for their support, best wishes and unforgettable times we spent together in Norrköping. I am thankful to both Linköping University and the Higher Education and Scientific Research, Khartoum-Sudan for financial support.

A special thanks to my family. Words cannot express how grateful I am to my mother for all of the sacrifices that she made in support of my family and me. Your prayer for me was what sustained me this far. I would also like to thank my sister and all of my brothers specially my brother Amar who supported me a lot during this journey. I would like to extend my appreciation to those people, who have helped and supported the study presented in this work, all my friends in and out of Sweden. At the end, I would like express my great appreciation to my beloved wife Dina who spent sleepless nights in support of me. 


\section{List of abbreviations}

\begin{tabular}{|c|c|}
\hline Abbreviation & Word or Phrase \\
\hline ISE & Ion Selective Electrode \\
\hline IEP & Isoelectric Point \\
\hline $\mathrm{COx}$ & Cholesterol Oxidase \\
\hline GOx & Glucose Oxidase \\
\hline $\mathrm{ZnO}$ & Zinc Oxide \\
\hline $\mathrm{Co}_{3} \mathrm{O}_{4}$ & Cobalt Oxide \\
\hline ACG & ACG Aqueous Chemical Growth \\
\hline $\mathrm{BiVO}_{4}$ & Bismuth Vanadate \\
\hline $\mathrm{BiZn}_{2} \mathrm{VO}_{6}$ & Bismuth Zinc Vanadate \\
\hline NCs & Nanocompounds \\
\hline NBs & Nanobelts \\
\hline NRs & Nanorods \\
\hline SEM & Scanning Electron Microscope \\
\hline TEM & Transmission Electron Microscopy \\
\hline XRD & X-ray Diffraction \\
\hline XPS & X-ray Photoelectron Spectroscopy \\
\hline PL & Photoluminescence \\
\hline $\mathrm{pH}$ & Potential of Hydrogen \\
\hline JCPDS & Joint Committee on Powder Diffraction Standards \\
\hline HMT & HexaMethyleneTetramine \\
\hline SDS & Sodium Dodecyl Sulfate \\
\hline SDBS & Sodium Dodecyl Benzene Sulfonate \\
\hline NaPTS & Sodium $P$-Toluenesulfonate \\
\hline CTAB & Cetyl Trimethyl Ammonium Bromide \\
\hline PEG & Polyethylene Glycol \\
\hline PEC & Photoelectrochemical \\
\hline PBS & Phosphate Buffered Saline \\
\hline $\mathrm{Ag} / \mathrm{AgCl}$ & Silver/Silver Chloride \\
\hline LOD & Limit of Detection \\
\hline
\end{tabular}




\section{List of figures}

Figure 1.1: (a) Schematic diagram of a chemical sensor and (b) proposed $\mathrm{ZnO}$ nanorods based modified chemical electrode.

Figure 2. 1: (a) The wurtzite crystal structure of $\mathrm{ZnO}$ and (b) the growth habit of the $\mathrm{ZnO}$ crystal.54,55

Figure 2. 2: (a) The hydrophobic part is interacting more strongly with oil drop than with water and (b) PEG with abundant hydrogen.

Figure 3. 1:(a) Schematic diagram for the growth process of ZnO NRs and (b) optical

photograph illustrating the substrates coated with $\mathrm{ZnO}$ seeds when introduced horizontally and

upside-down in the growth solution in normal laboratory glass beaker.

Figure 3. 2: $\mathrm{SEM}$ images of $\mathrm{Co}_{3} \mathrm{O}_{4}$ wire-like nanostructure synthesized with an equimolar concentration $(0.1 \mathrm{M})$ urea and cobalt chloride in $100 \mathrm{~mL}$ deionized water. ${ }^{112}$. .20

Figure 3. 3: (a) Scheme showing the growth process of the $\mathrm{BiZn}_{2} \mathrm{VO}_{6} \mathrm{NCs}$ and (b) SEM image of the $\mathrm{BiZn}_{2} \mathrm{VO}_{6}$ nanostructures grown for $4 \mathrm{~h}$ laying on the top of vertically aligned ordered $\mathrm{ZnO}$ nanostructure. ${ }^{106}$

Figure 3. 4: Illustration of the fabrication of modified electrodes: spin coating of seed layer on Au coated glass, growth of the nanostructures, immobilization of polymeric membrane by deep coating and proposed mechanism of CME where a DA accumulated. ${ }^{103}$

Figure 3. 5: (a) XRD pattern of ZnO NRs grown on Au-coated glass substrate and (b) the standard card of bulk $\mathrm{ZnO}$.

Figure 3. 6: A digital photograph of the SEM at IFM Department at Linköping University,

Sweden.

Figure 3. 7: (a) TEM image of a $\mathrm{BiZn}_{2} \mathrm{VO}_{6}$ and the inset shows the corresponding selected area electron diffraction (SAED) pattern and (b) EDX mapping showing the Bi, Zn, and V distributions. ${ }^{106}$

Figure 3. 8: Room temperature PL spectra of $\mathrm{BiZn}_{2} \mathrm{VO}_{6} \mathrm{NCs}$ grown on $\mathrm{Au}$ with and without the presences of PEG. 106

Figure 3. 9: UV-Vis. absorption spectrum of $\mathrm{BiZn}_{2} \mathrm{VO}_{6} \mathrm{NCs}$, an absorption peak at around $\sim 482$

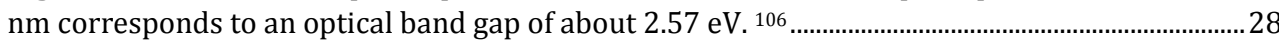

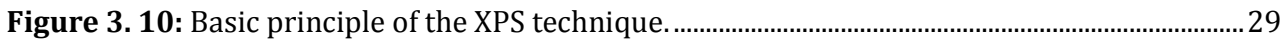

Figure 3. 11: XPS spectra of the as grown $\mathrm{Co}_{3} \mathrm{O}_{4}$ nanostructures on $\mathrm{Au}$ (a) a wide scan, (b) Co 2p, and (c) 01s spectra. ${ }^{103}$

Figure 3. 12: (a) Schematic diagram showing a typical potentiometric glucose biosensor and (b) a photograph of the three-electrode cell setup using a metal oxide nanostructure based CMEs. 31 Figure 4. 1:SEM images of ZnO NRs, (a) as grown and before membrane immobilization, (b) high magnification showing the relatively large aspect ratio of the grown $\mathrm{ZnO} \mathrm{NRs}$, (c) after polymer membrane immobilization and (d) after measurements. ${ }^{102}$

Figure 4. 2: (a) The calibration curve for the presented dopamine chemical sensor giving the linear calibration equation as: $y=49.857 x+246.6$ and (b) the response time measured in 0.01 $\mathrm{mM}$ concentration of dopamine. ${ }^{102}$

Figure 4. 3: $\mathrm{XRD}$ spectra of the $\mathrm{ZnO}$ nanostructures grown with and without the different surfactants. ${ }^{51}$

Figure 4. 4: $\mathrm{SEM}$ images of the as-grown $\mathrm{ZnO}$ nanostructures after adding the surfactants (a) $\mathrm{ZnO}$ :SDBS nano-wurtzite structure, (b) ZnO:SDS nano-foam-like structure, (c) ZnO:NaTPS nanohexagonal-like structure and (d) $\mathrm{ZnO}: \mathrm{CTAB}$ interconnected nano-disk-like structure. ${ }^{51}$

Figure 4. 5:Calibration curve for enzymatic glucose sensors where the $\mathrm{ZnO}$ nanostructures grown with assistance of: (a) CTAB, (b) NaPTS, (c) SDBS, (d) SDS, and (e) ZnO NRs with the standard growth condition i.e. without surfactants. The insets proposed Fermi lelevel position at $\mathrm{ZnO}$ surfaces. (f) Room temperature PL spectra of the product of $\mathrm{ZnO}$ nanostructures. ${ }^{51}$ 
Figure 4. 6: $\mathrm{SEM}$ images of $\mathrm{Co}_{3} \mathrm{O}_{4}$ nano-flowers comprised on nanowires fabricated on the $\mathrm{Au}$ coated glass substrate using different concentrations of urea with a low and high magnification. ${ }^{104}$.

Figure 4. 7: (a) Calibration curve of the fabricated $\mathrm{GOx} / \mathrm{C}_{3} \mathrm{O}_{4}$ nanoflowers/Au electrode to detect glucose molecules for the concentrations from $1 \mu \mathrm{M}$ to $10 \mathrm{mM}$ and the linear calibration equation is: $y=-56,9 x-213,7$ and (b) the selective response of the CMEs in the presence of common interferents at concentrations of $100 \mu \mathrm{L}$ of $100 \mathrm{mM}$ copper, ascorbic acid, uric acid, or urea, respectively. ${ }^{104}$.

Figure 4. 8: $\mathrm{SEM}$ images show the morphology of the $\mathrm{Co}_{3} \mathrm{O}_{4}$ nanostructures grown with a different amount of SDBS (a) 0.1 and (b) $0.05 \mathrm{~g}$ with high and low magnifications and both of them are dense with a high aspect ratio. ${ }^{103}$.

Figure 4. 9: $\mathrm{XRD}$ pattern of the $\mathrm{Co}_{3} \mathrm{O}_{4}$ nanostructures on Au coated glass. ${ }^{103}$.................................. 43

Figure 4. 10: Calibration curve showing the sensitivity and the linear response range of our constructed CMEs. ${ }^{103}$

Figure 4. 11: (a) UV-Vis absorption spectra and (b) plot of $(\alpha E)^{2}$ versus photon energy for the $\mathrm{Co}_{3} \mathrm{O}_{4}$ nanostructures. ${ }^{103}$

Figure 4. 12: SEM images of the ZnO NRs obtained with different concentrations of the PEG. ${ }^{105}$

Figure 4. 13: Schematic represent the four $\mathrm{H}$ sites in $\mathrm{ZnO} 0.141$

Figure 4. 14: Room temperature PL spectra of ZnO NRs grown on Au coated glass with and without presences of PEG showing a sharp UV peak accompanied by two broad visible emission peaks. ${ }^{105}$

Figure 4. 15: (a) UV-Vis absorption spectra of ZnO NRs grown on glass with different amount of PEG and (b) the plot of $(\alpha E)^{2}$ versus photon energy. ${ }^{105}$.

Figure 4. 16:XPS study of the as grown pristine ZnO NRs (solid line) and $0.1 \% \mathrm{w} / \mathrm{v}$ PEG doped

ZnO NRs with $0.1 \%$ w/v PEG on Au (a) 0 1s and, (b) Zn 2p spectra. ${ }^{105}$. 48

Figure 4. 17:(a) Mott-Schottky plots of the pristine and PEG-doped ZnO NRs with different amount in $0.1 \mathrm{M} \mathrm{LiClO}_{4}$ and (b) shows the increases of the capacitances upon the increase of the PEG amount. ${ }^{105}$.

Figure 4. 18:Different properties of a potentiometric chemical sensor using ZnO NRs based CMEs to detect glutamate molecules (a) and (b) shows a comparison calibration curve between the pristine and the PEG-doped ZnO NRs, respectively, (c) the response time and (d) the selective response in the presence of $100 \mu \mathrm{L}$ of $100 \mathrm{mM}$ of common interferents. ${ }^{105}$. .51

Figure 4. 19: SEM of (a) PEG-doped ZnO NRs, (b) PEG-doped ZnO nanobelts, (c) PEG-doped BiZn2V06 NC grown in $4 \mathrm{~h}$ and (d) side view of (c).106.

Figure 4. 20: (a) XRD patterns of $\mathrm{ZnO}$ nanobelts, $\mathrm{PEG}$-doped $\mathrm{ZnO}$ nanobelts, $\mathrm{BiVO}_{4}$, and $\mathrm{PEG}$ doped $\mathrm{BiZn}_{2} \mathrm{VO}_{6}$ nanocompound grown by the low-temperature aqueous solutions hydrothermal synthesis for 4 and $10 \mathrm{~h}$, (b) TEM image of a $\mathrm{BiZn}_{2} \mathrm{VO}_{6}$ and the inset shows the corresponding SAED pattern and (c) EDX mapping. ${ }^{106}$

Figure 4. 21: XPS spectra of (a) and (b) 01s and V2p of the as grown $\mathrm{BiVO}_{4}$ and $\mathrm{BiZn}_{2} \mathrm{VO}_{6} \mathrm{NCs}$ on $\mathrm{Au}$ coated glass, respectively, (c) Bi4f for both the $\mathrm{BiVO}_{4}$ and the $\mathrm{BiZn}_{2} \mathrm{VO}_{6}$ and (d) $\mathrm{Zn} 2 \mathrm{p}$ spectrum for $\mathrm{BiZn}_{2} \mathrm{VO}_{6} \mathrm{NCs}{ }^{106}$.

Figure 4. 22: (a) UV-Vis absorption spectrum of the $\mathrm{BiZn}_{2} \mathrm{VO}_{6}$ grown on glass with the same procedure as that which was used for the Au coated glass (b) the room temperature PL spectra of $\mathrm{BiZn}_{2} \mathrm{VO}_{6} \mathrm{NCs}$ grown on Au with and without the presences of PEG. ${ }^{106}$

Figure 4. 23: (a) Linear sweep voltammetry of the $\mathrm{ZnO}$ nanobelts, PEG-doped $\mathrm{ZnO}$ nanobelts, BiZn2VO6 and PEG-doped $\mathrm{BiZn}_{2} \mathrm{VO}_{6} \mathrm{NCs}$ electrodes in dark and under solar illumination (AM $1.5 \mathrm{G}$ ) and (b) Chronoamperometry I-t curves of all electrodes at an applied voltage of $+0.5 \mathrm{~V}$ with 50 s light on/off cycles. ${ }^{106}$ 


\section{Table of contents}

Abstract

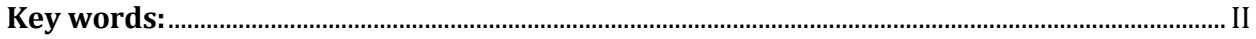

List of included papers ……...............................................................................................................

Related work but not included in the thesis: ..............................................................................

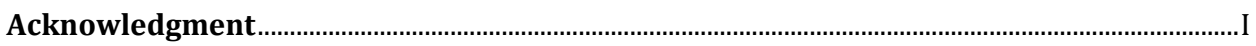

List of abbreviations ........................................................................................................................... II

List of figures........................................................................................................................................

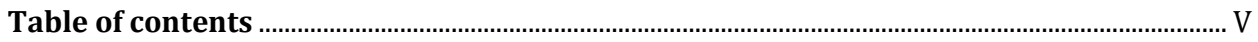

Chapter 1 Background and introduction ..........................................................................................

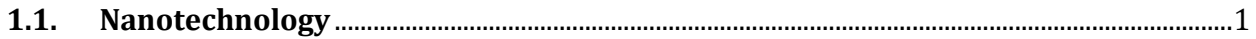

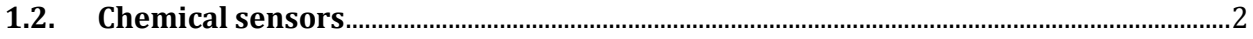

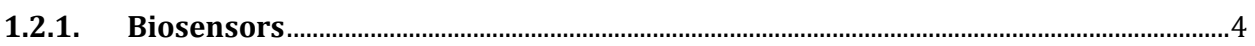

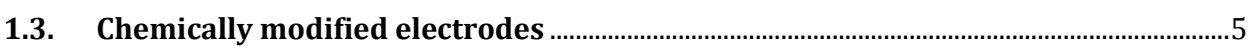

1.4. Metal oxide nanostructures ................................................................................................

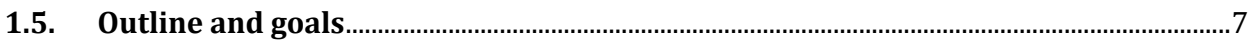

Chapter 2 Properties of some metal oxides.............................................................................................

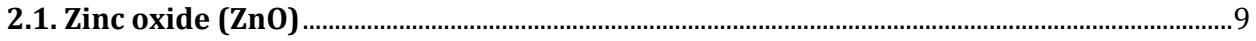

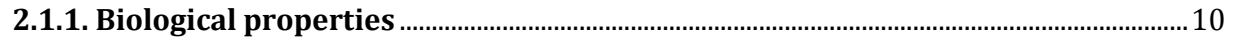

2.1.2. Zinc oxide based sensors.................................................................................................. 11

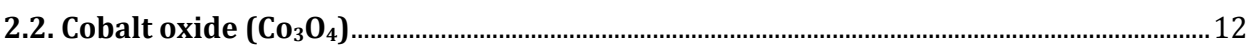

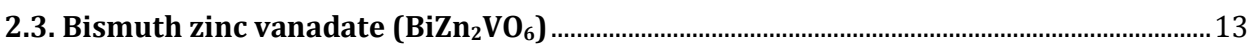

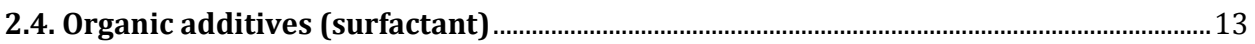

Chapter 3 Synthesis and characterization of the CMEs...................................................................17

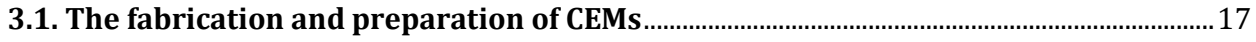

3.1.1. Substrate preparation.................................................................................................. 17

3.1.2. Preparation of $\mathrm{ZnO}, \mathrm{Co}_{3} \mathrm{O}_{4}$ and $\mathrm{BiVO}_{4}$ seed solutions................................................ 18

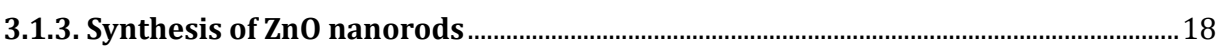

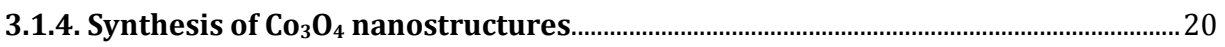

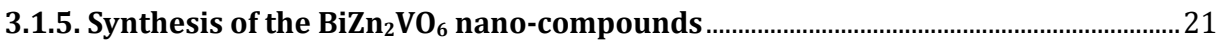

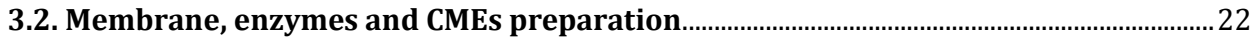

3.2.1. Dopamine membrane preparation and the buffer solution ........................................ 22

3.2.2. Immobilization of glucose oxidase on $\mathrm{ZnO}$ and $\mathrm{Co}_{3} \mathrm{O}_{4}$ nanostructures ...................23

3.2.3. Immobilization of ZnO NRs with L-glutamate oxidase (GluOx, EC 1.4.3.11).........23

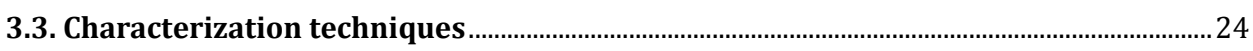

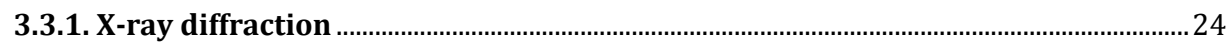




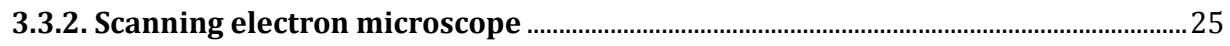

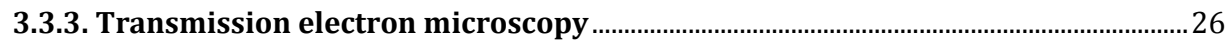

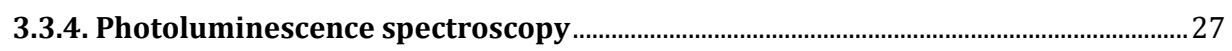

3.3.5. Ultraviolet-visible spectroscopy ……......................................................................... 28

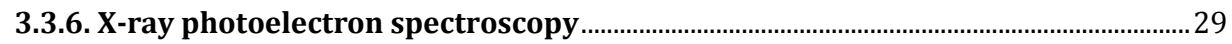

3.3.7. Electrochemical and photoelectrochemical characterizations .................................. 30

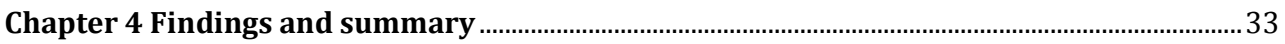

Incorporating $\beta$-cyclodextrin with ZnO nanorods: A potentiometric strategy for selectivity and detection of dopamine (paper I).

Habit-modifying additives and their morphological consequences on photoluminescence and glucose sensing properties of $\mathrm{ZnO}$ nanostructures, grown via aqueous chemical synthesis (paper II)

Effect of urea on the morphology of $\mathrm{Co}_{3} \mathrm{O}_{4}$ nanostructures and their application for potentiometric glucose biosensor (paper III)

Dopamine wide range detection sensor based on modified $\mathrm{Co}_{3} \mathrm{O}_{4}$ nanowires electrode (paper IV).

Efficient donor impurities in ZnO nanorods by polyethylene glycol for enhanced optical and glutamate sensing properties (paper $\mathrm{V}$ )

Low-temperature growth of polyethylene glycol-doped $\mathrm{BiZn}_{2} \mathrm{VO}_{6}$ nano-compounds with enhanced photoelectrochemical properties (paper VI)

Chapter 5 Conclusion and future prospects …….............................................................................5

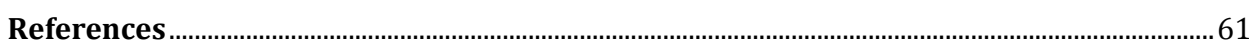




\section{Chapter 1 Background and introduction}

\subsection{Nanotechnology}

The term nanotechnology ${ }^{1,2}$ comes from the combination of the Greek numerical prefix nano meaning one billionth used primarily with the metric system i.e. $\left(10^{-9} \mathrm{~m}\right)$ and the word technology. Nanotechnology is "the construction and utilization of functional structures with at least one characteristic dimension measured in nanometers". ${ }^{3}$ Despite the fact that nanotechnology has appeared only recently. However, in 1959 Nobel laureate physicist Richard Feynman first described nanotechnology while he did not named this new research filed. He suggested "nanotechnology" during a famous speech entitled "There is Plenty of Room at the Bottom" at an American Physical Society meeting in Caltech. Feynman had envisioned and described the potential that can be gained when manipulating and controlling matter at small scale. ${ }^{4}$ In 1974, the term nanotechnology was introduced and defined by the Scientist Norio Taniguchi, Tokyo Science University in a conference paper as "mainly consists of the processing, separation, consolidation and deformation of materials by one atom or by one molecule".1,5 In 1981, Nobel laureate physicist Gerd Binning and Heinrich Rohrer have developed an instrument for imaging atoms and molecules on surfaces called scanning tunneling microscope (STM). ${ }^{6,7}$ After a while, in 1985 fullerenes have been discovered by Nobel laureates in chemistry Harry Kroto, Richard Smalley and Robert Curl.8,9 This was followed by the preparation of needlelike tubes of carbon by the physicist Sumio Iijima, from NEC Corporation in $1991 .{ }^{10}$ Since then the existence of nanoscale-materials have been revolutionizing towards the fabrication of nanodevices and the development of new devices with improved performance relative to that of the same bulk material.

\section{Why do people are interested in nanoscale materials?}

In fact, artificial nanoscale materials have been recognized according to the literature since the fourth century AD. ${ }^{11}$ Romans have used nanoparticles of gold and silver to decorate glasses and cups. The first book on preparing and size measurements of gold nanoparticles during the first decade of the $20^{\text {th }}$ century was written by Nobel laureates in chemistry Richard Adolf Zsigmondy. ${ }^{12,13}$ However, from the mid-1980s the 
progress in nanometer-scale science and technology in general have been developed and has become popular. ${ }^{2}$ At the present time, the impact of nanotechnology is clearly seen everywhere around us and is great support and help in solving many problems such as energy shortage, climate change, fatal diseases and also can create new products that would be appreciated in electronics, medicine and for many other fields.

Functional low dimensional (LD) nanostructures such as nanorods, nanowires, nanotubes and nanobelts are gaining vast consideration in the state of the art applications of the nanotechnology e.g. in electronics, optoelectronics and the medical filed. The most salient attribute of LD nanostructures is the use for both efficient transport of charged carriers combined with optical excitation. These two factors make LD nanostructures promising for a variety of applications. In particular, applications with great potential like the demonstration of photoelectrochemical (PEC) cell using visible light spectrum are becoming hot topic of research at the moment. In addition to the above mentioned advantageous of LD nanostructures, their relatively high surface area to volume ratio and their modified charged carriers transport properties makes quantum confinement effects very sensitive to relatively small perturbations.

\subsection{Chemical sensors}

The sensor field has grown enormously since the first well-known published paper on the oxygen electrode in 1956 by the biochemist Leland C. Clark Jr, who is known as the father of the biosensor concept.14, 15 Further, in 1962, Clark and Lyons introduced the "enzyme electrode," as a new terminology in the field of biosensors. In their published work in which glucose oxidase was entrapped at an oxygen electrode using a dialysis membrane. They found that, as the glucose concentration was increasing the oxygen concentration was decreasing. ${ }^{15,16}$ According to the international union of pure and applied chemistry (IUPAC) nomenclature, "a chemical sensor is a device that transforms chemical information, ranging from the concentration of a specific sample component to total composition analysis into an analytically useful signal". The chemical information, mentioned above, may originate from a chemical reaction of an analyte or from a physical property of the system investigated. ${ }^{17}$ A chemical sensor (schematically shown in Figure 1a) is usually composed of two main parts; the first is the receptor part and the second is the transducer part. In some cases, a third part is included. This third part can be a membrane for selectivity tuning. 
Today, membranes have become an important part of our daily life with constant advances in their preparation technology. ${ }^{18,19}$ Membranes are used in a wide range of applications e.g. for drinking water purification, in food and in drug industries and to separate a specific molecule or substances. Depending on their functional properties, membranes are used for specific application. ${ }^{18}$ It is very common that synthetic membranes are used in research laboratories and in the industry for separation processes, i.e. as a selective material. The selective part of the membrane can be made of polymeric material, ceramics, glass or made of metals. The pressure, concentration, electrical or chemical gradient across the membrane could be the driving force of the transport process. Polymeric membranes are usually made of polymers, function as a selective element that can only pass through a specific chemical species and block others. Hence, these polymeric membranes are a key part of potentiometric sensors. ${ }^{18-20}$ In the receptor part or the selective layer of a sensor which may contains a biological element such as enzymes, antibodies or a chemically selective layer "membrane" that has two important characteristics i.e. semi permeability and the selectivity. Hence, the chemical information is converted to another energy form, which is then detected and measured by the transducer part of the sensor.

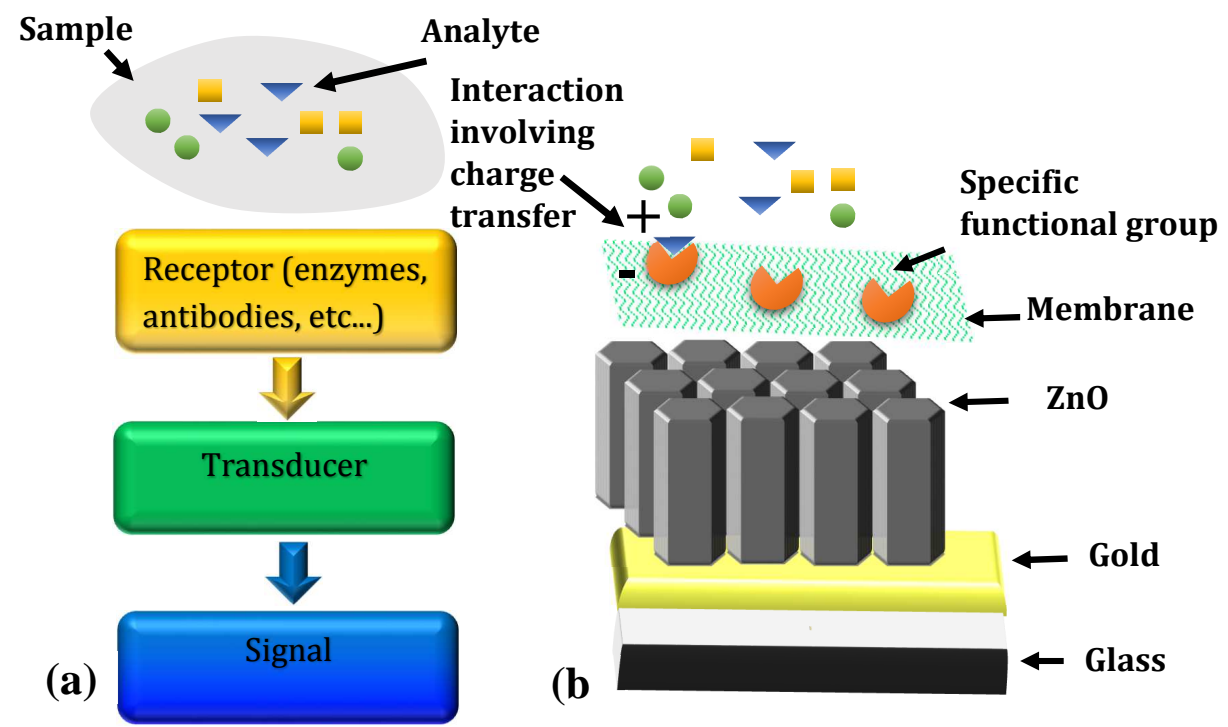

Figure 1.1: (a) Schematic diagram of a chemical sensor and (b) proposed ZnO nanorods based modified chemical electrode. 
The transducer part has the capability of converting the chemical energy into another detectable analytical signal form. ${ }^{17}$ The principle operation of the transducer is usually used to define the class of the chemical sensor to be either optical, electrical or electrochemical etc.... However, the latter and specifically a certain subgroup from it would be considered in this thesis.

Electrochemical devices operate by transforming the interaction between the analyte in question and the electrode into measurable useful signal. This interaction may be stimulated by electric signal or could be due to spontaneous interaction at no stimulating current. ${ }^{17}$ Furthermore, electrochemical sensors can be categorized as, colorimetric, amperometric, conductometric or potentiometric sensors. One of the subgroups is the potentiometric sensor, where the built in potential of the working electrode e.g. ion selective electrode (ISE), a redox electrode or metal/metal oxide electrode, is measured versus a reference electrode, usually silver/silver chloride $(\mathrm{Ag} / \mathrm{AgCl})$ electrode. ${ }^{18-23} \mathrm{It}$ is worth to mention that, biosensors are not categorized as a separate class of sensors due to the fact that their working process is generally the same as that of chemical sensors. ${ }^{20,23}$ In principle the latter have a chemical or molecular target to be measured and biosensors target a biomolecule via receptor (biological sensing element) of interest for measurement.

\subsubsection{Biosensors}

Generally, there are two categories of biosensors, ${ }^{23}$ the first is affinity biosensors while the second is catalytic biosensors. Affinity biosensors operation is based on the irreversible and non-catalytic binding of molecules by the receptor element. Biological analytes like antibodies, nucleic acids, dyes, cell membrane receptors and other specific biological binding elements are typical examples of bio-affinity agents. By utilizing affinity interactions, biosensors are able to separate individual or other selected compounds in any complex mixture of biomolecules and this separation can either be based on chemical or biological activity. The second class of biosensor, i.e. the catalytic biosensors are operating based on catalytic reactions. Here, for catalytic biosensors, biocatalysts such as enzyme, which is an element, that recognize and bind to the analyte in question. Then, this binding is followed by catalytic reactions, which then converts the undetectable signal to a detectable signal like e.g. electrical signal. 


\subsection{Chemically modified electrodes}

Previously, metals and semiconductors have been used a lot as sensing layer. In 1952, Brattain and Bardeen reported that the potential of the semiconductor germanium (Ge) can be changed in different gaseous ambients. ${ }^{24}$ Seyama et al., used metal oxides such as zinc oxide (ZnO) in gas sensors for first time in 1962.25 Later in 1967, Shaver demonstrated that the sensitivity of tungsten oxide $\left(\mathrm{WO}_{3}\right)$ could be enhanced by "activation" through the deposition of a small amount of platinum. ${ }^{26}$ In 1969, also biosensors have witnessed a progress where Guibault and Montalvo reported the first sensing of urea using the potentiometric approach based on enzyme modification of the surface of Beckman cationic electrode, which is responsive to ammonium ions. ${ }^{27}$ However, the term chemically modified electrodes (CMEs) was introduced by Moses et. al., in their published work in 1975 in which tin oxide $\left(\mathrm{SnO}_{2}\right)$ was modified by a functional group to be more chemically predictive electrode. ${ }^{28,29}$ The international union of pure and applied chemistry defined CMEs as "the electrodes made of a conducting or semiconducting material which is coated with a selected monomolecular, multimolecular, ionic or polymeric film of a chemical modifier and that by means of faradaic (charge-transfer) reactions or interfacial potential differences (no net charge transfer) exhibits chemical, electrochemical and/or optical properties of the film".30 Briefly, To suit a specific purpose of detection, CMEs surface is modified according to the needed purpose. Usually, for the direct oxidation to be achieved at bare electrode surfaces large over potentials are required. ${ }^{31}$ In addition to that, modification on the electrode surface may have fundamental demands that include selectivity and/or electron-transfer creation or catalysis of slow electrode reactions. $^{32}$ Therefore, CMEs have been used in several applications such as electroanalysis, ${ }^{33}$ molecular electronics, ${ }^{34}$ electrochromic display devices, ${ }^{35}$ chemical sensing ${ }^{36}$ and solar energy conversion. ${ }^{37}$

The sensor electrode size requirements make the CMEs a highly desirable option ${ }^{23}$ that is being intensely pursued since 1940s. It is important to recall that, to detect and measure the concentration of oxygen in biological tissues, David and Brink have used microelectrodes during the $40 \mathrm{~s}^{38}$ In fact, the fabrication of a thermodynamically stable electrochemical interface for a CME is a challenging task. Early studies, suggested the use of either incorporated redox-active component into the ISE membranes like lipophilic silver complex or involving a polymeric layer between the electrode and the ISE membranes that could provide a suitable electronic and ionic conductivity. ${ }^{39}$ Metal oxide 
nanostructures are playing an important role as the means to this end. The chemical structural and electronic surface composition of metal oxide nanostructures provide a suitable CMEs platform. ${ }^{40}$

\subsection{Metal oxide nanostructures}

Metal oxide nanostructures are of interest as electrode materials for sensor applications (Fig. 1b) and energy conversion because of; (1) they provide large surface area to volume ratio that could carry high degree of the membrane molecules and exposing large surface for the oxidation of the analyte molecules on the surface of the modified electrodes. (2) provide biological activity on the electrode surface for enzymes immobilizing (biocompatibility) and relatively it is simple to coat different membrane on the electrode surface, and (3) provide fast electron transfer to catalyze slow electrode reactions (redox-active).

In general, there are two types of catalytic materials used in sensors technology. These are metals and semiconductor metal oxides. In the case of metals, the incomplete $\mathrm{d}$-shell free electrons bear the responsibility of sensing. This is why metals like Pt, Pd, Rh, and Ir are commonly used as active catalysts since they possess incomplete d-shells. While metal oxide sensing mechanisms depend on a different mechanism for sensing. For metal oxides, the existence of specific lattice point defects allows a certain change of the electrical conductivity in the meal oxide. Although in metals, also, the conductivity is modified but this modification is relatively small and it is difficult to detect. Hence and due to this most of the gas sensors were fabricated using metal oxides. ${ }^{41}$ Nevertheless, the interaction of metal oxide and aqueous solutions is rather complex. Usually, metal oxideaqueous interfaces are reactive due to the acid-base, ligand exchange and/or redox reactions involving protons (hydronium ions) and/or hydroxyl groups. The localization of these species at interfaces (adsorption) may result from electrostatic chemical reactions, and hydrophobic interactions between the surface and the sorbates. ${ }^{42}$

Metal-oxides nanostructures are considered to be one of the most fascinating functional materials and have been widely deployed in various technological applications. ${ }^{43}$ For sensing application using metal oxides microstructures, the first report was published in 1991 by Yamazoe where demonstrated that upon size reduction of $\mathrm{SnO}_{2}$ the sensing characteristics can be improved. ${ }^{44}$ After a decay in 2001, C. M. Lieber and coworks reported a highly sensitive sensor based on boron-doped silicon nanowires. ${ }^{45}$ They have demonstrated that semiconductors nanostructures are superior to their bulk 
counterpart. Then, the interest among researchers working in nanoscience towards the synthesis or fabrication of nanostructures with desired dimensionality and size have been intensified. ${ }^{46}$ In sensing technology, the higher sensitivity and lower limit of detection are driving force for new synthesizing morphologies and even new materials, e.g. composites. Thus, synthesis methods of metal oxide nanostructures are playing important role as the means to this end. Generally, there are two possible strategies: top down or bottom up approaches. At present time, since each approach has its own limitations, the most promising approach seems to be the combination of the bottom up growth methodologies with top down device fabrication technologies. ${ }^{47}$ There are several experimental techniques to prepare metal oxide nanostructures such as the vapor-liquid-solid (VLS) that was discovered since 1960s by Wagner and Ellis for synthesis of Si whiskers or nanowires, ${ }^{48}$ chemical vapor deposition and electrochemical deposition. All these are physical methods, while chemical methods also start to appear as promising methods. Among these chemical methods, the aqueous chemical growth (ACG). The ACG which can be considered to belong to "green chemistry", is a low-temperature method for the synthesis of metal oxide nanostructures. ${ }^{49}$ The ACG usually provides highly yield of the desired nanomaterial and facilitate scaling the nanodvices. ${ }^{50}$ In addition to the low cost of this synthesis route, the ACG can be operated at sufficiently low-temperatures $\left(<100^{\circ} \mathrm{C}\right)$ that allow the nanomaterials to be synthesized on any substrate e.g. plastic and paper. Furthermore, the simplicity to control the nanostructure morphology by different organic molecules is another advantage..$^{51}$

\subsection{Outline and goals}

The goal of this thesis is to synthesis of metal oxide nanostructures by low cost wet chemical methods. Furthermore, these nanostructures are to be used for the development of CMEs with associated enhanced sensing and catalytic properties via doping with organic additives. The overall goal is pursued as follow:

First, potentiometric chemical sensors were utilized to selectively detect and quantify the amount of chosen analytes such as, dopamine, glucose or glutamate molecules. $\mathrm{ZnO}$ and $\mathrm{Co}_{3} \mathrm{O}_{4}$ nanostructures have been used as chemical sensors based CMEs to detect dopamine and glucose molecules while the glutamate molecules have been investigated by $\mathrm{ZnO}$ based CMEs. The second part of this thesis is to demonstrate visible 
light-driven photoelectrochemical activities using $\mathrm{BiZn}_{2} \mathrm{VO}_{6}$ nanocompounds based CMEs. 


\section{Chapter 2 Properties of some metal oxides}

In traditional metal oxide semiconductors, the sensing mechanism relies on the change to their surface potential at elevated temperature. Recently, the existence of nanomaterials have revolutionized the fabrication of chemical sensors without sophisticated steps. It is well established that, the addition of relatively small amount of impurities, can cause both the sensitivity as well as the selectivity of sensors to be enhanced. These added impurities usually act as donors (or acceptors). This will alter the doping concentration and hence the conductivity can be improved. These impurities can be realized by incorporating organic or inorganic additive materials to the metal oxide nanostructures. Among the metal oxides nanostructures, zinc oxide (ZnO), cobalt oxide $\left(\mathrm{Co}_{3} \mathrm{O}_{4}\right)$ and bismuth zinc vanadate $\left(\mathrm{BiZn}_{2} \mathrm{VO}_{6}\right)$ have attracted the attention of researchers in many laboratories for the development of different functional devices. Thus, have been considered in the present work. Organic additives that have been used in the present work are as follow: urea, sodium dodecyl sulfate (SDS), sodium dodecyl benzene sulfonate (SDBS), sodium p-toluenesulfonate (NaPTS), cetyl trimethyl ammonium bromide (CTAB) and polyethylene glycol (PEG). As mentioned above these organic additives were employed as dopants.

\subsection{Zinc oxide (ZnO)}

Zinc oxide is a promising metal oxide. It is unintentional n-type doped semiconductor material having a wurtzite structure under ambient condition. ${ }^{52-54}$ The wurtzite structure has hexagonal unit cell as shown in Figure 2.1a. Marino et al., have shown that the crystal structure of $\mathrm{ZnO}$ is a hexagonal closed packing with $\mathrm{Zn}$ surrounded by four oxygen atoms and consequently has two polar surfaces. ${ }^{53}$ The different surfaces of $\mathrm{ZnO}$ have different surface energies. The (0001) plane which is Zinc terminated possesses the maximum surface energy, while the (0001)plane which is oxygen terminated possesses the minimum energy. Due to this, and compared to other directions, the [0001] direction is the fastest growth direction (see Figure $2.1 \mathrm{~b}$ ). Both the (0001)

and (0001) are polar surfaces which are Zinc or Oxygen terminated, respectively. While other surfaces which are non-polar have equal numbers of $\mathrm{O}$ and $\mathrm{Zn}$ atoms. 


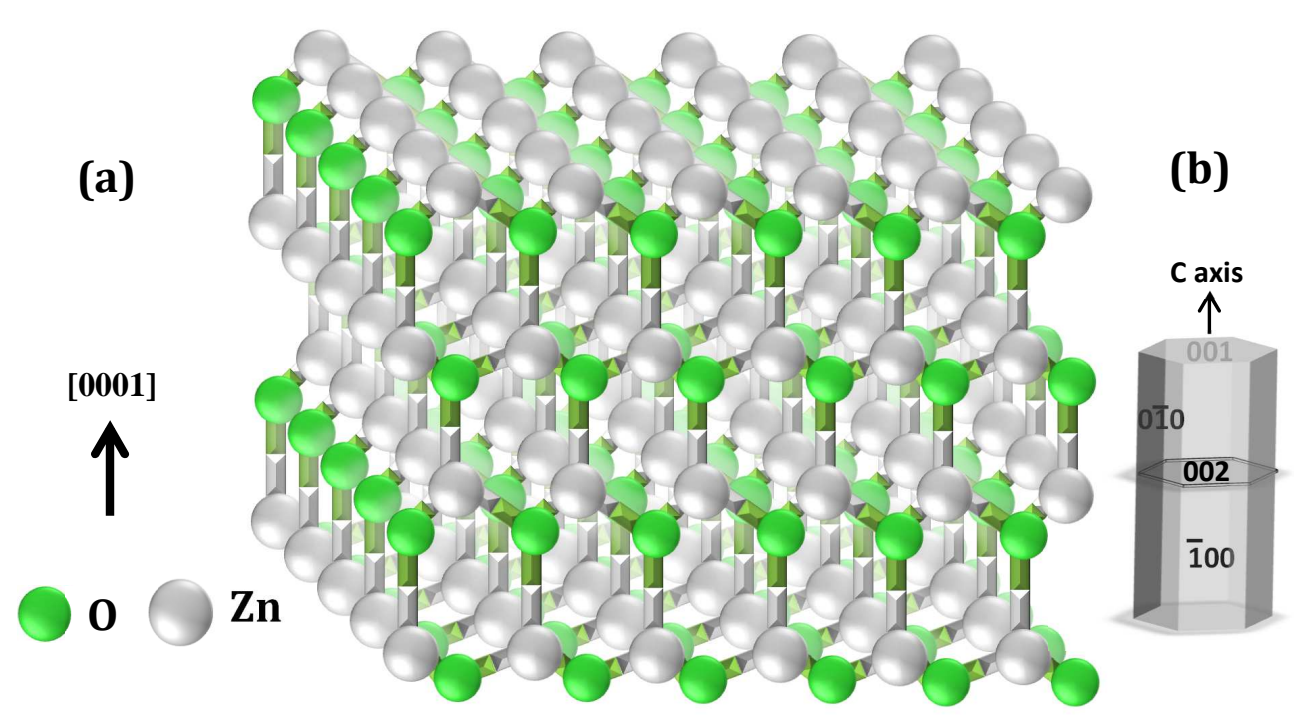

Figure 2. 1: (a) The wurtzite crystal structure of $\mathrm{ZnO}$ and (b) the growth habit of the ZnO crystal. ${ }^{54,55}$

\subsubsection{Biological properties}

$\mathrm{ZnO}$ is an important multifunctional material. However, for commercial industrial products in the near future, nanomaterials are expected to have a great impact. Therefore, here we deal with $\mathrm{ZnO}$ as a biological element; Zinc $\left(\mathrm{Zn}^{++}\right)$itself, is a trace mineral that is second only to iron in the body. Unlike iron, where $80 \%$ of a total of about $3 \mathrm{~g}$ in a human is in the heme group alone, similarly the total amounts of zinc in the human body spread among thousands of proteins. Zinc is essential for protein and DNA synthesis and maintenance. Furthermore, it is important for many physiological processes like wound healing, cell division and growth, stable proper sensation of the tasting and smelling. Zinc is also important for normal childhood growth in addition to a vital role in proper metabolism of carbohydrates and for adjusting proper sexual appetite. Since many decades ago, scientists know the role of zinc in the growth of microorganisms, plants and animals, but zinc role in humans was only known in 1963.56

In recent past, it was discovered that $\mathrm{Zn}^{++}$is released from $\mathrm{ZnO}$ nanostructure in uterine solution (biological solutions), ${ }^{57}$ which is in agreement with the results of Z. L. Wang et al.,. 58 They demonstrated that $\mathrm{ZnO}$ nanowires would be degraded into mineral 
ions after immersion in horse blood. Moreover, zinc ion is expected to be transferred from the oxygen with lower stability constant to a ligand that has the higher stability. ${ }^{59}$ However, there is consensus that zinc ion usually in cell biology is coupled with specific ligand (Cys and His) through tetrahedral coordination's fabricating what is so called zinc finger. 60 The number of the Cys and/or His is varying depending on the function of the finger. Nevertheless, it is important to note that, exposure to zinc oxide fumes from wedding can lead to metal fume fever. ${ }^{61}$

\subsubsection{Zinc oxide based sensors}

In addition to $\mathrm{TiO}^{62}$ and $\mathrm{SnO}_{2}{ }^{63}$ as being popular materials used to build gas sensors, $\mathrm{ZnO}$ with its attractive properties has been utilized for the same purpose. The principle of gas sensors operation is rely on the change of conductivity of a material as gas molecules are absorbed at its surface. ${ }^{25}$ The exist of point defects on the surface of $\mathrm{ZnO}$ material, makes it very sensitive to gas detection as adsorbed gases can produce a large change in the surface conductivity. This change of the conductivity occurs at the grains due to charge transfer and band bending. The dominant defects identified in these surfaces as with other oxides are 0 vacancies. These surface defects do not produce any new filled electronic states in the bandgap i.e. not relying on the bulk properties. ${ }^{52}$ In the intrinsic range, $\mathrm{ZnO}$ is sensitive to $\mathrm{O}_{2}, \mathrm{O}_{3}, \mathrm{H}_{2}, \mathrm{CO}$, and simple hydrocarbons. Moreover, $\mathrm{ZnO}$ is known as a good sensing material to detect reducing gases such as $\mathrm{H}_{2}, \mathrm{CH}_{4}$, and $\mathrm{CO}^{64}$ Nevertheless, as a gas sensor material, $\mathrm{ZnO}$ is not a good candidate because it suffers from long terms stability and its selectivity can be poor if the ambient is changed.

Due to the relatively high surface area to volume ratio of $\mathrm{ZnO}$ nanostructures, they have become attractive as gas sensors with potential to overcome some fundamental limitations. Recently, and due to the polar and nonpolar surfaces, bio-safety (antibacterial), biocompatibility, low cost as well as the electronic and the optical characteristics of nanostructures that are superior to the bulk of this material, research on nanostructures of $\mathrm{ZnO}$ has intensified. As it is well known, the electronic and optical properties of $\mathrm{ZnO}$ nanocrystals depend on their size and morphology.65 This can be attributed to the surface-to-volume ratio rather than to the quantum confinement. ${ }^{66} \mathrm{ZnO}$ nanostructures have received high interest due to their potential for opto-electronics and sensor devices. For instance in light-emitting diodes, solar cells, photo-catalysis and 
biosensors. The interest for optoelectronic application is because, $\mathrm{ZnO}$ has a wide band gap of $3.37 \mathrm{eV}$ and a relatively high exciton binding energy of $60 \mathrm{meV}$ along with the defect emissions that covers the whole visible region. ${ }^{67,68} \mathrm{ZnO}$ exhibits remarkable properties for sensing applications due to its biocompatibility and high isoelectric point (IEP) 9.569 (The IEP is the $\mathrm{pH}$ value at which a molecule has no net surface electrical charge). These properties are suitable for the adsorption and immobilization of proteins or enzymes with relatively low IEP through electrostatic attraction, e.g., cholesterol oxidase (COx) and glucose oxidase (GOx) with IEP value of $\sim 4.6$ and 4.2 respectively. Due to these properties, an enhanced direct electron transfers between the enzyme's active sites and the electrode can be achieved. ${ }^{70}$ It is worth mentioning that, the physical and chemical properties of metal oxides can be tuned through adjusting and controlling their structure and morphology 71,72 and therefore, issues related to $\mathrm{ZnO}$ morphology have been considered in this work.

\subsection{Cobalt oxide $\left(\mathrm{Co}_{3} \mathrm{O}_{4}\right)$}

Cobalt oxide has three well-known polymorphs: ${ }^{61}$ the cobalt monoxide (CoO), the dicobalt trioxide; $\left(\mathrm{Co}_{2} \mathrm{O}_{3}\right)$ and the tricobalt tetraoxide $\left(\mathrm{Co}_{3} \mathrm{O}_{4}\right)$. The latter, is the most functional material used for many applications including energy storage, ${ }^{73}$ heterogeneous catalysts, ${ }^{74}$ electrochromic devices, ${ }^{75}$ sensors ${ }^{76}$ and recently in overall water-splitting. ${ }^{77}$ Due it's potentials as a robust solar selective absorber it has been employed for efficient water splitting. ${ }^{78}$ As early as ancient times, $\mathrm{Co}_{3} \mathrm{O}_{4}$ has been used as agent for coloring glass, while during our modern time it has been used in pigments in glazing pottery and porcelain and for coloring of enamels. Also cobalt is a supplier of vitamin B12 for plants and animals. As a separate metal, cobalt was isolated in 1735 and confirmed as an element during $1780 .{ }^{61}$ In addition to low cost and environmentally benign nature, $\mathrm{Co}_{3} \mathrm{O}_{4}$ is a ptype semiconductor and has both direct and indirect band gap of $2.10 \mathrm{eV}$ and $1.60 \mathrm{eV}$, respectively. ${ }^{79}$ It crystallizes in a spinel structure with the $\mathrm{Co}^{3+}$ ions occupying the octahedral sites, and $\mathrm{Co}^{2+}$ ions occupying tetrahedral sites with the oxygen ions forming a close-packed face centered cubic lattice. ${ }^{80}$ This arrangement of ions leads to the fact that the $\mathrm{Co}_{3} \mathrm{O}_{4}$ has explicit surface features with different polar terminations. ${ }^{81}$ In addition, $\mathrm{Co}_{3} \mathrm{O}_{4}$ has a paramount electro-catalytic activity ${ }^{74,76,77}$ and 82 and relatively high IEP value of $\sim 8.83$ 


\subsection{Bismuth zinc vanadate $\left(\mathrm{BiZn}_{2} \mathrm{VO}_{6}\right)$}

Among the researched nanomaterials, bismuth zinc vanadate $\left(\mathrm{BiZn}_{2} \mathrm{VO}_{6}\right)$ nanocompound has a new crystal structure type and belong to the mixed metal oxide structures family, usually denoted by $\mathrm{BiM}_{2} \mathrm{AO}_{6}(\mathrm{M} \equiv \mathrm{Mg}, \mathrm{Ca}, \mathrm{Cd}, \mathrm{Cu}, \mathrm{Pb}, \mathrm{Mn}$ or $\mathrm{Zn} ; \mathrm{A} \equiv \mathrm{V}, \mathrm{P}$ or As). This family of metal oxide nanostructures possess a unique physical and chemical properties with interesting applications e.g. converting visible light to chemical energy and pollutant degradation. ${ }^{84-86}$ Typically, they are prepared by solid-state reactions that involves high-temperature $\left(>700^{\circ} \mathrm{C}\right)$ which are considered to be expensive and environmentally unfavorable. Furthermore, the products may contain undesirable phases, which are usually inhomogeneous with regard to large particle size and can be characterized by low surface area that is unfavorable in the photocatalysis. Due to this, they have not been used frequently in these applications. However, recent advances in the wet chemical methods which could pave the way for these materials to be used in various applications. $\mathrm{BiZn}_{2} \mathrm{VO}_{6}$ compound with a band gap $\left(\mathrm{Eg}_{\mathrm{g}}\right)$ experimentally measured and calculated to be $\sim 2.4^{85}$ and $1.6 \mathrm{eV},{ }^{87}$ respectively, makes it suitable for visible light driven water oxidation. In addition, it could merge both advantageous of its component parts $\left(\mathrm{ZnO}\right.$, and $\left.\mathrm{BiVO}_{4}\right)$ materials. Note, $\mathrm{ZnO}(\mathrm{Eg} \sim 3.3 \mathrm{eV})$ only utilize the ultraviolet component $(<5 \%)$ of the solar spectrum beside that it has also high recombination rate. ${ }^{88}$ The same scenario is valid for the $\mathrm{BiVO}_{4}$. Although it is the most promising photocatalyst for water oxidation, poor photo-induced electron transportation, slow kinetics of oxygen evolution and a high charge recombination, are example of its limitations. ${ }^{89}$ Thus, $\mathrm{BiZn}_{2} \mathrm{VO}_{6}$ compound is expected to combine the high electron mobility of $\mathrm{ZnO}$ to facilitate charge transport and the robust light absorption of $\mathrm{BiVO}_{4}$ component.

\subsection{Organic additives (surfactant)}

Surfactants are used routinely in numerous industrial applications and products, like detergents, fabric softeners, emulsions soaps, paints, adhesives and inks. Surfactant molecules have both hydrophobic (water avoiding) and hydrophilic (water liking) portions in their structure (Figure 2.2a). Keeping in mind that the surfactants can be classified to anionic (-), cationic (+), amphoteric (- and +), or nonionic, depending on their hydrophilic part (the head group). Therefore, most important uses of surfactants are in lowering the surface or interfacial tension between two liquids. Due to this fact, 
surfactant molecules are showing a crucial role in the growth process of metal oxide nanocrystals. ${ }^{90}$ To the best of our knowledge, as one of the several methods for nanoscale material synthesis, surfactant based wet chemical processes has been very popular among researchers since the pioneering work by Pileni in 1993. ${ }^{91}$ Where he used reverse micelles to synthesize either well-defined nanosized crystallites or chemically modified enzymes. Although many researchers studied the effect of organic additives such as surfactants on the growth of metal oxide nanostructures, the full explanation has not been yet realized. However, the most practical explanation is that the surfactants or organic additives are considered as habit modifying additives that can tune the morphology. ${ }^{55}$ The habit-modifying additives are usually adsorbed selectively on one face and hence inhibit further growth on this face. Therefore, there is a consensus that surfactants are usually used to tune the morphology of the grown nanostructures and improve the performance of an electrode. Inamdar et al. investigated the effect of the surfactant on the growth of ZnO film morphology and the associated their optical and photo-electrochemical performance. ${ }^{92}$ Wang et al. described that, the addition of surfactant has a duel effect; one in the morphology and the other is enhancing the sensitivity. ${ }^{93}$ Among the many organic additives, sodium dodecyl sulfate (SDS), sodium dodecyl benzene sulfonate (SDBS), sodium $p$-toluenesulfonate (NaPTS), cetyl trimethyl ammonium bromide (CTAB), urea or polyethylene glycol (PEG) have been utilized for the presented research work.
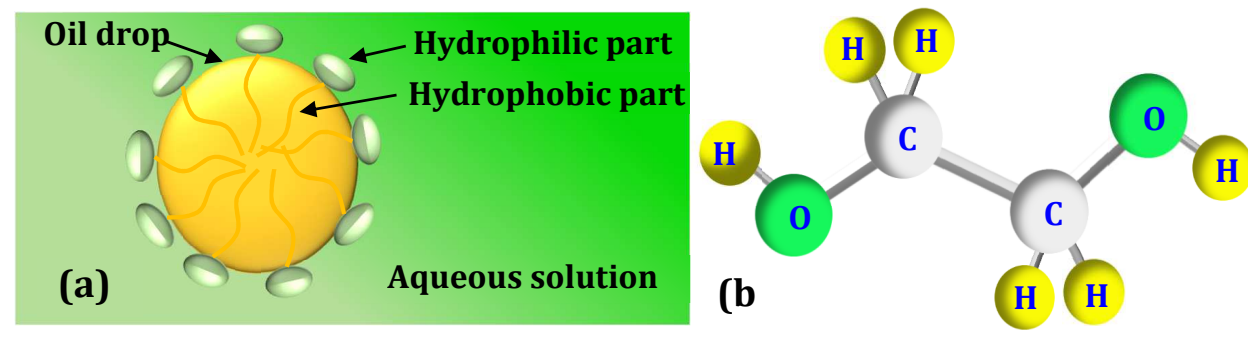

Figure 2. 2: (a) The hydrophobic part is interacting more strongly with oil drop than with water and (b) PEG with abundant hydrogen.

In recent past, some authors have utilized PEG (Figure 2.2b) for growth of ZnO. Tian et al. reported that PEG was acting as a reaction media for the growth of the $\mathrm{ZnO}$ microspheres.94 While Ghule et al. utilized the PEG as a stabilizing agent for $\mathrm{ZnO}$ nanorods, ${ }^{95}$ and Inamdar et al. found that the PEG to be dominant in modifying the morphology of $\mathrm{ZnO}$ thin films. ${ }^{92}$ Long et al. synthesized $\mathrm{ZnO}$ by using hexamethylenetetramine (HMT) as precursors while adding different amounts of PEG as 
the dispersant to grow flower-like structures, ${ }^{96}$ and Teterycz et al. formed $\mathrm{ZnO}$ nanobals by mixing zinc acetate and PEG. ${ }^{97}$ Moreover, recently we have used PEG as growth template to synthesize cupric oxide ( $\mathrm{CuO})$ and cobalt oxide $\left(\mathrm{Co}_{3} \mathrm{O}_{4}\right)$ nanostructures. ${ }^{98,99}$ In fact, the PEG is completely miscible with water and has found many applications in current technology as antifreeze when mixed with water. ${ }^{100}$ This is probably due its strong hydrogen bonding interaction in water with the hydroxyl oxygen atoms of PEG. ${ }^{101}$ Therefore, we assume that disruption of hydrogen bonding when dissolved in water is a hydrogenated-environment for growth of $\mathrm{ZnO}$ nanostructures (Figure 2.2b). Here, we show the successful experiments on the utilization of PEG as a hydrogen supplier for the growth of $\mathrm{ZnO}$ nanorods (NRs) using a wet chemical process. 


\section{Chapter 3 Synthesis and characterization of the CMEs}

\subsection{The fabrication and preparation of CEMs}

In this thesis, chemically modified electrodes (CEMs) have been fabricated utilizing glass substrates coated with gold $\mathrm{Au}$ ) then followed by the growth of different metal oxide nanostructures by the aqueous chemical growth (ACG) method. Further, organic additives were chosen to tune the morphology and other properties of the grown metal oxide. Then, we have correlated the observed properties in sensing and photoelectrochemical (PEC) applications to the applied chemical modification.

First, a potentiometric chemical sensor was utilized to detect the presence and quantify the amount of some analytes in solutions, specifically, dopamine, glucose and glutamate molecules were the chosen analytes. $\mathrm{ZnO}$ and $\mathrm{Co}_{3} \mathrm{O}_{4}$ nanostructures have been involved in the chemical sensors based CMEs to detect dopamine and glucose molecules. $102,103,51$ and 104 and the glutamate molecules have been investigated by $\mathrm{ZnO}$ based CMEs. ${ }^{105}$ The second part of this thesis we investigated the potential of $\mathrm{BiZn}_{2} \mathrm{VO}_{6}$ nano-compounds (NCs) based CMEs for PEC processes. 106

All reagents were of analytical grade and were used without being submitted to any additional purification. All the chemicals were purchased from Sigma-Aldrich (Stockholm, Sweden), below and in brief, the details of the preparation steps are given.

\subsubsection{Substrate preparation}

Usually we start with the substrate preparation step. This is important to avoid any possible contamination and any unwanted particles on the electrode. First, to fabricate CMEs, a $2 \times 1 \mathrm{~cm}^{2}$ glass substrates, were dipped in ultrasonic bath using isopropanol and acetone sequentially for 5-10 minutes. Then washed with deionized water and dried by a nitrogen gas. Secondly, the cleaning step was followed by the deposition of the Au thin layer on the glass substrate. In order to coat the glass by $\mathrm{Au}$, they were affixed into the vacuum chamber of an evaporator instrument (Satis CR 725, Zurich, Switzerland) at the pressure of $\left(2 \times 10^{-6} \mathrm{mbar}\right)$. After this, an adhesive layer of $20 \mathrm{~nm}$ of Titanium (Ti) was evaporated on the substrates and then a $100 \mathrm{~nm}$ thickness layer of Au thin film was evaporated. 


\subsubsection{Preparation of $\mathrm{ZnO}_{,} \mathrm{Co}_{3} \mathrm{O}_{4}$ and $\mathrm{BiVO}_{4}$ seed solutions}

In order to synthesize $\mathrm{ZnO}$ nanostructures, $\mathrm{ZnO}$ nanoparticles (seed-layer) were prepared by colloidal chemical techniques according to Henglein et al., report with tiny modifications. ${ }^{107}$ In a typical synthetic route, a $0.01 \mathrm{M}$ of zinc acetate dehydrate $(274 \mathrm{mg})$ mixed with $125 \mathrm{ml}$ of methanol absolute methanol (99\%), kept at $60{ }^{\circ} \mathrm{C}$ under continuous stirring. Then, a $109 \mathrm{mg}$ of potassium hydroxide $(\mathrm{KOH})$ was dissolved in $65 \mathrm{ml}$ of methanol $(0.03 \mathrm{M})$. Drop-wise from the later solution was added to the former solution under continuous stirring for 2 hours. These solutions were transferred into a Teflon glass bottle and kept at room temperature before it was spun coated on the Au coated glass substrate for several times to insure uniform spatial distribution. The main reason of this seed layer is to be as nucleation site that is initiating and directing the growth as well as to overcome the thermodynamic barrier between heterogeneous materials. ${ }^{108}$ The expected average size of this $\mathrm{ZnO}$ nanoparticles in the seed layer solution is around 3-5 $\mathrm{nm} .{ }^{109}$ The same techniques have been applied for the preparation of $\mathrm{Co}_{3} \mathrm{O}_{4}$ and $\mathrm{BiVO}_{4}$. However, a $0.01 \mathrm{M}$ cobalt acetate anhydrous in methanol was prepared and left for stirring at $60{ }^{\circ} \mathrm{C}$ for two hours. $\mathrm{BiVO}_{4}$ samples were later used as control samples for x-ray diffraction (XRD) and X-ray photoelectron spectroscopy (XPS) measurements. The seed solution was prepared by using an equimolar concentration of $0.02 \mathrm{M}$ of bismuth(III) nitrate pentahydrate and ammonium metavanadate in $25 \mathrm{ml}$ methanol. This seed solution was either applied by dip- or spin coating on a cleaned Au coated glass substrates. The substrates containing the seed particles were then annealed at $120{ }^{\circ} \mathrm{C}$ for $5 \mathrm{~min}$ before dipping into the growth solution. ${ }^{106}$

\subsubsection{Synthesis of $\mathrm{ZnO}$ nanorods}

The synthesis of the nanorods (NRs) have been accomplished by the ACG process under hydrothermal-like condition, that was developed by Vayssieres et al.110 The second step (see Figure 3.1), after the substrates seeded with zinc acetate dehydrate layer via spin coating technique at $1000 \mathrm{rpm}$ for $20 \mathrm{~s}$. The samples were annealed at a temperature of $120^{\circ} \mathrm{C}$ for $5 \mathrm{~min}$. Then after that, the substrates coated with $\mathrm{ZnO}$ seeds were introduced horizontally and upside-down to an equimolar concentration of $0.05 \mathrm{M}$ of hexamethylenetetramine $\left(\mathrm{C}_{6} \mathrm{H}_{12} \mathrm{~N}_{4}\right)$ and zinc nitrate hexahydrate $\left(\mathrm{Zn}\left(\mathrm{NO}_{3}\right)_{2} \cdot 6 \mathrm{H}_{2} \mathrm{O}\right)$ and kept in the preheated electric oven at $90^{\circ} \mathrm{C}$ for $4-6 \mathrm{~h}$. 

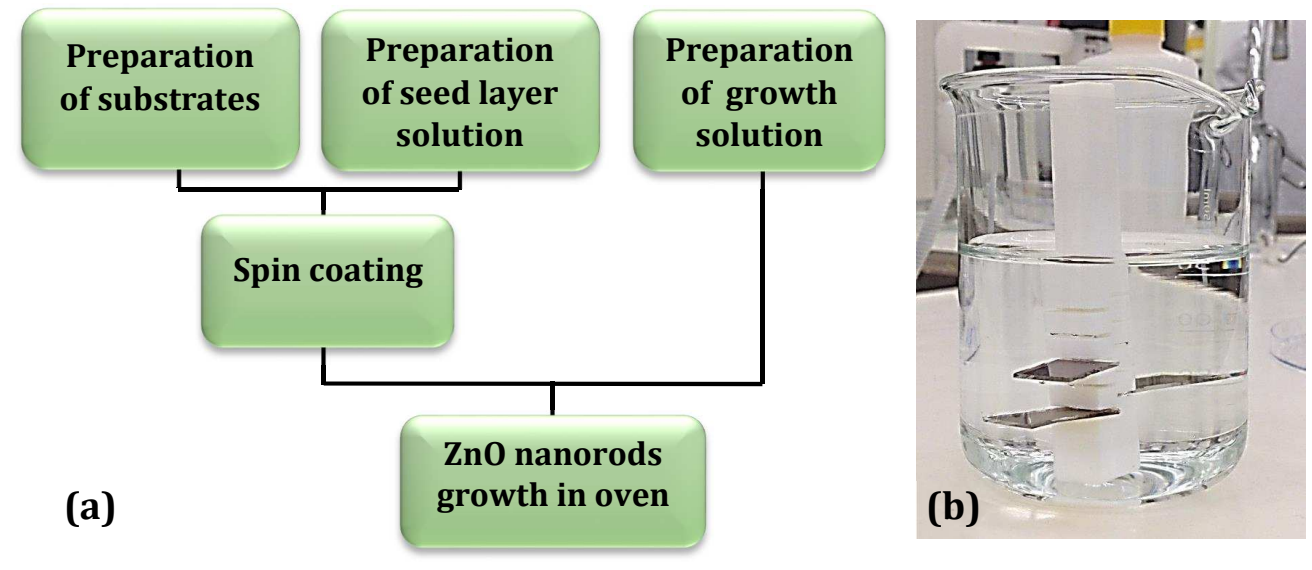

Figure 3. 1:(a) Schematic diagram for the growth process of $\mathrm{ZnO} \mathrm{NRs}$ and (b) optical photograph illustrating the substrates coated with $\mathrm{ZnO}$ seeds when introduced horizontally and upside-down in the growth solution in normal laboratory glass beaker.

The possible reactions involved in the synthesis of ZnO NRs are summarized below: ${ }^{111}$

$$
\begin{array}{ll}
\left(\mathrm{CH}_{2}\right)_{6} \mathrm{~N}_{4}+6 \mathrm{H}_{2} \mathrm{O} & \rightarrow 6 \mathrm{COH}_{2}+4 \mathrm{NH}_{3} \\
\mathrm{NH}_{3}+\mathrm{H}_{2} \mathrm{O} & \rightarrow \mathrm{NH}_{4}^{+}+\mathrm{OH}^{-} \\
2 \mathrm{OH}^{-}+\mathrm{Zn}^{2+} & \rightarrow \mathrm{Zn}(\mathrm{OH})_{2} \rightarrow \mathrm{ZnO}(\mathrm{s})+\mathrm{H}_{2} \mathrm{O}
\end{array}
$$

The HMT $\left(\left(\mathrm{CH}_{2}\right)_{6} \mathrm{~N}_{4}\right)$ plays a role as a buffer medium and supplies the ammonia $\left(\mathrm{NH}_{3}\right)$ during the growth. The $\mathrm{NH}_{3}$ reacts with water and generates hydroxide $\left(\mathrm{OH}^{-}\right)$ions and finally $\mathrm{OH}^{-}$ions react with $\mathrm{Zn}^{2+}$ ion and yields $\mathrm{Zn}(\mathrm{OH})_{2}$. During growth the expected $\mathrm{pH}$ value might be between 6.5 and 7.111 The produced $\mathrm{Zn}(\mathrm{OH})_{2}$ is thermodynamically unstable and it would be dehydrated when it is incorporated into the crystal, therefore could be referred as a growth unit. ${ }^{55}$ Before the substrates were placed into the solution, and to prepare contact pads for the electrochemical measurements, a small part of the $\mathrm{Au}$ coated glass was covered. Finally, the samples were rinsed with deionized water for several times to avoid any residual salts on the surface of the nanostructures and then dried with flowing nitrogen gun.

For other doped ZnO nanostructures the only difference in the synthesis was that, the growth solutions were prepared separately then in each growth solution a certain amount of SDS, SDBS, NaPTS, CTAB, urea or PEG were added into the growth solution. 


\subsubsection{Synthesis of $\mathrm{Co}_{3} \mathrm{O}_{4}$ nanostructures}

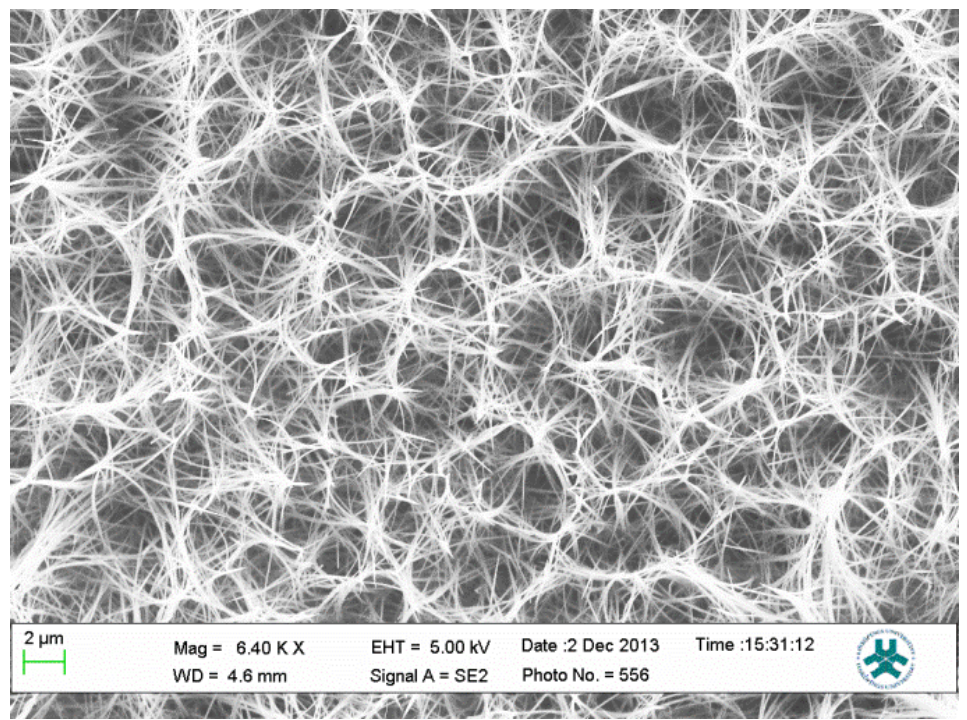

Figure 3. 2: $\mathrm{SEM}$ images of $\mathrm{Co}_{3} \mathrm{O}_{4}$ wire-like nanostructure synthesized with an equimolar concentration $(0.1 \mathrm{M})$ urea and cobalt chloride in $100 \mathrm{~mL}$ deionized water. ${ }^{112}$

Usually the growth solution of the $\mathrm{Co}_{3} \mathrm{O}_{4}$ nanostructures is prepared by mixing an equimolar concentration $(0.1 \mathrm{M})$ urea $\left(\mathrm{CH}_{4} \mathrm{~N}_{2} \mathrm{O}\right)$ and cobalt chloride $\left(\mathrm{CoCl}_{2}\right)$ in $100 \mathrm{~mL}$ deionized water resulting in $\mathrm{Co}_{3} \mathrm{O}_{4}$ wire-like nanostructure. A scanning electron microscopy (SEM) image of the resulting $\mathrm{Co}_{3} \mathrm{O}_{4}$ nanowires is shown in Figure 3.2.112 However, here in this thesis the concentration of the urea was varied in order to monitor the effect on the morphology of the synthesized $\mathrm{Co}_{3} \mathrm{O}_{4}$ nanostructures.

The amount of urea added in the growth solution was in the order of $0.23,0.27,0.3$, and $0.4 \mathrm{M}$ respectively, while the concentration of the cobalt chloride was kept constant at $0.1 \mathrm{M}$. The substrates containing $\mathrm{Co}_{3} \mathrm{O}_{4}$ nano-particles were fixed horizontally in the Teflon sample holder and dipped into the growth solution for 5 hours in a preheated electric oven at $90{ }^{\circ} \mathrm{C}$. keeping in mind that, the seed solution was applied to the cleaned $\mathrm{Au}$ coated glass substrates by the dip coating method and then annealed at $120{ }^{\circ} \mathrm{C}$ for 5 minutes. After the completion of growth duration, the samples were cooled naturally at room temperature then washed with deionized water in order to remove any residual particles from the surface of the grown samples. The cobalt hydroxide nanostructures were annealed at $450{ }^{\circ} \mathrm{C}$ for 3 hours to convert the hydroxide phase to oxide phase. The 
possible reactions involved in the synthesis of cobalt oxide nanostructures can be represented by the following equations:

$$
\begin{array}{ll}
\mathrm{CoCl}_{2} & \rightarrow \mathrm{Co}^{2+}+2 \mathrm{Cl}^{-} \\
\left(\mathrm{H}_{2} \mathrm{~N}\right)_{2} \mathrm{CO}+\mathrm{H}_{2} \mathrm{O} & \rightarrow 2 \mathrm{NH}_{3}+\mathrm{CO}_{2} \\
\mathrm{NH}_{3}+\mathrm{H}_{2} \mathrm{O} & \rightarrow \mathrm{NH}_{4}^{+}+\mathrm{OH}^{-} \\
\mathrm{Co}^{2+}+2 \mathrm{OH}^{-}+\mathrm{SDS} & \rightarrow \mathrm{Co}(\mathrm{OH})_{2}
\end{array}
$$

\subsubsection{Synthesis of the $\mathrm{BiZn}_{2} \mathrm{VO}_{6}$ nanocompounds}
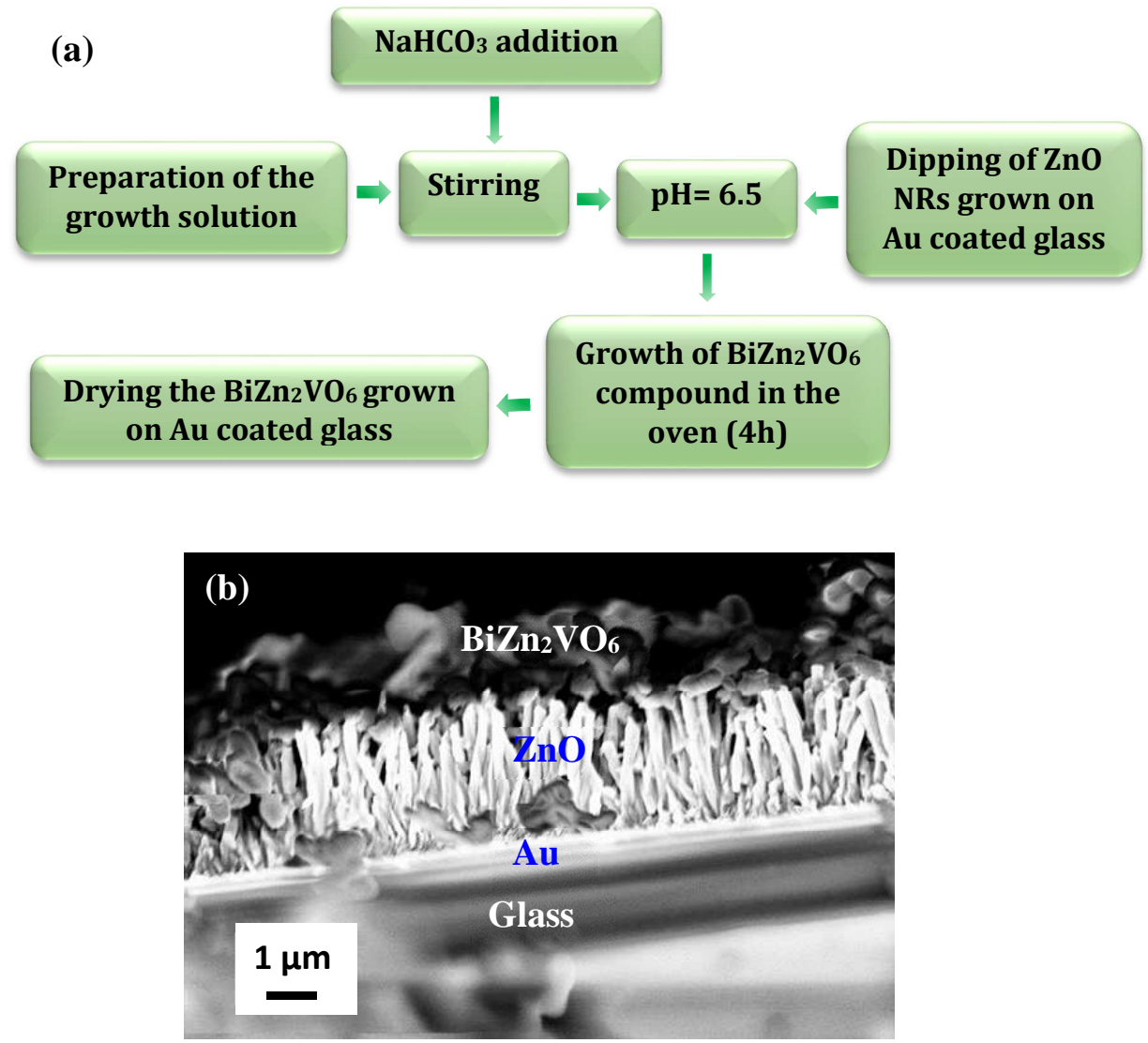

Figure 3. 3: (a) Scheme showing the growth process of the $\mathrm{BiZn}_{2} \mathrm{VO}_{6} \mathrm{NCs}$ and, (b) SEM image of the $\mathrm{BiZn}_{2} \mathrm{VO}_{6}$ nanostructures grown for $4 \mathrm{~h}$ laying on the top of vertically aligned ordered $\mathrm{ZnO}$ nanostructure. 106

The mixed metal oxide $\mathrm{BiZn}_{2} \mathrm{VO}_{6}$ nanocompounds (NCs) was formed by $\mathrm{BiVO}_{4}$ growth on top of the ZnO nanostructure, according to Zhou's and co-workers report with tinny modification at resulting in relatively shorter growth duration. ${ }^{113}$ In a typical 
synthetic route, equimolar concentration of $0.02 \mathrm{M}$ of bismuth(III) nitrate pentahydrate $\left(\mathrm{Bi}\left(\mathrm{NO}_{3}\right)_{3} \cdot 5 \mathrm{H}_{2} \mathrm{O}\right)$ and ammonium metavanadate $\left(\mathrm{NH}_{4} \mathrm{VO}_{3}\right)$ were dissolved in $10 \mathrm{~mL}$ of nitric acid and a 70\% $\left(\mathrm{HNO}_{3}\right)$ solution. $20 \mathrm{ml}$ deionized water was added into this solution under vigorous stirring until the salts were completely dissolved. Then, $\sim 12.8 \mathrm{~g}$ sodium hydrogen carbonate $\left(\mathrm{NaHCO}_{3}\right)$ was added to adjust the $\mathrm{pH}$ value to 6.5 until the formation of a yellow homogeneous solution. The as-grown ZnO NRs on the Au-coated glass were placed facing upwards in the bottom of this yellow solution. They were covered with aluminum foil and placed in the pre-heated oven for 4 or $10 \mathrm{~h}$ at $80^{\circ} \mathrm{C}$. The final products were washed with deionized water and then dried with blowing nitrogen gas. Finally they were dried at $80{ }^{\circ} \mathrm{C}$ for $10 \mathrm{~h}$ in a conventional laboratory oven (see Figure 3.3). ${ }^{106}$

\subsection{Membrane, enzymes and CMEs preparation}

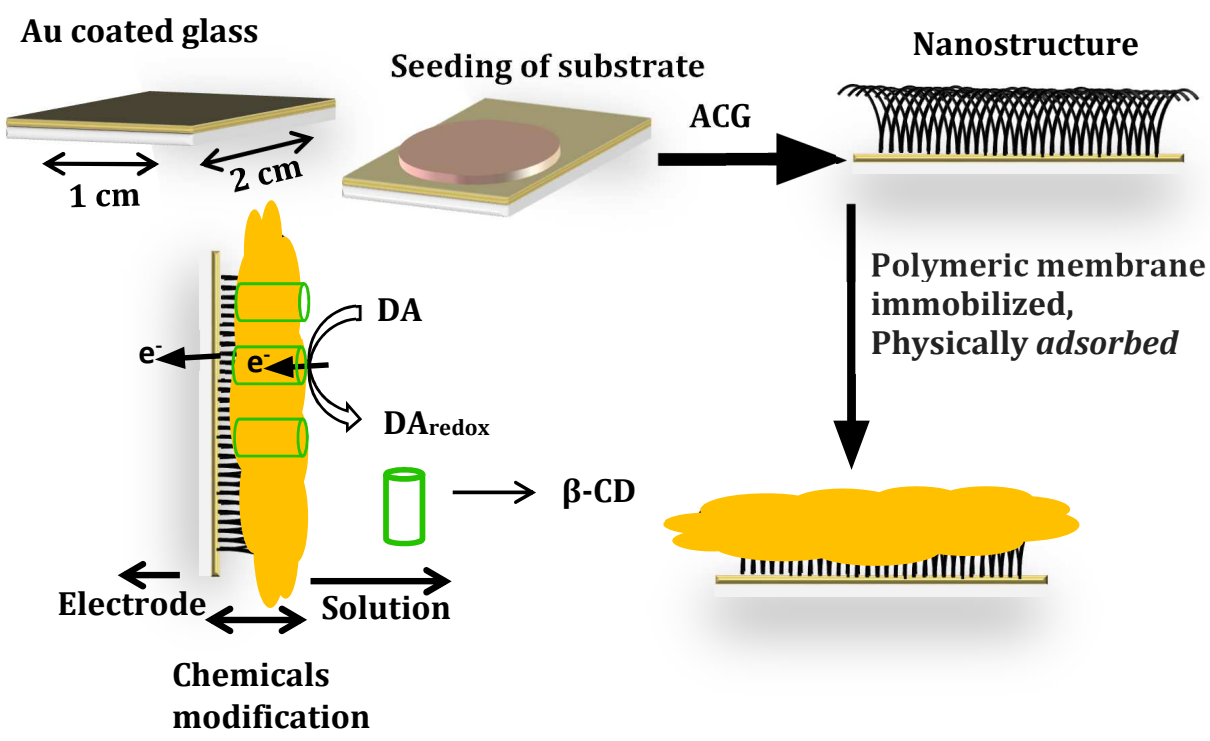

Figure 3. 4: Illustration of the fabrication of modified electrodes: spin coating of seed layer on $\mathrm{Au}$ coated glass, growth of the nanostructures, immobilization of polymeric membrane by deep coating and proposed mechanism of CME where a DA accumulated. ${ }^{103}$

\subsubsection{Dopamine membrane preparation and the buffer solution}

Dopamine (DA, $\left.\mathrm{C}_{6} \mathrm{H}_{3}(\mathrm{OH})_{2}-\mathrm{CH}_{2}-\mathrm{CH}_{2}-\mathrm{NH}_{2}\right)$ is a small and relatively simple molecule that performs diverse functions and in the 50s Carlsson has identified it as a 
neurotransmitter in the brain. ${ }^{114}$ Many of the neurological processes like e.g. pleasure, cognition, learning and motivation have all found to be implicated by the DA. Neurologists found that DA exists with around $50 \mathrm{nmol} / \mathrm{g}$ in the caudate nucleus in the brain. Several neurological disorders have been found to be related to abnormal dopamine receptor signaling and in the dopaminergic neve function. Parkinson disease patients have shown complete depletion of DA from the caudate nucleus in the brain. ${ }^{114}$ High levels are also known to be cardiotoxic leading to heart electrophysiology dysfunction. Usually, the concentration of DA in biological systems is in the range of $10^{-8}$ to $10^{-6}$ M.115

Therefore, the DA membrane ${ }^{116}$ (see Figure 3.4) and the buffer solution were prepared using powdered polyvinyl chloride (PVC) (0.18 g) as a plasticized polymer which was dissolved in tetrahydrofuran $(6 \mathrm{~mL})$ and mixed with $\beta$-cyclodextrin $(\beta$-CD) used as ionophore $(0.04 \mathrm{~g}$ ), potassium tetrakis (4-chlorophenyl) borate as ionic additive (0.01 g) and 2-fluorophenyl 2-nitrodiphenyl ether (0.4 g). A stock solution as a buffer containing dopamine hydrochloride (1.89 g) in deionized water $(100 \mathrm{~mL})$ was prepared and later diluted with a $100 \mathrm{mM}$ sodium acetate-acetic acid ( $\mathrm{pH}$ 5.5). The as grown nanostructures were dipped three times into the membrane solution. After that, all the electrodes were left to dry in a fume hood at room temperature for one night. All the functionalized CMEs were kept in a free water vapor moisture environment at room temperature when not in use.

\subsubsection{Immobilization of glucose oxidase on $\mathrm{ZnO}$ and $\mathrm{Co}_{3} \mathrm{O}_{4}$ nanostructures}

It is known that, glucose detection is a necessary test for all patients having diabetes. A glucose oxidase (GOx) solution was prepared by dissolving $30 \mathrm{mg}$ of enzyme in $3 \mathrm{~mL}$ of $10 \mathrm{mM}$ phosphate buffered saline (PBS) of $\mathrm{pH}=7.3$ and $300 \mu \mathrm{L}$ of Glutaraldehyde.51, 104 Then, using the drop casting process, the GOx was physically adsorbed on the $\mathrm{ZnO}$ nanostructures surfaces through electrostatic attraction and the samples were left to dry in a fume hood at room temperature for 3 hours. A $100 \mathrm{mM}$ of glucose analyte was prepared in $10 \mathrm{mM}$ PBS having a $\mathrm{pH}$ of 7.3 and the low concentrations of glucose were prepared in PBS by dilution. ${ }^{51,104}$

\subsubsection{Immobilization of ZnO NRs with L-glutamate oxidase (GluOx, EC 1.4.3.11)}

L-glutamate acid (Glu) is an important amino acid that is usually applied to food items for improving/enhancing the taste. For the vertebrate central nervous system, Glu 
is a major excitatory neurotransmitter. ${ }^{117,118}$ It is reported that abnormal concentrations of Glu may indicate disorder such as trauma, stroke, epilepsy and hypoglycemia. ${ }^{118}$ A 20 $\mu \mathrm{L}$ of L-glutamate oxidase (GluOx) solution was added to a $200 \mu \mathrm{L}$ PBS solution ( $\mathrm{pH}=7.3$ ) (0.01 M). A $2.5 \mathrm{mg}$ of bovine serum albumin (BSA) was used as an enzyme stabilizer and a $10 \mu \mathrm{L}$ of glutaraldehyde solution was used as the cross linker ${ }^{119}$ and they were added to this solution and immobilized on the ZnO NRs through electrostatic physical adsorption process. After that, all the electrodes were left to dry in a fume hood at room temperature for one night. All the functionalized biosensor electrodes were kept in a dry Petri-plate at $4{ }^{\circ} \mathrm{C}$ when not in use. Before the insertion of the GluOx immobilized sensor electrode in the Glu solution, it was soaked in PBS in order to achieve a stable response as well as to remove the extra molecules of the GluOx that might be on the surface of the electrode. A stock solution of $10 \mathrm{mM}$ of Glu was prepared in few drops of $0.01 \mathrm{M} \mathrm{HCl}^{120}$ and finally mixed with 0.01 M PBS. Known low concentrations of Glu for testing and calibrating the sensor were obtained by dilution.

\subsection{Characterization techniques}

\subsubsection{X-ray diffraction}

X-ray is an electromagnetic radiation with very short wavelength of a round $1 \AA$ (10$10 \mathrm{~m})$. In 1912, the atoms in a single crystal of copper sulfate pentahydrate $\left(\mathrm{CuSO}_{4} .5 \mathrm{H}_{2} \mathrm{O}\right)$ were detected with high precision that is enabled by the periodicity of the crystal lattice by means of X-ray diffraction (XRD). ${ }^{121}$ Since then, XRD technique has been used as a powerful structural characterization for crystal quality and investigation of the composition of the synthesized material.

In this work, the XRD patterns were carried out by a Phillips PW 1729 powder diffractometer equipped with $\mathrm{CuK} \alpha$ radiation $(\lambda=1.5418 \AA$ ) using a generator voltage of $40 \mathrm{kV}$ and a current of $40 \mathrm{~mA}$. Figure 3.5a shows a typical XRD patterns of ZnO NRs grown on Au coated glass substrate. ${ }^{102}$ All the diffraction peaks of the XRD pattern can be indexed to $\mathrm{ZnO}$ with hexagonal wurtzite structure and all peaks agreed well with the standard card (JCPDS NO 36-1451) of bulk ZnO (Figure 3.5b). ${ }^{122}$ 

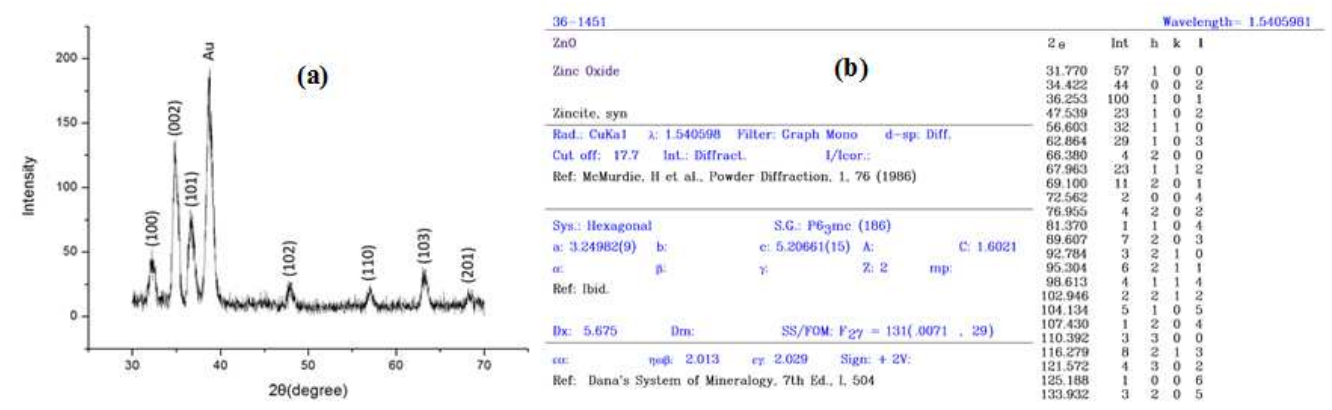

Figure 3. 5: (a) XRD pattern of ZnO NRs grown on Au-coated glass substrate and (b) the standard card of bulk $\mathrm{ZnO}$.

\subsubsection{Scanning electron microscope}

Scanning electron microscope (SEM) is a powerful technique that utilizes a focused electron beam to obtain information by scanning over a sample surface. The highresolution images produced by SEM provide topographical, morphological and compositional information that makes it invaluable in a variety of science and industry applications. An electron microscope works on the same basic principles as optical microscopes, but uses a focused beam of energetic electrons rather than photons in order to obtain a magnified image of an object. A variety of signals are observed when the beam of the energetic electrons interacted and decelerated by the sample, this interaction is due to the significant kinetic energy carried by the accelerated electrons. These signals include secondary electrons, backscattered electrons, diffracted backscattered electrons, that are used to determine crystal structures and orientations of minerals, characteristic Xrays (used for elemental analysis), photons (used in cathodoluminescence analysis) and heat radiation. For imaging the sample surface, both secondary and backscattered electrons are used. However, the secondary electrons are very useful for revealing the morphology and topography, while backscattered electrons are useful for providing information about the compositional contrast. ${ }^{123}$ The morphological analysis in this work were performed by SEM instrument using a LEO 1550 Gemini field emission gun at $5 \mathrm{kV}$. Figure 3.6 shows the SEM facility at Linköping University. 


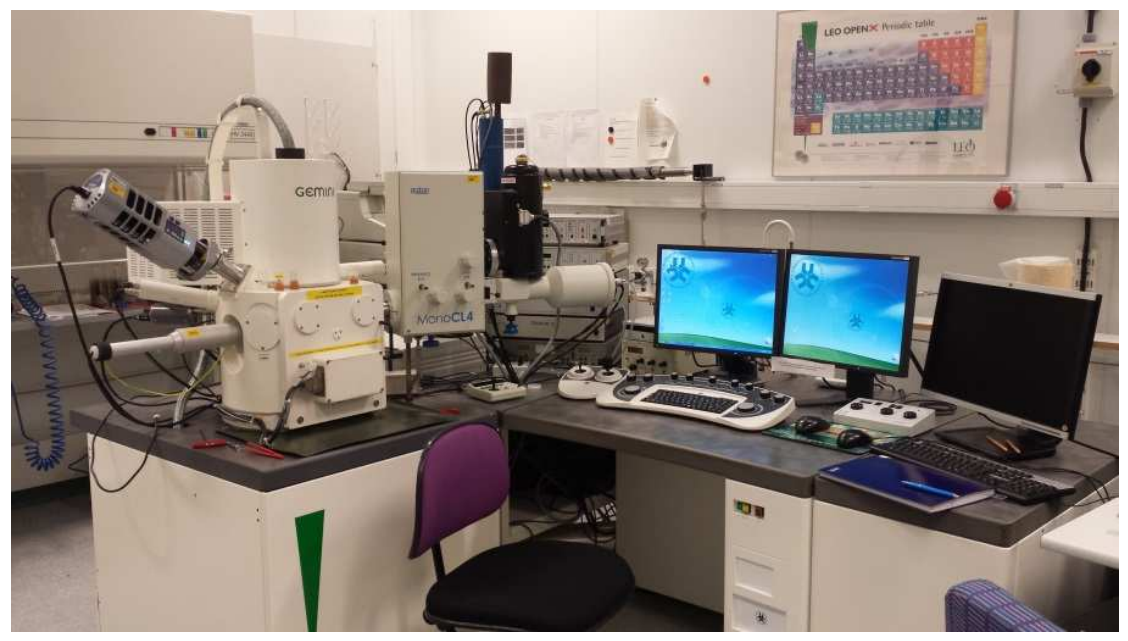

Figure 3. 6: A digital photograph of the SEM at IFM Department at Linköping University, Sweden.

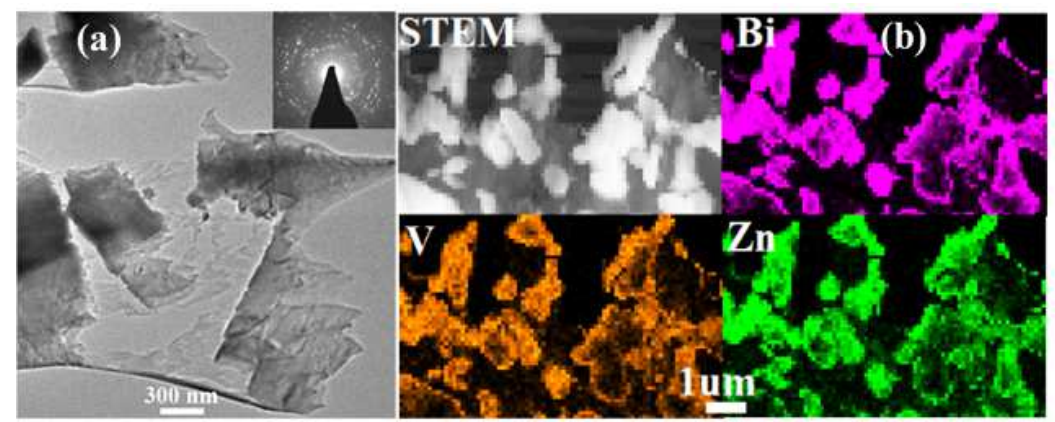

Figure 3. 7: (a) TEM image of a BiZn2V06 and the inset shows the corresponding selected area electron diffraction (SAED) pattern. (b) EDX mapping showing the Bi, $\mathrm{Zn}$, and V distributions. 106

\subsubsection{Transmission electron microscopy}

The transmission electron microscopy (TEM) is a microscopy technique and can also be used for imaging the grown materials. Furthermore, TEM can provide much more information such as discrimination between a single crystalline, polycrystalline and glassy or amorphous structure material. In addition to composition of the material estimations, one can characterize lattice parameter and the lattice distances. All these properties are due to fact that TEM uses high-energy electrons, which strike the specimen, and parts of it are transmitted depending upon the thickness and electron transparency of the specimen. However, the specimen preparation is an important step of the TEM 
analysis. For the research work conducted within the present thesis, the TEM experiments were performed using a FEI Tecnai G2 TF20 UT field emission microscope operated at $200 \mathrm{kV}$. This microscope is also equipped with an energy dispersive $\mathrm{x}$-ray spectrometer (EDX). Figure 3.7 shows typical TEM images of BiZn2 $V_{6}$. In Figure 3.7a a well-defined diffraction spots indicating a polycrystalline nature of the $\mathrm{BiZn}_{2} \mathrm{VO}_{6}$ is shown. Furthermore, an EDX mapping in Figure 3.7b of the sample demonstrates that the Zn distribution overlaps with the Bi and V distributions. ${ }^{106}$

\subsubsection{Photoluminescence spectroscopy}

Photoluminescence (PL) technique is a non-destructive helpful analysis. By using PL one can investigate and study the optical properties of semiconductor materials of different types e.g. bulk material, thin films or nanostructures. PL is the spontaneous emission of light from a material that occurs when excited by photons (often ultra-violet). Usually carriers aim to recombine when a beam of light excites the sample. This recombination is manifested as emission of a photon with energy close to the near band edge emission or alternatively the emission happens through transition due to deep levels. ${ }^{106}$ Then, the PL spectrum can be collected and analyzed. By PL measurement, one can obtain a variety of material parameters such as the optical band gap determination, impurities and defect detection. In this work, the PL properties of the prepared $\mathrm{ZnO}$ and $\mathrm{BiZn}_{2} \mathrm{VO}_{6}$ nanostructures were studied at room temperature $(300 \mathrm{~K})$. A microphotoluminescence setup was used to study the optical properties of some of the samples presented in this thesis. A Nd:YVO laser having a wavelength $\lambda=266 \mathrm{~nm}$ was used as the excitation source and the excited sample area was a circle having a diameter of around $1.5 \mu \mathrm{m}$. To collect the emitted luminesce, it was mirrored into a single monochromatic grating equipped with liquid nitrogen cooled Si-Charge coupled device (CCD) camera. Figure 3.8 shows typical PL spectra of the as-grown $\mathrm{BiZn}_{2} \mathrm{VO}_{6}$ and PEG-doped $\mathrm{BiZn}_{2} \mathrm{VO}_{6}$ NCs on Au coated glass. ${ }^{106}$ 


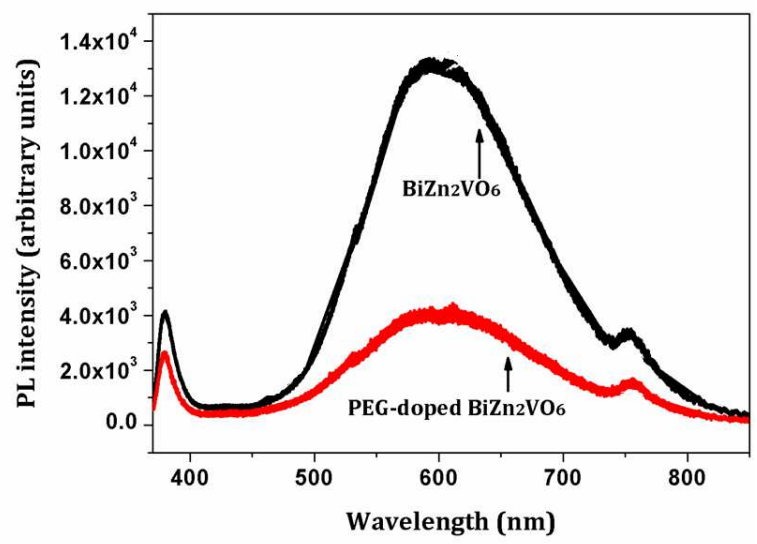

Figure 3. 8: Room temperature PL spectra of $\mathrm{BiZn}_{2} \mathrm{VO}_{6} \mathrm{NCs}$ grown on $\mathrm{Au}$ with and without the presences of PEG. ${ }^{106}$

\subsubsection{Ultraviolet-visible spectroscopy}

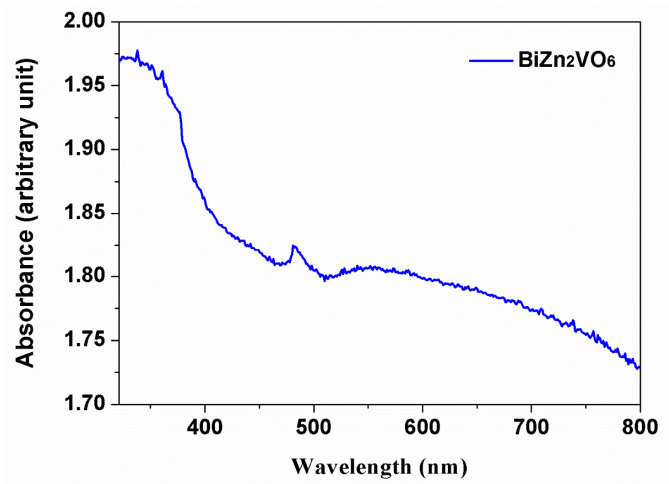

Figure 3. 9: UV-Vis. absorption spectrum of $\mathrm{BiZn}_{2} \mathrm{VO}_{6} \mathrm{NCs}$, an absorption peak at around $\sim 482 \mathrm{~nm}$ corresponds to an optical band gap of about $2.57 \mathrm{eV} .106$

Ultraviolet-visible (UV-vis) Spectroscopy is absorption or reflectance spectroscopy in the UV and visible range of the electromagnetic spectrum. UV-vis is also used to study the optical properties of the grown materials. UV-vis provide indication about the optical band gap of the material by simply corresponding the absorption peak (see Figure 3.9) or by calculations using the Tauc model. ${ }^{124}$ In PL we deal with the transitions from excited states to the lowest energy state. However, while in UV-vis spectroscopy one can deal with the transitions for lowest energy state to the higher energy state. Optical absorption spectra in this work was obtained by a PerkinElmer Lambda 900 UV-visible spectrophotometer. For the measurements, the different nanostructures were grown on glass substrate and a blank glass slide was used as a reference. 


\subsubsection{X-ray photoelectron spectroscopy}

X-ray photoelectron spectroscopy (XPS) is a powerful technique to study the surface chemistry (up to $10 \mathrm{~nm}$ of depth) of a material. Upon irradiating by X-rays some electrons released from the material surface, then the kinetic energy and the number of electrons can be measured (see Figure 3.10). Moreover, XPS can also be used to measure the elemental composition, the chemical state, electronic state and might be used to get more information about the elements within the material being analyzed.

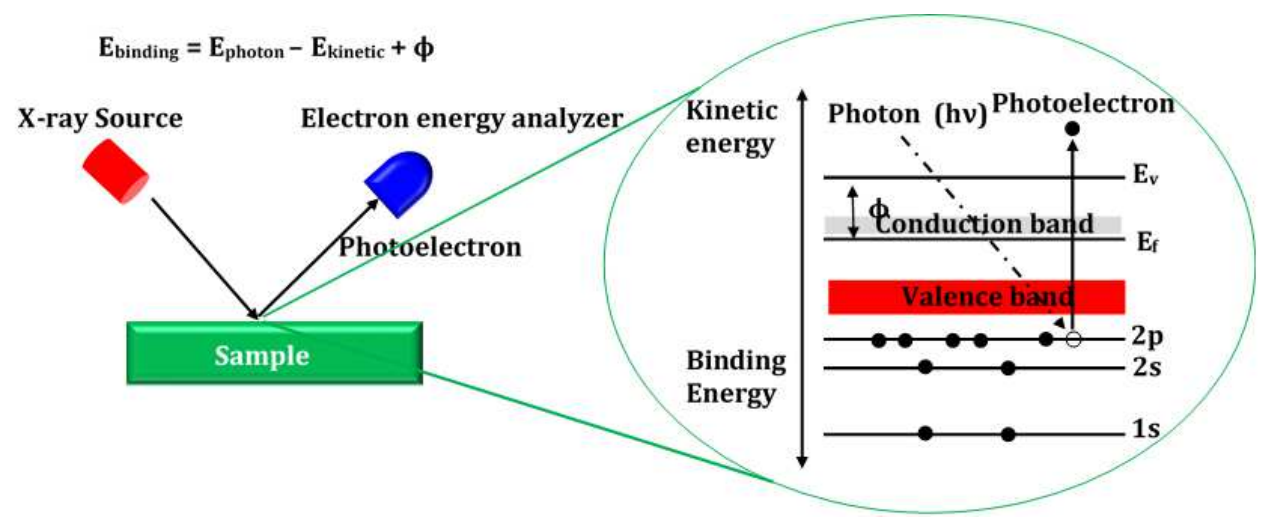

Figure 3. 10: Basic principle of the XPS technique.

In this work, the surface chemical composition of the grown metal oxide nanostructures was investigated by XPS technique and measured by Scienta ESCA200 using a vacuum generator with a monochromatic $\mathrm{Al}(\mathrm{K} \alpha)$ radiation. Figure 3.11, shows typical XPS spectra indicating a $\mathrm{Co}_{3} \mathrm{O}_{4}$ nanostructure. ${ }^{103} \mathrm{~A}$ wide and short XPS scans are shown in Figure 3.11 (a-c). Figure 3.11b represented Co 2p XPS spectrum of the product. The spin-orbital splitting peaks at $\sim 780 \mathrm{eV}$ and $\sim 795 \mathrm{eV}$ are assigned to the Co $2 \mathrm{p}_{2} / 3$ and Co $2 \mathrm{p}_{1 / 2}$, respectively. The decomposition of the Co $2 \mathrm{p}$ spectrum contains the contribution of $\mathrm{Co}^{3+}$ octahedral and of $\mathrm{Co}^{2+}$ tetrahedral. The peaks positions are in agreements with the reported data for pure $\mathrm{Co}_{3} \mathrm{O}_{4}$ crystals. The peak at $\sim 770 \mathrm{eV}$ is corresponding to the Auger peak of cobalt. ${ }^{125}$ The peaks at $\sim 789 \mathrm{eV}$ and $\sim 803 \mathrm{eV}$ are attributed to $2 \mathrm{p}_{2 / 3}$ and $2 \mathrm{p}_{1 / 2}$ shake-up satellite of $\mathrm{Co}^{3+}$, respectively. ${ }^{126}$ The $01 \mathrm{~s}$ XPS peaks (Figure 3.11c) at $\sim 530 \mathrm{eV}$, which corresponds to the oxygen species in the $\mathrm{Co}_{3} \mathrm{O}_{4}$ phase and at $\sim 531 \mathrm{eV}$ might be due to the hydroxyl group and adsorbed water.126,127 


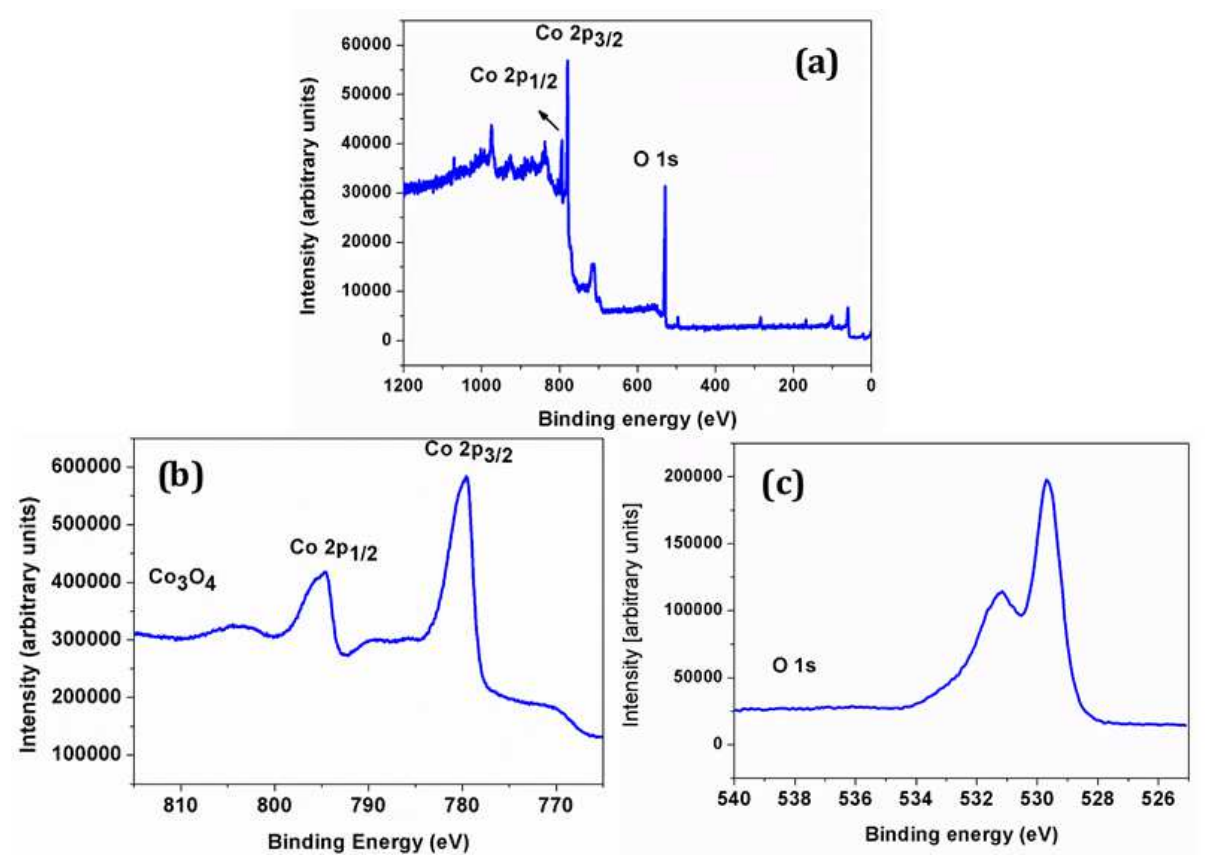

Figure 3. 11: XPS spectra of the as grown $\mathrm{Co}_{3} \mathrm{O}_{4}$ nanostructures on $\mathrm{Au}(\mathrm{a})$ a wide scan, (b) Co $2 \mathrm{p}$, and (c) 01 s spectra. ${ }^{103}$

\subsubsection{Electrochemical and photoelectrochemical characterizations}

The potentiometric sensor (see Figure 3.12a), in which the potential of the CMEs is measured against a $\mathrm{Ag} / \mathrm{AgCl}$ as a reference electrode in $3 \mathrm{M} \mathrm{KCl}$ at room temperature by a pH meter (Metrohm AG model 744, Herisau, Switzerland) and using an electrical instrument (Keithley 2400) to measure the response time of the CMEs. A three-electrode cell setup (see Figure 3.12b) was used for the PEC, the linear sweep voltammetry (LSV)), chronoamperometry and electrochemical impedance spectroscopy (EIS). The later was performed to study the Mott-Schottky analysis. Using an SP-200 potentiostat (Bio-Logic, Claix, France), a platinum sheet was used as the counter electrode and a $\mathrm{Ag} / \mathrm{AgCl}$ was used as a reference electrode. The electrolyte used was $0.1 \mathrm{M}$ Lithium perchlorate $\left(\mathrm{LiClO}_{4}\right)$ in propylene carbonate solution at a pH of 7 to avoid $\mathrm{ZnO}$ decomposition. The LSV was carried out at a scan rate of $0.1 \mathrm{~V} / \mathrm{s}$. Chronoamperometry $I$ - $t$ curves were tested a bias voltage of $0.5 \mathrm{~V}$ (vs $\mathrm{Ag} / \mathrm{AgCl}$ ). All electrodes were illuminated from the front side of the samples by a solar simulator (LCS-100, Newport, model 94011A). The total area of the photoelectrode was $2 \mathrm{~cm} \times 1 \mathrm{~cm}$, while the light is illuminated on a $1 \mathrm{~cm} \times 1 \mathrm{~cm}$ that was 
immersed in the electrolyte. The solar simulator uses a $100 \mathrm{~W}$ ozone free xenon lamp and includes an AM1.5G air mass filter with output power of 1 Sun. The EIS was performed at an amplitude of $20 \mathrm{mV}$ in a frequency range of $0.1 \mathrm{~Hz}-5 \mathrm{kHz}$ and a potential range of -1.0 $\mathrm{V}$ to $+1.0 \mathrm{~V}$.

(a)

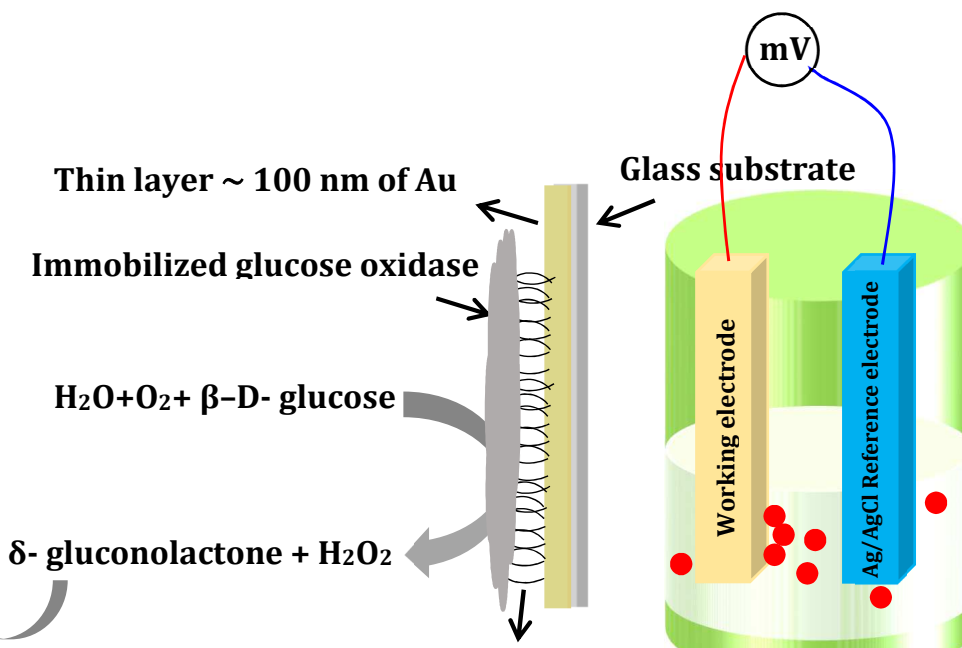

Metal oxide nanostructures

$\uparrow$

Glucose analyte in phosphate buffer solution

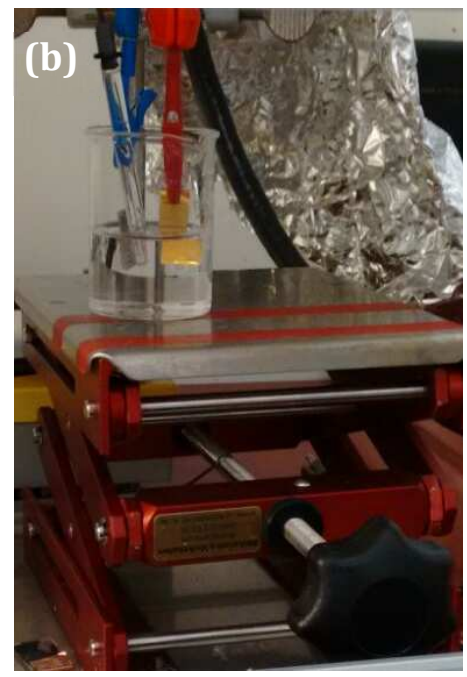

Figure 3. 12: (a) schematic diagram showing a typical potentiometric glucose biosensor and (b) a photograph of the three-electrode cell setup using a metal oxide nanostructure based CMEs. 


\section{Chapter 4 Findings and summary}

This thesis is concerned with synthesis of some metal oxide nanostructures $\mathrm{ZnO}$, $\mathrm{Co}_{3} \mathrm{O}_{4}, \mathrm{BiZn}_{2} \mathrm{VO}_{6}$ ) by the low-temperature wet chemical approach and the effects of organic additives on structural, sensing and catalytic properties. Briefly, this research work is described as follow; the $\mathrm{ZnO}$ and $\mathrm{Co}_{3} \mathrm{O}_{4}$ nanostructures were used for chemical and bio-sensing applications and the $\mathrm{BiZn}_{2} \mathrm{VO}_{6} \mathrm{NCs}$ was used for PEC activity. Here, in this chapter a summary of the findings from the six included papers are presented and discussed.

\section{Incorporating $\beta$-cyclodextrin with ZnO nanorods: A potentiometric strategy for selectivity and detection of dopamine (paper I)}
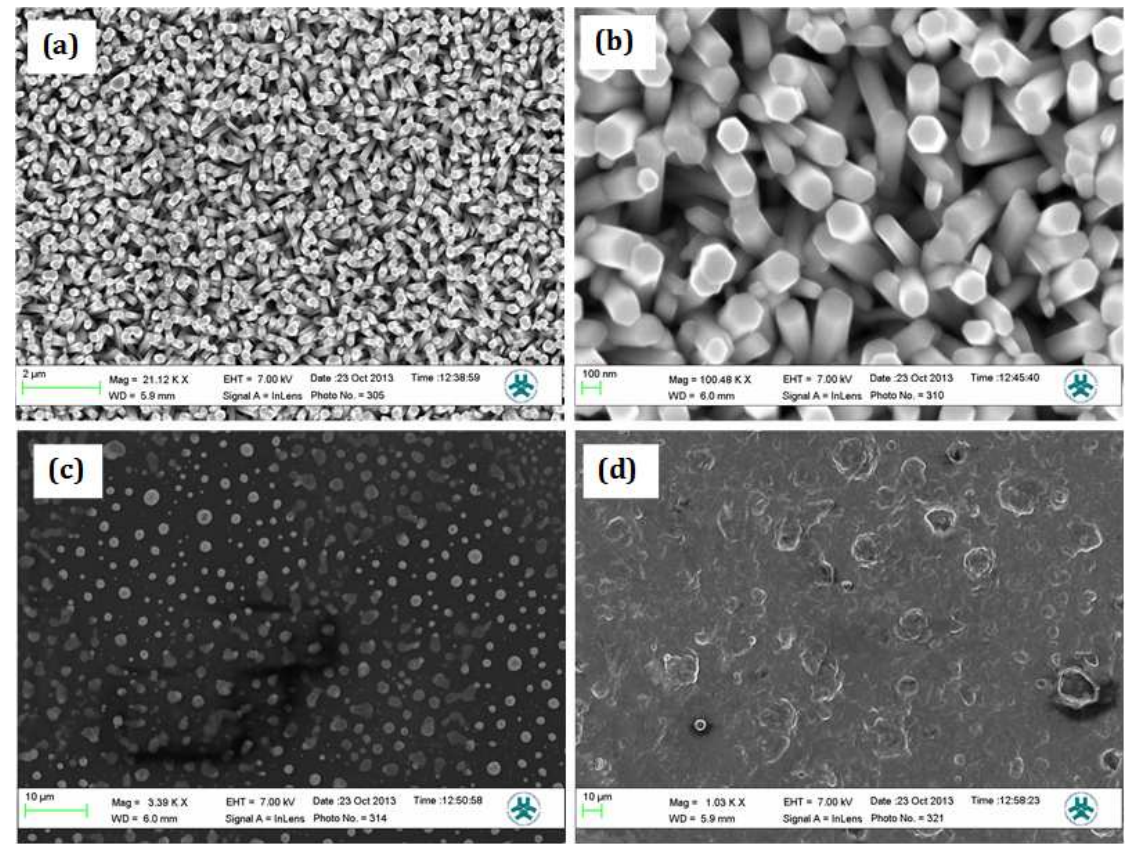

Figure 4. 1:SEM images of $\mathrm{ZnO} \mathrm{NRs}$, (a) as grown and before membrane immobilization, (b) high magnification showing the relatively large aspect ratio of the grown ZnO NRs, (c) after polymer membrane immobilization and (d) after measurements. ${ }^{102}$

ZnO NRs based CMEs were grown on the Au coated glass substrate by the low temperature aqueous chemical growth (ACG) method. Due to the affinity of ZnO towards the dopamine molecule to form a strong electronic coupling (metal-ligand bond) between 
the $\mathrm{ZnO}$ and the enediol, we expect good electrostatic interaction. ${ }^{128}$ This is a ligand hybrid system that comes from the interaction of hydroxyl groups with $\mathrm{Zn}^{++}$ion. Therefore, we have prepared perm-selective membrane coated on ZnO NRs as CMEs to endow the electrode with the property of a selective transport of dopamine molecules. A polymeric membrane (see Figure 4.1c and d) was immobilized on the ZnO NRs surface through electrostatic adsorption process. Figure 4.1a and b are SEM images that show the ZnO nanostructures grown densely with a rod shape like with a hexagonal cross section and having diameters between 100 and $200 \mathrm{~nm}$ with an average length of around $1.5 \mu \mathrm{m}$. To test the sensitivity of our constructed chemical sensors we performed measurements while changing the dopamine molecule concentration from $1 \mu \mathrm{M}$ to $100 \mathrm{mM}$ in a buffer solution. Figure 4.2a shows that the electromotive force is changing when the composition of the test electrolyte is modified by different concentrations of the dopamine. This observation can be understood in term of the metal-ligand bond that would be formed through a $\beta$-CD ionophore and hence the charge could be transferred into the buffer solution. The actual cell diagram that creates the electrochemical potential is:

$$
[A u|Z n O| B u f f e r \| C l-|A g C l| A g]
$$

The obtained results revealed that the proposed sensor possesses a good linearity and sensitivity of $49 \mathrm{mV} /$ decade in a concentration range of $1 \times 10^{-6}$ and up to $1 \times 10^{-1} \mathrm{M}$ at room temperature. In addition, a response time of less than $10 \mathrm{~s}$ was observed as shown in Figure $4.2 \mathrm{~b}$. The high sensitivity and fast response time could be attributed to the high surface to volume ratio of the ZnO NRs, which are firmly coupled with the dopamine molecules.
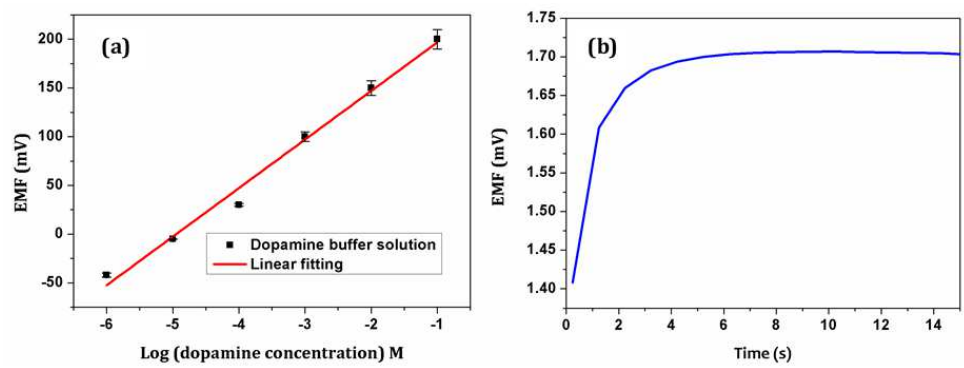

Figure 4. 2: (a) The calibration curve for the presented dopamine chemical sensor giving the linear calibration equation as: $\mathrm{y}=49.857 \mathrm{x}+246.6$ and (b) the response time measured in $0.01 \mathrm{mM}$ concentration of dopamine. ${ }^{102}$ 


\section{Habit-modifying additives and their morphological consequences on photoluminescence and glucose sensing properties of ZnO nanostructures, grown via aqueous chemical synthesis (paper II)}

Different surfactants (SDS, SDBS, NaPTS and CTAB) have been used in this work. They have been added into the growth solution to act as a source of impurities and as habit modifying additives that would yield a desired morphology of the ZnO nanostructured. ${ }^{51}$ It is worth to mention that, the morphology of the $\mathrm{ZnO}$ nanostructures is sensitive to the external conditions such as the solution $\mathrm{pH}$ value, the choice of the catalyst and the surfactant. It has been believed that, one or more of different parameters can influence the anisotropic shape of an inorganic nanocrystal. Examples of these parameters are the kinetic energy barrier, the temperature, the time and the nature of the capping molecules. ${ }^{129}$ Here, the capping molecule is the only investigated parameter. However, the surfactant access with the existence of HMT might be producing a complex surrounding the nanostructures environment and thus modulating the kinetic energy is accompanied. The results of the morphology, crystal quality and the PL properties of the $\mathrm{ZnO}$ nanostructures are summarized below. Moreover, the grown $\mathrm{ZnO}$ nanostructures were used to fabricate low cost efficient glucose biosensor.

The crystal quality was found be the same for all the samples as described below. Figure 4.3 shows the XRD patterns of the $\mathrm{ZnO}$ with and without the surfactant-assisted growth of the $\mathrm{ZnO}$ nanostructures. All the X-ray spectra shows well-defined peak at $34.4^{0}$ that corresponds to (002) plane, which indicates that the growth orientation is along the c-axis. All the other peaks can be assigned to hexagonal wurtzite structure of $\mathrm{ZnO}$. However, the morphology was observed to be altered by the use of the different surfactants. The growth processes with the SDBS and the SDS have resulted in nanowurtzite structures and nano-foam-like structures as shown in Figure 4.4a and Figure $4.4 \mathrm{~b}$ respectively. Meanwhile, an interconnected and stacked spiral nano-hexagonal-like structures are shown in Figure 4.4c and Figure 4.4d, when the CTAB and the NaPTS are incorporated in the growth solutions, respectively. Several interfacial phenomena can be considered in the growth mechanism of these structures e.g., adsorption, surface tension, and the critical micelle concentration..$^{90}$ This is because the surfactant molecules have both hydrophobic and hydrophilic portions in their structures. However, the adsorption phenomenon is more decisive factor for the capping molecules. 


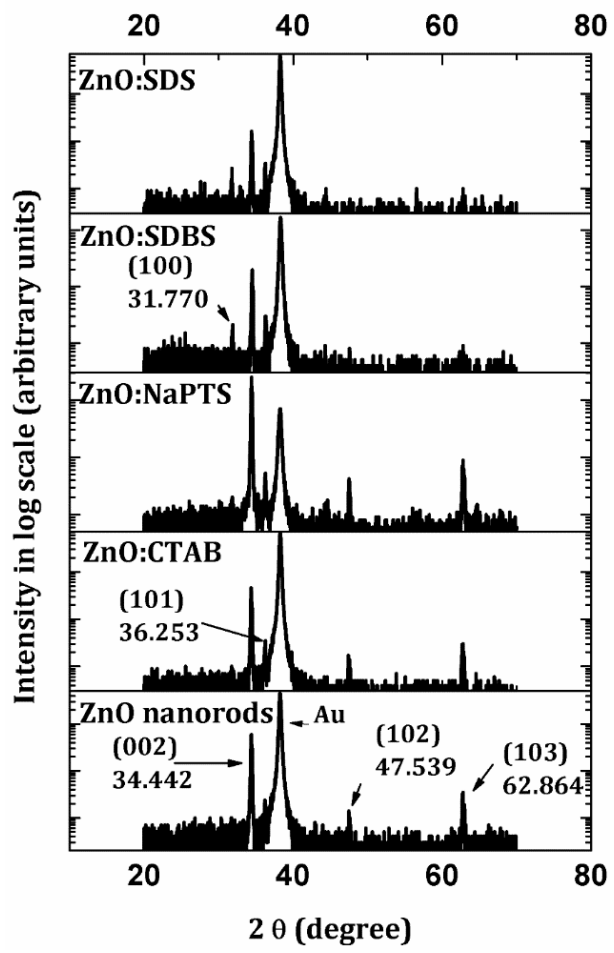

Figure 4. 3: XRD spectra of the $\mathrm{ZnO}$ nanostructures grown with and without the different surfactants. ${ }^{51}$

The adsorption of surfactant molecules on the high-energy face of crystals is in the order NaPTS $>$ CTAB $>$ SDS $>$ SDBS. ${ }^{130}$ In the first two cases the capping molecules strongly inhabited the usual growth habit of ZnO NRs i.e., along the c-axis which is a well-known direction that have the higher growth velocity compared to the other growth directions. Whereas for the case of the SDBS and from the SEM image that is shown in Figure 4.4a, it is clear that this surfactant has an equal dimensional contribution on the planes. While the SDS has the same contributions but has longer chain length of the hydrophobic part and this fact makes the morphology to have a foam shape like structure. ${ }^{131}$ Briefly, with a certain amount of the head group (cationic or anionic) of the surfactant e.g., CTAB would be dissociated in water into $\mathrm{CTA}^{+}$and $\mathrm{Br}^{-} .{ }^{132}$ The electrostatic attraction between $\mathrm{CTA}^{+}$ and $\mathrm{Zn}(\mathrm{OH})_{2}$ endows the surfactant capability to act as an ionic carrier resulting in a kinetic inhibition of growth along the [0001] direction. From Figure 4.5a, the ZnO:CTAB has shown wider range of detection " $1 \times 10^{-6}-1 \times 10^{-2} \mathrm{M}^{\prime}$ as compared to the others surfactants. The sensor sensitivity was $66 \mathrm{mV} /$ decade. This sensing property is attributed to the fact that CTAB is cationic surfactant while the rest vary between anionic surfactants 
and neutral molecules. Furthermore, we can also conclude that these adsorbed molecules have direct contributions on the optical band gap of ZnO. The PL properties of the prepared ZnO nanostructures at room temperature showed a paramount UV peak and the "green-yellow" is to some extent suppressed as shown in Figure 4.5f. The UV intensity and shape are depending on the surfactants that are absorbed by the surface of the $\mathrm{ZnO}$ and might be considered as impurities. Table I shows the PL peak position in the UV region and the full width at half maxima (FWHM).
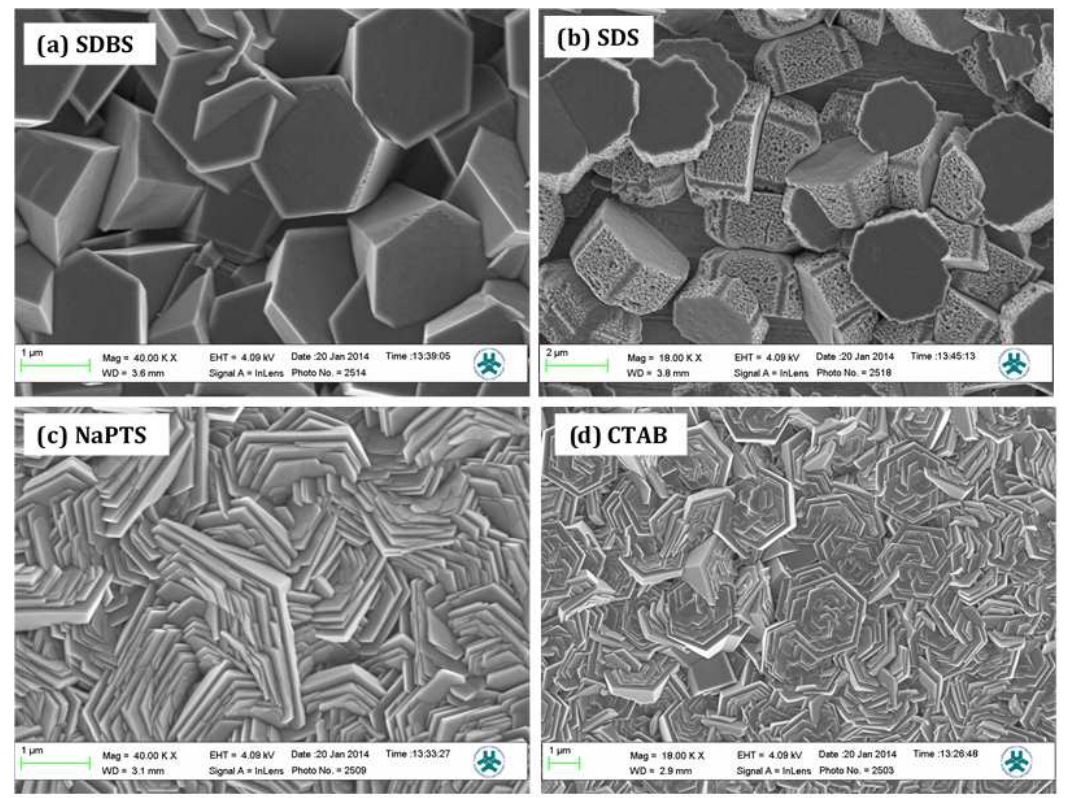

Figure 4. 4: SEM images of the as-grown $\mathrm{ZnO}$ nanostructures after adding the surfactants (a) ZnO:SDBS nano-wurtzite structure, (b) ZnO:SDS nano-foam-like structure, (c) ZnO:NaTPS nano-hexagonal-like structure and (d) ZnO:CTAB interconnected nano-disklike structure. ${ }^{51}$

Table I: Summary of the PL properties of $\mathrm{ZnO}$ nanostructures grown with and without surfactants. 51

\begin{tabular}{lcccc}
\hline Type of Materials & $\begin{array}{c}\text { UV peak position } \\
\text { (nm) }\end{array}$ & $\begin{array}{c}\text { FWHM } \\
\text { (nm) }\end{array}$ & $\begin{array}{c}\text { UV peak position } \\
\mathbf{( e V )}\end{array}$ & FWHM (eV) \\
\hline ZnO & 381.35 & 13.87826 & 3.253 & 0.11888 \\
\hline Zn0:CTAB & 379.52 & 17.97788 & 3.269 & 0.15564 \\
\hline Zn0:NaPTS & 379.83 & 17.68345 & 3.266 & 0.15282 \\
\hline Zn0:SDBS & 380.21 & 15.58057 & 3.263 & 0.13436 \\
\hline Zn0:SDS & 380.097 & 16.83327 & 3.264 & 0.14519 \\
\hline
\end{tabular}



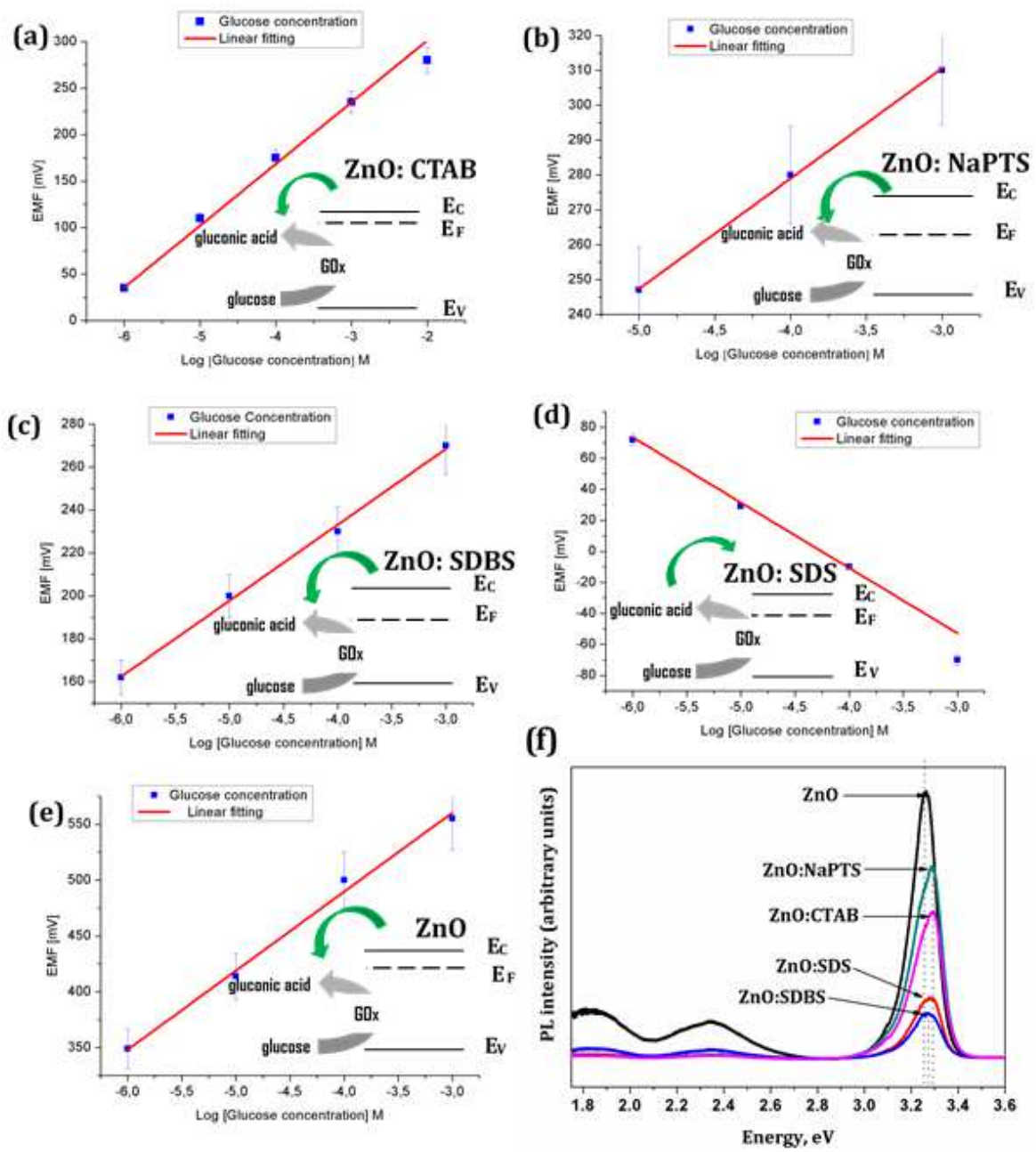

Figure 4. 5: Calibration curve for enzymatic glucose sensors where the ZnO nanostructures grown with assistance of: (a) CTAB, (b) NaPTS, (c) SDBS, (d) SDS and (e) $\mathrm{ZnO}$ NRs with the standard growth condition i.e. without surfactants. The insets proposed Fermi level position at $\mathrm{ZnO}$ surfaces and (f) Room temperature PL spectra of the product of $\mathrm{ZnO}$ nanostructures. ${ }^{51}$

\section{Effect of urea on the morphology of $\mathrm{Co}_{3} \mathrm{O}_{4}$ nanostructures and their application for potentiometric glucose biosensor (paper III)}

In this work, we investigated the effect of urea concentration on the morphology of the $\mathrm{Co}_{3} \mathrm{O}_{4}$ nanostructures. The amount of urea added in the growth solution was in the - 

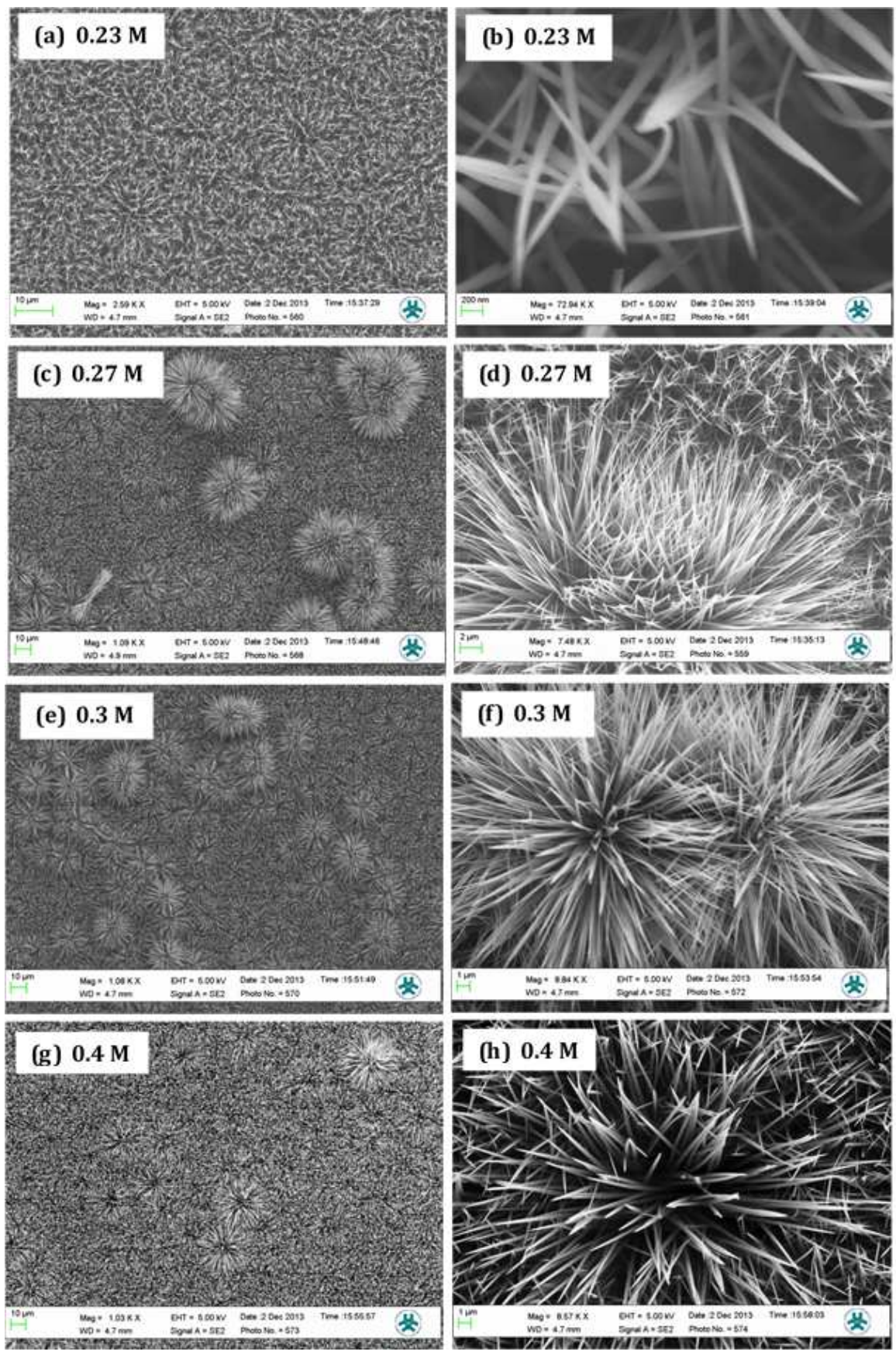

Figure 4. 6: $\mathrm{SEM}$ images of $\mathrm{Co}_{3} \mathrm{O}_{4}$ nano-flowers comprised on nanowires fabricated on the $\mathrm{Au}$ coated glass substrate using different concentrations of urea with a low and high magnification. ${ }^{104}$ 
order of $0.23,0.27,0.3$ and $0.4 \mathrm{M}$ respectively, while the concentration of the cobalt chloride was kept constant at $0.1 \mathrm{M}$. Then after the $\mathrm{Co}_{3} \mathrm{O}_{4}$ nanostructures were successfully grown, they were used for the development of a sensitive glucose biosensor. ${ }^{104}$ The majority of available data reveals that the $\mathrm{Co}_{3} \mathrm{O}_{4}$ nanostructures have been used as the main catalytic part. Here, we have used a heterogeneous catalysis of $\mathrm{Co}_{3} \mathrm{O}_{4}$ and $\mathrm{GOx}$ enzyme, we believe that, the properties of each component can be retained due to the compatibility of $\mathrm{Co}_{3} \mathrm{O}_{4}$. Beside the fact that, the potentiometric measurements which is to some extent benign to GOx and can even be used to acquire improved properties due to a synergistic effect.

The SEM images of the $\mathrm{Co}_{3} \mathrm{O}_{4}$ nanostructures synthesized using different concentrations of urea (with low and high magnifications) are shown in Figure 4.6 (a-h). The $\mathrm{Co}_{3} \mathrm{O}_{4}$ nanostructures were highly dense on the substrate and exhibit morphology of flowers like and have been grown on the nanowires like structures i.e. new morphology has been grown on top of the nanowires when increasing the concentration of the urea. That might be due to the change in the $\mathrm{pH}$ of the growth solution with the change of the concentration of the urea. ${ }^{133}$ With more amount of urea the solution becomes more basic i.e., with higher $\mathrm{pH}$, and that will affect the morphology.
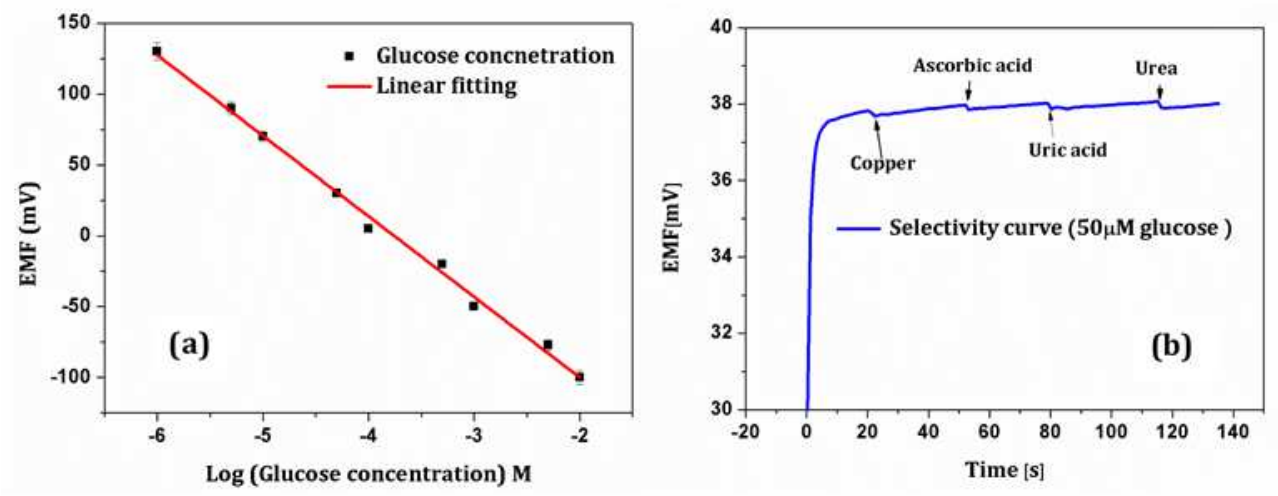

Figure 4. 7: (a) Calibration curve of the fabricated $\mathrm{GOx} / \mathrm{C}_{3} \mathrm{O}_{4}$ nanoflowers/Au electrode to detect glucose molecules for the concentrations from $1 \mu \mathrm{M}$ to $10 \mathrm{mM}$ with a linear calibration equation is: $y=-56,9 x-213,7$ and (b) the selective response of the CMEs in the presence of common interferents at concentrations of $100 \mu \mathrm{L}$ of $100 \mathrm{mM}$ copper, ascorbic acid, uric acid or urea, respectively. ${ }^{104}$

Furthermore, the GOx was immobilized on the nanoflowers of $\mathrm{Co}_{3} \mathrm{O}_{4}$ in order to be used as CME for sensing of glucose molecules using the potentiometric method. The GOx 
immobilized $\mathrm{Co}_{3} \mathrm{O}_{4}$ nanoflowers based electrode detected a wide range of the glucose concentrations from $1 \mu \mathrm{M}$ to $10 \mathrm{mM}$ with a sensitivity of $-56.85 \mathrm{mV} /$ decade as shown in Figure 4.7a. The high sensitivity of the presented glucose sensor based on the nanoflowers of $\mathrm{Co}_{3} \mathrm{O}_{4}$ could be attributed to their relatively large surface area to volume ratio, which can carry high degree of the GOx molecules and exposed large surface for the oxidation of the glucose molecules on the surface of the enzyme immobilized $\mathrm{Co}_{3} \mathrm{O}_{4}$ nanoflowers. The selectivity of the presented glucose biosensor was measured with a $50 \mu \mathrm{M}$ of the glucose and a $0.5 \mathrm{mM}$ of the copper ion, ascorbic acid, uric acid and urea, respectively and the observed response is shown in Figure 4.7b. The presented $\mathrm{GOx} / \mathrm{Co}_{3} \mathrm{O}_{4}$ nanoflowers/Au based sensor is very selective in the detection of glucose due to the favorable oxidation offered by the GOx for only the glucose molecules using the potentiometric method.

\section{Dopamine wide range detection sensor based on modified $\mathrm{Co}_{3} \mathrm{O}_{4}$ nanowires electrode (paper IV)}

After we successfully demonstrated that, the ZnO NRs based CMEs has wide linear dynamic concentration range $1 \times 10^{-6}$ to $1 \times 10^{-1} \mathrm{M}$ for the detection of dopamine molecules with a fast response time. However, the lower detection limit needs to be improved because the concentration of dopamine in biological systems is in the range of $10^{-8}$ to $10^{-6}$ M. Moreover, the effect of the organic additives on modifying the morphology and their associated effect on the sensing and even on the electronic structures, as demonstrated in paper I, II and III, it was appealing to seek a more sensitive sensor. In the present paper,103 an anionic SDBS surfactant was used to achieve assisted growth procedure. After the SDBS-doped $\mathrm{Co}_{3} \mathrm{O}_{4}$ nanowires were successfully grown on Au coated glass substrates by the ACG method, the same polymeric membrane used in paper I was used here as well.

SEM images at low and high magnification for $\mathrm{Co}_{3} \mathrm{O}_{4}$ nanowires grown at relatively high concentration $2.8 \mathrm{mM}(0.1 \mathrm{~g}$ in $100 \mathrm{ml})$ of the SDBS are shown in Figure 4.8a and b respectively. Further, the $\mathrm{Co}_{3} \mathrm{O}_{4}$ nanowires achieved with $1.4 \mathrm{mM}(0.05 \mathrm{~g})$ of the SDBS are shown Figure 4.8c and d. Relatively thin $\mathrm{Co}_{3} \mathrm{O}_{4}$ nanowires grown with a diameter of around $50 \mathrm{~nm}$ are shown. We believed that the SDBS in the growth solution would initiate the growth by the formation of an electrical double layer at the interface. Since the whole system has been subjected to $\sim 90{ }^{\circ} \mathrm{C}$ there would be an aggregation of the SDBS molecules on the substrate. ${ }^{134}$ This aggregates that is in the form of micelles have a crucial effect into 
the thermodynamics of the system and hence in controlling and forming a template for the growth of $\mathrm{Co}_{3} \mathrm{O}_{4}$ nanowires.
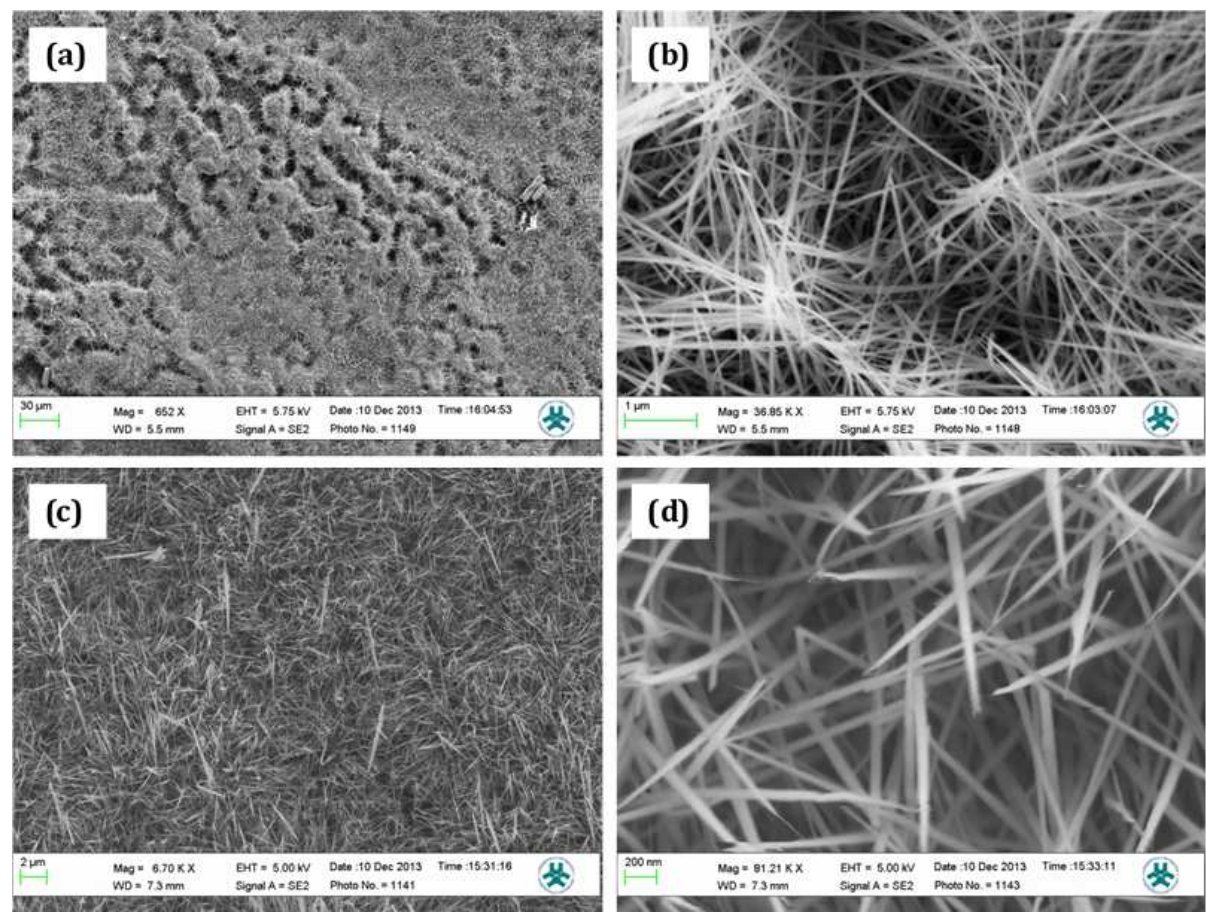

Figure 4. 8: $\mathrm{SEM}$ images show the morphology of the $\mathrm{Co}_{3} \mathrm{O}_{4}$ nanostructures grown with a different amount of SDBS (a) 0.1 and (b) $0.05 \mathrm{~g}$ with high and low magnifications and both of them are dense with a high aspect ratio. ${ }^{103}$

In order to describe the crystal structure, the XRD pattern of the annealed sample of $\mathrm{Co}_{3} \mathrm{O}_{4}$ nanostructures is shown in Figure 4.9. All of the five diffraction peaks could be indexed to cubic crystalline $\mathrm{Co}_{3} \mathrm{O}_{4}$, and these peaks position is consistent with the values reported in the JCPDS NO 42-1467. However, the peaks are less intense, as compared to the Au peak.

The developed CME can be described by polymeric membrane/SDBS-doped $\mathrm{Co}_{3} \mathrm{O}_{4}$ nanowires/Au. It was studied by a potentiometric method where the system has employed the $\mathrm{Co}_{3} \mathrm{O}_{4}$ CMEs as the indicator electrodes versus $\mathrm{Ag} / \mathrm{AgCl}$ as a reference electrode. In Figure 4.10 upon changing the dopamine molecule concentration from $1 \mathrm{nM}$ to $10 \mathrm{mM}$ in the buffer solution the electromotive force is changed. The wide range of detection of the SDBS-doped $\mathrm{Co}_{3} \mathrm{O}_{4}$ based CMEs was first attributed to the high surface- 


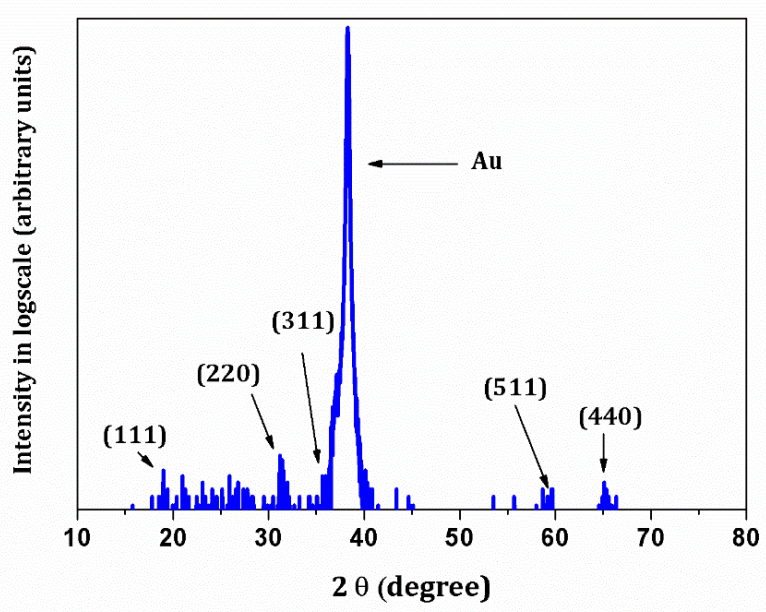

Figure 4. 9: $\mathrm{XRD}$ pattern of the $\mathrm{Co}_{3} \mathrm{O}_{4}$ nanostructures on $\mathrm{Au}$ coated glass. ${ }^{103}$

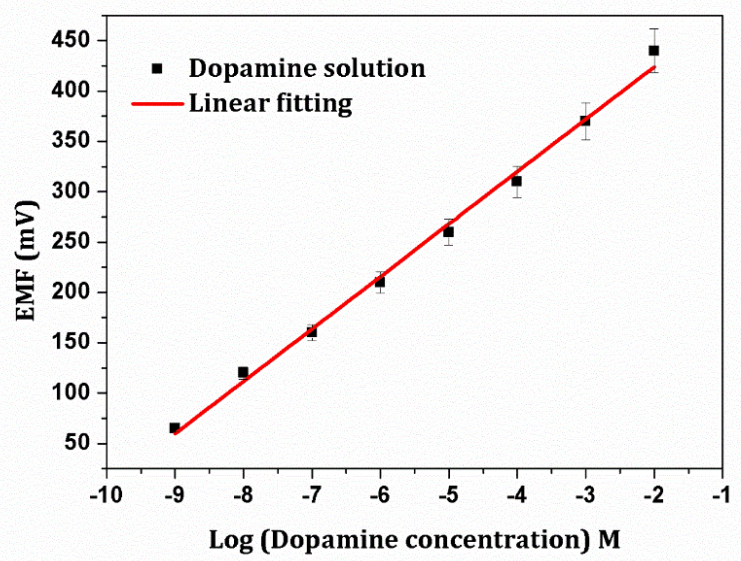

Figure 4. 10: Calibration curve showing the sensitivity and the linear response range of our constructed CMEs. ${ }^{103}$

area to volume ratio of the nanowires and their better electro-catalytic properties. Secondly, these results might be connected to the presence of the surfactant that has a duel effect; one in modifying the morphology and the other is by enhancing the sensitivity via point defects, upon dehydration of the cobalt hydroxide phase is existed. Since it is known that defects have a significant impact on the surfaces of metal oxides and would enhance the catalytic activity of the $\mathrm{Co}_{3} \mathrm{O}_{4 .}{ }^{135}$ 
Furthermore, to obtain information about the electronic structure and the transition from point defects, UV-Vis. spectroscopy was used. As shown in Figure 4.11a, the absorption spectra for three $\mathrm{Co}_{3} \mathrm{O}_{4}$ nanostructures grown with $0,1.4$ and $2.8 \mathrm{mM}$ on glass substrate is displayed. Two absorption peaks were observed at $\sim 2.35 \mathrm{eV}$ and $1.57 \mathrm{eV}$. The first peak can be attributed to charge transfer from $\mathrm{O}^{-2} \rightarrow \mathrm{Co}^{+2}$, and the second one from $\mathrm{O}^{-2} \rightarrow \mathrm{Co}^{+3} .136$ To determine the photon energy "optical band gap", we plot $(\alpha \mathrm{E})^{2}$ versus $\mathrm{E}$ in Figure $4.11 \mathrm{~b}$ for all three $\mathrm{Co}_{3} \mathrm{O}_{4}$ nanostructures, where $\alpha$ and $\mathrm{E}$ are the absorption coefficient and photon energy, respectively. The linear extrapolation of $(\alpha E)^{2}$ give two band gap values of each $\mathrm{Co}_{3} \mathrm{O}_{4}$ nanostructure $\sim 3.65 \mathrm{eV}-2.05 \mathrm{eV}$ for the structure grown without SDBS, $\sim 3.95 \mathrm{eV}-2.09 \mathrm{eV}$ for $\mathrm{Co}_{3} \mathrm{O}_{4}$ grown using $1.4 \mathrm{mM}$ SDBS and finally $\sim 4 \mathrm{eV}$ $-2.29 \mathrm{eV}$ for $\mathrm{Co}_{3} \mathrm{O}_{4}$ grown with a $2.8 \mathrm{mM}$ SDBS. It is well established that the band gap of bulk materials can largely be increased when compared with counterparts of the nanomaterial. ${ }^{137}$ These results confirmed that, SDBS as impurities may be dominant and have a direct influence on the electronic energy states within the band gap of the $\mathrm{Co}_{3} \mathrm{O}_{4}$ nanostructure. ${ }^{135}$
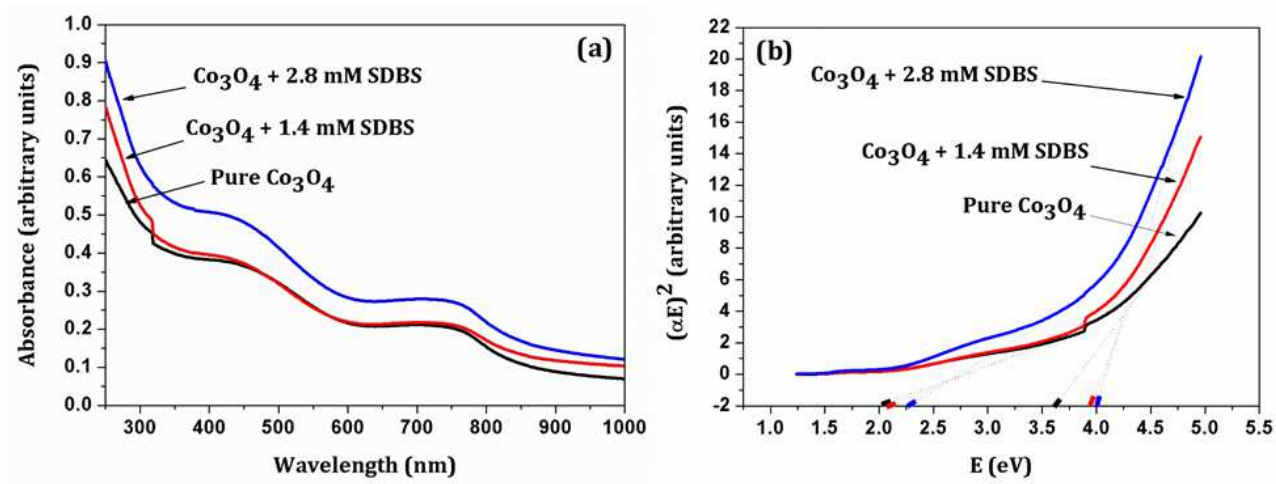

Figure 4. 11: (a) UV-Vis absorption spectra and (b) plot of $(\alpha E)^{2}$ versus photon energy for the $\mathrm{Co}_{3} \mathrm{O}_{4}$ nanostructures. ${ }^{103}$

\section{Efficient donor impurities in ZnO nanorods by polyethylene glycol for enhanced optical and glutamate sensing properties (paper $V$ )}

Now it is clear that low dimensional (LD) nanostructures such as NRs, nanowires are the most reliable in term of the electron transport based CMEs. In this work, polyethylene glycol (PEG)-doped ZnO NRs was found to efficiently improve the optical and chemical sensing characteristics toward glutamate. ${ }^{105}$ From the results, the PEG is 
suggested to be used as an efficient donor impurities for ZnO NRs with preserving the favorable LD NRs morphology structure.

Figure 4.12a-d shows that all the ZnO NRs were dense, vertically aligned and with diameters in the range of 200-400 nm. However, ZnO NRs doped with $0.1 \%$ (w/v) of PEG exhibited low-density distribution compared to the other NRs (Figure 4.12c). In the experiment, water equimolar zinc nitrate hexahydrate and HMT of $0.05 \mathrm{M}$ were mixed with different concentrations of PEG. However, as the PEG concentration is increased from 0 to $0.05,0.1$ or $0.15 \%$ (w/v) of PEG solution, the morphology is preserved as $\mathrm{ZnO}$ NRs that are usually grown when using HMT as a buffer medium. ${ }^{51}$
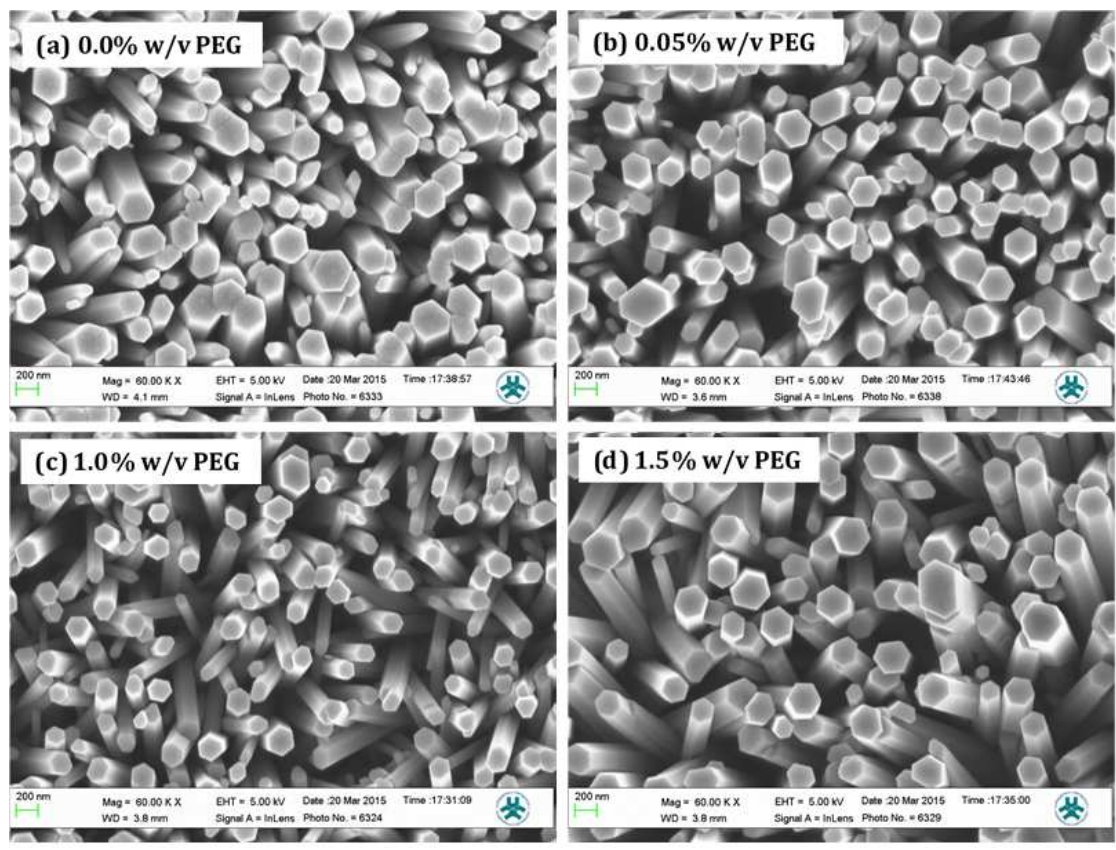

Figure 4. 12: SEM images of the ZnO NRs obtained with different concentrations of the PEG.105

Many researchers have also incorporated organic additives to the $\mathrm{ZnO}$ material, and their exclusive results were demonstrated by introducing new morphology. Accordingly, some characteristics e.g. optical, electrical and catalytic have been modulated. ${ }^{92,138}$ In contrast, the incorporation of inorganic material into ZnO NRs with a certain concentration has no role on the morphology, but the aforementioned characteristics were notably modified. ${ }^{139,140}$ Note that the PEG is completely miscible with water and has found many applications in current technology as antifreeze when mixed with water. ${ }^{100}$ 


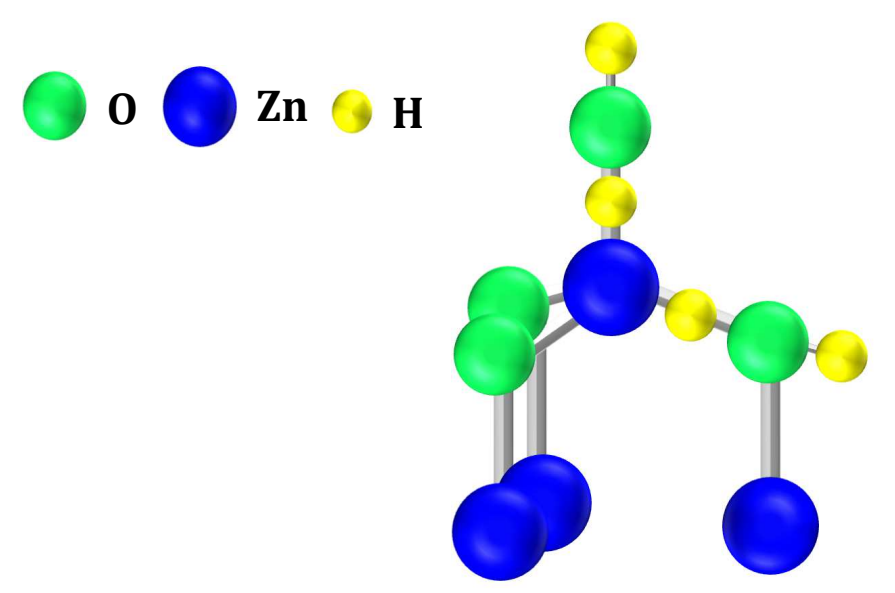

Figure 4. 13: Schematic represent the four $\mathrm{H}$ sites in $\mathrm{ZnO} .^{141}$

This is probably due to its strong hydrogen bonding interaction in water. ${ }^{101}$ Therefore, we believe that the disruption of hydrogen bonding when dissolved in water, provides a rich hydrogenated environment for the growth of ZnO NRs. It is important also to note that, hydrogen is relatively very small in volume and the possibility of the incorporation inside the ZnO NRs structure is highly expected. Limpijumnong et al., and E.V. Lavrov et al.,141,142 have investigated the configuration of hydrogen when incorporated into ZnO under hydrostatic pressure and they reported that, the hydrogen has four possible locations to reside in $\mathrm{ZnO}$ i.e. it might be a shallow donor or might not be a shallow donor (Figure 4.13). Lavrov et al., have also reported that hydrogen related shallow donor in $\mathrm{ZnO}$ were studied by photoconductivity and infrared absorption spectroscopy. ${ }^{143}$

For $\mathrm{ZnO}$, the intrinsic optical transitions between carriers from the conduction band (electrons) and the valence band (holes) results in a sharp UV luminescence. In addition to the UV luminesce; there is the defect-related transitions called the "visible luminescence", and appears as a wide band emission. Both emissions can clearly be seen in Figure 4.14.144 The photoluminescence intensity (UV in this case) is explicitly increased. However, this dependence observed, except of the cases with PEG exceeding $0.1 \%(\mathrm{w} / \mathrm{v})$. This observation is also in agreement with Tsiarapas et al. ${ }^{145}$ They correlated the best results for Schottky diodes to a certain amount (33.3\%) of hydrogen. Therefore, one can infer that, a low amount of PEG introduces hydrogen, which acts as impurities and lead to increase the passivation of nonradioactive defect. ${ }^{146-148}$ 


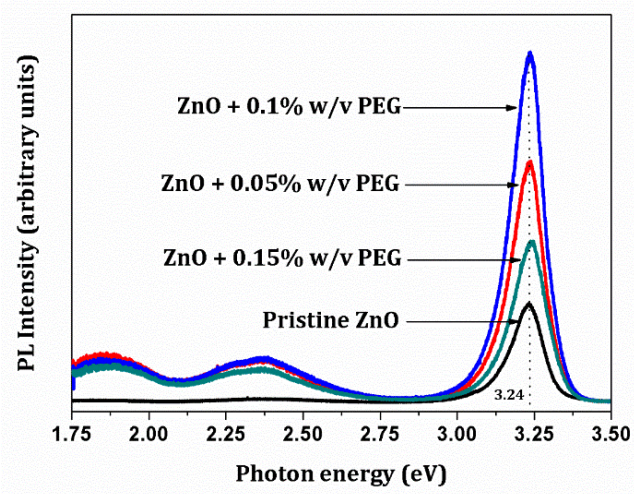

Figure 4. 14: Room temperature PL spectra of $\mathrm{ZnO}$ NRs grown on Au coated glass with and without presences of PEG showing a sharp UV peak accompanied by two broad visible emission peaks. ${ }^{105}$

Figure 4.15a shows that all the absorbance spectra for the ZnO NRs grown with various amounts of PEG exhibited spectral features and are very similar to those reported for pure $\mathrm{ZnO}$. The absorption peaks for the PEG grown with $0,0.1,0.15 \%(\mathrm{w} / \mathrm{v}$ ) of the PEG was observed at $\sim 2.82 \mathrm{eV}, 2.66 \mathrm{eV}$ and $2.62 \mathrm{eV}$, respectively. It can be seen that the absorption edge moves towards a higher wavelength with increased PEG concentration. Next, we plotted $(\alpha h v)^{2}$ versus $\mathrm{E}$ in Figure $4.15 \mathrm{~b}$ for all three ZnO NRs. The linear extrapolation of $(\alpha h v)^{2}$ gives the optical band gap value of each ZnO NRs. For the pristine ZnO NRs the obtained value was $\sim 3.16 \mathrm{eV}$. While for the NRs grown with addition of 0.1 , and $0.15 \%(\mathrm{w} / \mathrm{v})$ of PEG, the corresponding values were $\sim 2.95 \mathrm{eV}$ and $2.67 \mathrm{eV}$, respectively. It is also worth mentioning that, in semiconductor nanocrystals the dimension of the nanostructures impurities and defects concentration can affect the physics of the band gap. ${ }^{54,149}$ That means the band gap of bulk materials can be larger when compared with nanomaterial forms and can be decreased or increased depending on the dopant nature. Therefore, the decrease in the optical band gap as the PEG concentration is increased could be ascribed to the PEG impurities that could act as shallow donors into the band gap of $\mathrm{ZnO}$.

Now let us look on the electronic structure that has been investigated using oxygen 1s (O 1s) and zinc 2p (Zn 2p) XPS spectra of pristine and 0.1\% w/v PEG-doped ZnO NRs. From Figure 14.16a the spin-orbital splitting peaks at $\sim 1022.5 \mathrm{eV}$ and $\sim 1045.8 \mathrm{eV}$, are assigned to the $\mathrm{Zn} 2 \mathrm{p}_{3 / 2}$ and the Zn $2 \mathrm{p}_{1 / 2}$, respectively. However, from the 01 s spectra (see Figure $14.16 \mathrm{~b}$ ) a pronounced peak in the case of the pristine ZnO NRs at $\sim 532 \mathrm{eV}$ is- 

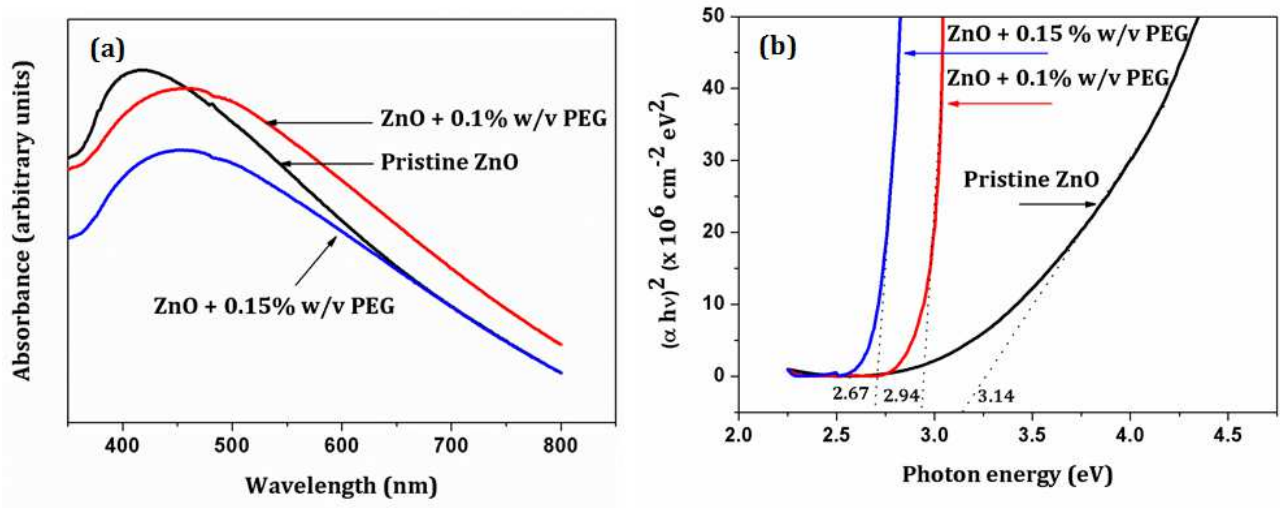

Figure 4. 15: (a) UV-Vis absorption spectra of ZnO NRs grown on glass with different amount of PEG and (b) the plot of $(\alpha E)^{2}$ versus photon energy. ${ }^{105}$
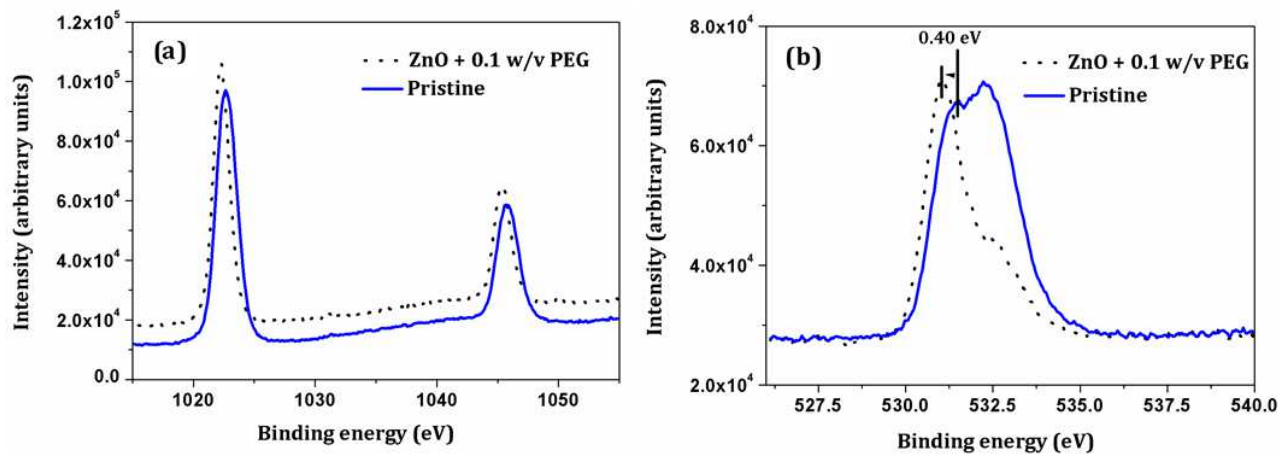

Figure 4. 16: XPS study of the as grown pristine ZnO NRs (solid line) and $0.1 \% \mathrm{w} / \mathrm{v}$ PEG doped ZnO NRs with 0.1\% w/v PEG on Au (a) 0 1s and, (b) Zn 2p spectra. ${ }^{105}$

observed. While for the $0.1 \%$ (w/v) PEG-doped ZnO NRs this peak appears as a weak shoulder, indicated that the $\mathrm{OH}$ bonding could be incorporated inside the $\mathrm{ZnO}$ structure. The later result is in a good agreement with Van de Walle work in Ref.,150 where he suggested that, the addition of a proton turning the oxygen into an element behaving much like fluorine and hence, it may appears as a weak shoulder compared to the case of the pristine ZnO NRs. As it is well known that, the electrical and optical properties of semiconductors could be affected with some impurities and small concentrations of native point defects. Accordingly, a shift of $\sim 0.4 \mathrm{eV}$ to the lower binding energy was observed in the core level of the 01s for PEG-doped ZnO NRs as shown in Figure 4.16b, which could be explained as an enhancement to the n-type conductivity of $\mathrm{ZnO}$ material. 

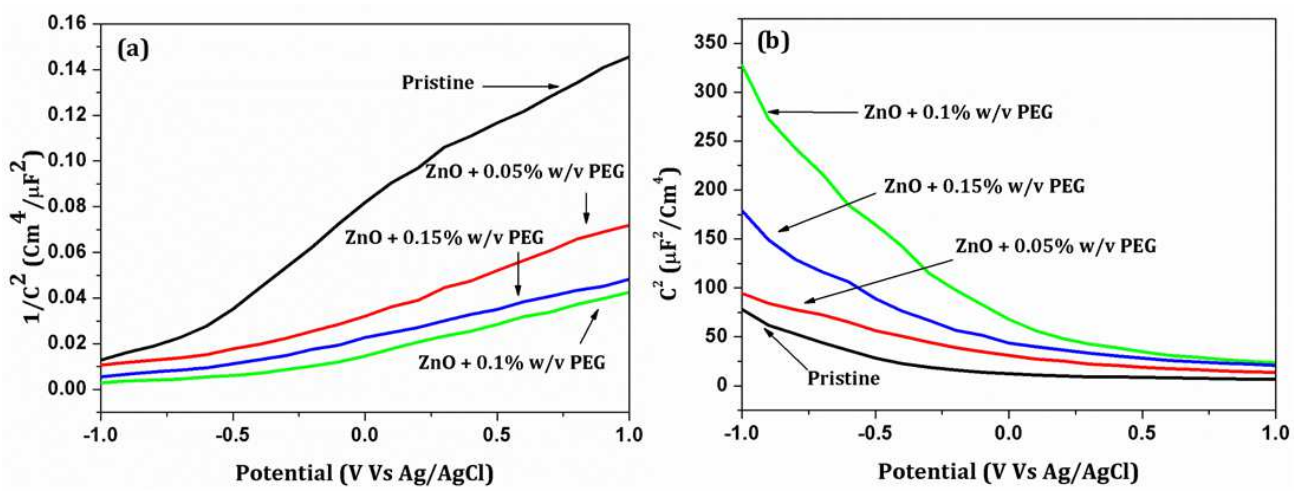

Figure 4. 17:(a) Mott-Schottky plots of the pristine and PEG-doped ZnO NRs with different amount in $0.1 \mathrm{M} \mathrm{LiClO}_{4}$ and (b) shows the increases of the capacitances upon the increase of the PEG amount. 105

Moreover, from the Mott-Schottky method, the doping density $\left(\mathrm{N}_{\mathrm{d}}\right)$ into ZnO NRs was estimated. The Mott-Schottky plot of $1 / C^{2}=\frac{2}{N_{d} e \varepsilon_{s}}\left[\left(V-V_{f b}\right)-k T / e\right]$ versus the voltage is shown in Figure 4.17a. Where $\mathrm{C}$ is the capacitance, $\mathrm{V}$ is the electrode potential, $\mathrm{K}$ is the Boltzmann constant, $\mathrm{T}$ is the temperature, e is the electron charge, and $\varepsilon_{s}=10$ is the dielectric constant of $\mathrm{ZnO}$. From Figure $4.17 \mathrm{a}$, the $\mathrm{N}_{\mathrm{d}}$ from the slope of the straight line can be calculated and the flat band voltage $\left(\mathrm{V}_{\mathrm{fb}}\right)$ could also be obtained from the intercept. ${ }^{151}$ All the obtained results for $\mathrm{N}_{\mathrm{d}}$ and $\mathrm{V}_{\mathrm{fb}}$ at the selected frequency (around 1.5 $\mathrm{kHz}$ ) are summarized in Table II. Note in Table II the free carrier concentration for the 1.5\% (w/v) PEG-doped ZnO NRs is less than the 0.1\% w/v PEG-doped ZnO NRs.

Table II: Effect of doping on the flat band voltage $\left(\mathrm{V}_{\mathrm{fb}}\right)$ and the doping density $\left(\mathrm{N}_{\mathrm{d}}\right)$.

\begin{tabular}{|c|c|c|}
\hline ZnO NRs & $\mathbf{V}_{\mathrm{fb}}(\mathrm{V})$ & $\mathrm{N}_{\mathrm{d}}\left(\mathrm{cm}^{-3}\right)$ \\
\hline Pristine & -1.09 & $2.81 \times 10^{19}$ \\
\hline$+0.05 \%(\mathrm{w} / \mathrm{v}) \mathrm{PEG}$ & -1.1 & $5.37 \times 10^{19}$ \\
\hline$+0.1 \%(w / v)$ PEG & -0.87 & $1.39 \times 10^{20}$ \\
\hline$+0.15 \%(\mathrm{w} / \mathrm{v}) \mathrm{PEG}$ & -0.82 & $7.58 \times 10^{19}$ \\
\hline
\end{tabular}

Furthermore, the capacitances increased when the amount of the doping increases. In Figure $4.17 \mathrm{~b}$ at $0.1 \%\left(\mathrm{w} / \mathrm{v}\right.$ ) PEG the capacitance reached a value around $325 \mu \mathrm{F}^{2} / \mathrm{Cm}^{4}$ while it was $75 \mu \mathrm{F}^{2} / \mathrm{Cm}^{4}$ for the pristine $\mathrm{ZnO}$ NRs. This capacitance reached a value of $\sim$ $200 \mathrm{C}^{2} \mu \mathrm{F}^{2} / \mathrm{Cm}^{4}$ for an amount of $0.1 \%(\mathrm{w} / \mathrm{v})$ of the PEG as compared to the pristine sample that showed a maximum capacitance of $\sim 60 \mathrm{C}^{2} \mu \mathrm{F}^{2} / \mathrm{Cm}^{4}$. However, at an amount of $0.15 \%(\mathrm{w} / \mathrm{v})$ of PEG the capacitance has reached around $175 \mu \mathrm{F}^{2} / \mathrm{Cm}^{4}$. This behavior 
can usually be observed for II-VI semiconductors and is called self-compensation mechanism. ${ }^{152}$ Self-compensation mechanism is a recombination of free carriers from dopant with opposite charge native point defects (vacancies, interstitials. etc.).

Now it is clear that from XPS and Mott Schottky investigations the most suitable amount of $\mathrm{ZnO}$ doping by PEG is a $0.1 \% \mathrm{w} / \mathrm{v}$ PEG, since the $\mathrm{n}$-type conductivity has been significantly modified. Moreover, 0.1\% w/v PEG-doped ZnO NRs based CMEs were compared with the pristine $\mathrm{ZnO}$ for the detection of glutamate (Glu) molecules. Figure 4.18a and b shows a comparison calibration curves between the PEG-doped ZnO NRs and the pristine ZnO NRs. As can be seen that from Figure 4.18 b, the GluOx/PEG-doped ZnO NRs/Au electrode was showed a wider range of detection for the Glu concentration with a superior sensitivity of $91.15 \mathrm{mV} /$ decade and the lower limit of detection was found to be $0.05 \times 10^{-6} \mathrm{M}$. Furthermore, some properties of the present chemical sensors like response time and the selectivity were studied by a potentiometric method. The response time is plotted in Figure 4.18c shows a value less than $10 \mathrm{~s}$ is the time needed for the CME to reach the saturation mode, which was measured in $1 \mathrm{mM}$ of Glu. A wide range of detection and a good sensitivity of the GluOx/PEG-doped ZnO NRs/Au electrode and the fast response time are all due to the enhancement of the electro-catalytic property that is dictated by the existence of PEG beside the high surface area-to-volume ratio. In order to evaluate the GluOx selectivity, a $100 \mu \mathrm{L}$ of $100 \mathrm{mM}$ glucose, ascorbic acid urea or $\mathrm{Cu}^{2+}$ ion respectively were added to a $0.1 \mathrm{mM}$ Glu solution. Figure $4.18 \mathrm{~d}$ shows that the interference is not significantly affecting the Glu signal intensity even with a very sharp signal of urea. This urea signal can be explained according to previously reported work. ${ }^{153}$ During the interaction of the urea with a water molecule, two products are released in the reaction vessel including ammonia and carbon dioxide. The ammonia and the $\alpha$ xoglutarate are converted to glutamate in a reaction catalyzed by the GluOx. Mostly the specificity may be attributed to the existence of GluOx. ${ }^{154}$ 

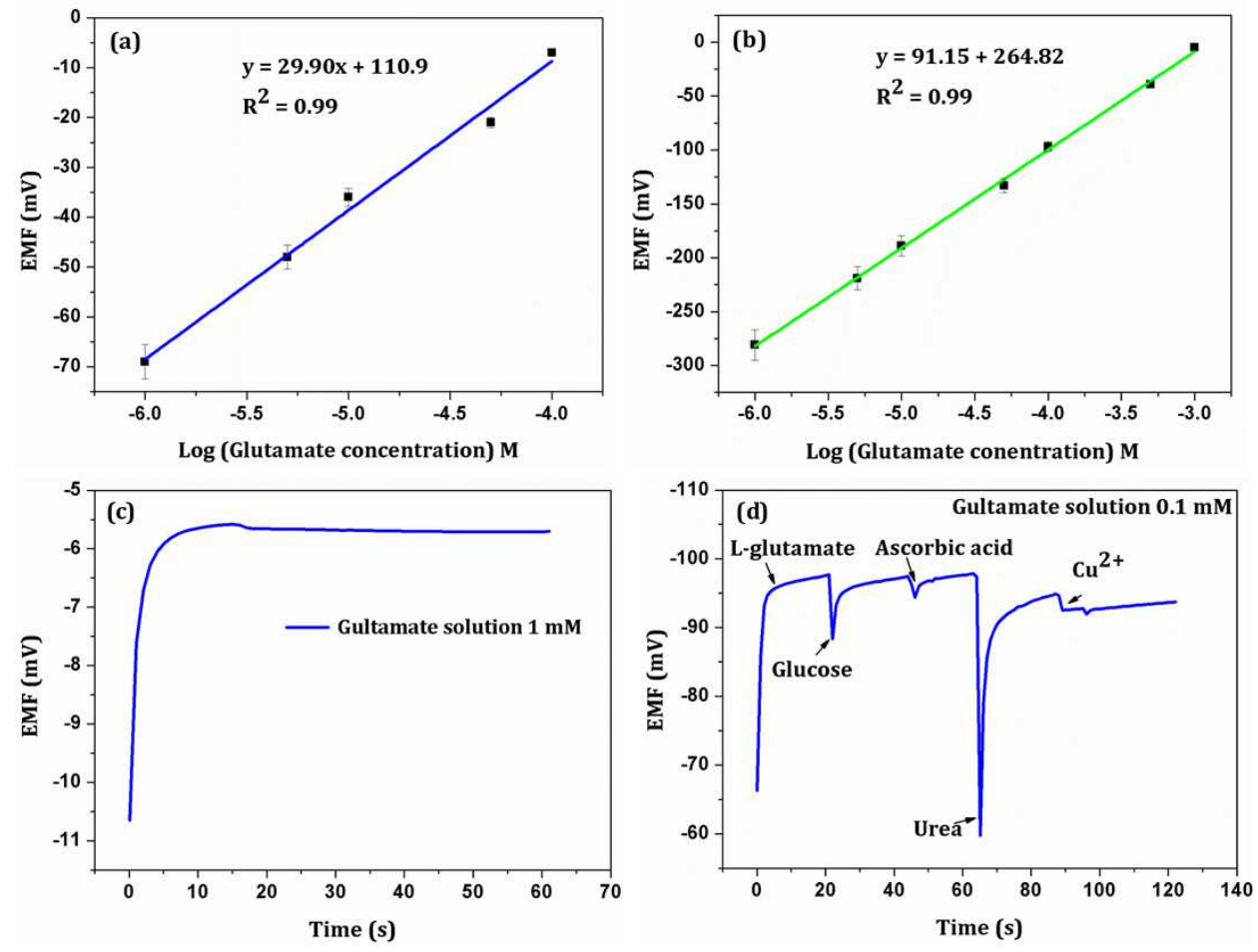

Figure 4. 18:Different properties of a potentiometric chemical sensor using ZnO NRs based CMEs to detect glutamate molecules (a) and (b) shows a comparison calibration curve between the pristine and the PEG-doped ZnO NRs, respectively, (c) the response time and (d) the selective response in the presence of $100 \mu \mathrm{L}$ of $100 \mathrm{mM}$ of common interferents. ${ }^{105}$

\section{Low-temperature growth of polyethylene glycol-doped $\mathrm{BiZn}_{2} \mathrm{VO}_{6}$ nano- compounds with enhanced photoelectrochemical properties (paper VI)}

In this part of the research work, the $\mathrm{BiZn}_{2} \mathrm{VO}_{6} \mathrm{NCs}$ that have been prepared by a low temperature $\left(80-90^{\circ} \mathrm{C}\right)$ using $\mathrm{BiVO}_{4}$ growth on $\mathrm{ZnO}$ NBs. Then, the NCs were doped with PEG to tune the electronic structure of the materials. Furthermore, the PEC activity of the prepared materials were investigated in $0.1 \mathrm{M}$ lithium perchlorate in carbonate propylene under a simulated solar irradiation (AM1.5G). ${ }^{106}$ The results of this work are discussed below; 

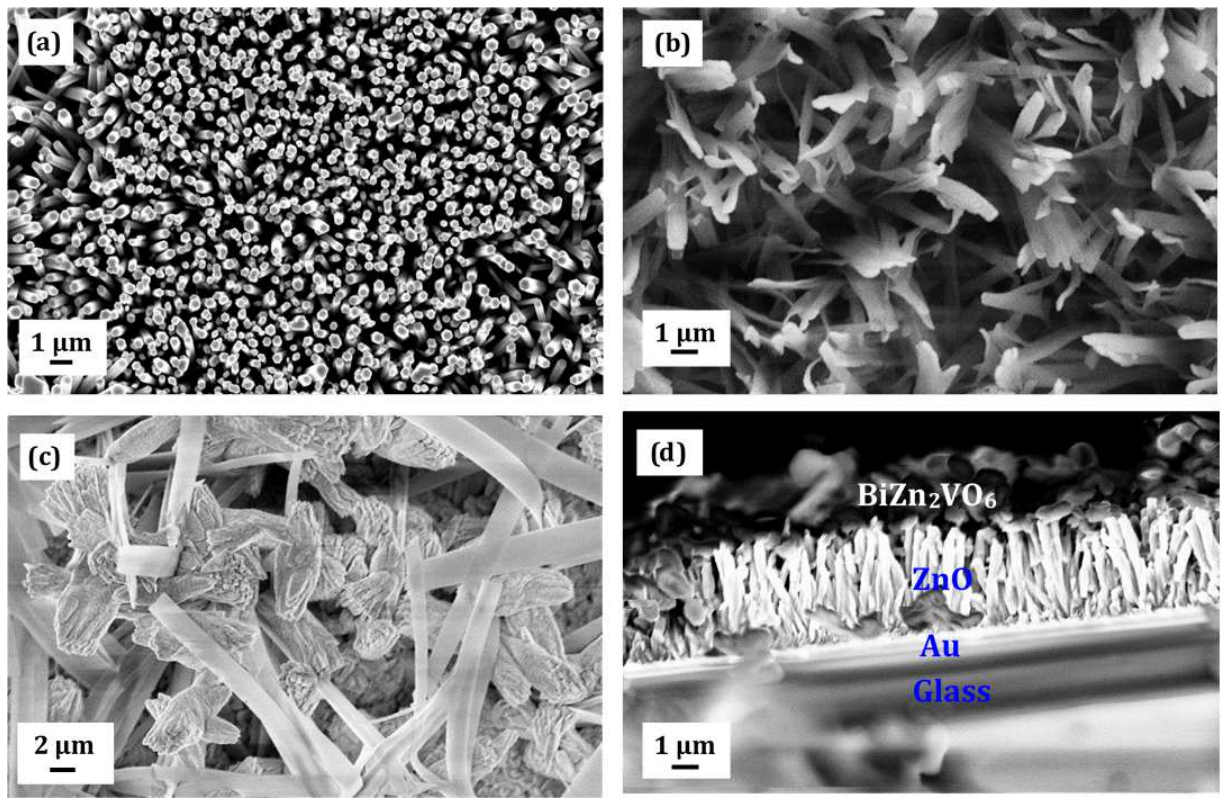

Figure 4. 19: SEM of (a) PEG-doped ZnO NRs, (b) PEG-doped ZnO nanobelts, (c) PEGdoped BiZn2V06 NC grown in $4 \mathrm{~h}$ and (d) side view of (c). ${ }^{106}$

The starting $\mathrm{ZnO}$ nanostructures in this work were $\mathrm{ZnO}$ NRs, which were converted into NB structures during the $\mathrm{BiZn}_{2} \mathrm{VO}_{6}$ growth. In order to obtain the same morphology for the $\mathrm{ZnO}$ nanostructure part of all samples, also the control $\mathrm{ZnO}$ samples were converted into ZnO NBs. To achieve this, the as-prepared ZnO NRs electrodes were immersed into a solution containing $10 \mathrm{~mL}$ of Nitric acid, 70\% $\mathrm{HNO}_{3}$, and $20 \mathrm{ml}$ deionized water. Sodium hydrogen carbonate $\left(\mathrm{NaHCO}_{3}\right)$ was added to adjust the $\mathrm{pH}$ value to 6.5. Then this beaker placed in an oven for 4 hours at $80{ }^{\circ} \mathrm{C}$. Figure $4.19 \mathrm{a}$ and b show SEM images that indicating the etching effect and the clear tuning of the $\mathrm{ZnO}$ morphology from NRs to NBs. This expected behavior shows that the $\mathrm{ZnO}$ can be etched by the lower $\mathrm{pH}$ of the $\mathrm{BiVO}_{4}$ growth solution $(\mathrm{pH} \approx 6.0-6.5)$. $\mathrm{BiZn}_{2} \mathrm{VO}_{6}$ exhibited a morphology of rice-like nanostructures is shown in Figure4.19c and d. In this work, different growth durations were investigated. However, long growth durations were resulted in the denser morphologies and larger width of the $\mathrm{BiZn}_{2} \mathrm{VO}_{6}$ structures.

Figure 4.20a shows the XRD patterns of the as prepared $\mathrm{ZnO} \mathrm{BiVO}_{4}$ and $\mathrm{BiZn}_{2} \mathrm{VO}_{6}$ grown by the low-temperature ACG with 4 and $10 \mathrm{~h}$ growth durations. In the XRD patterns, the hexagonal wurtzite structure of the pristine and the doped $\mathrm{ZnO}$ NBs were - 


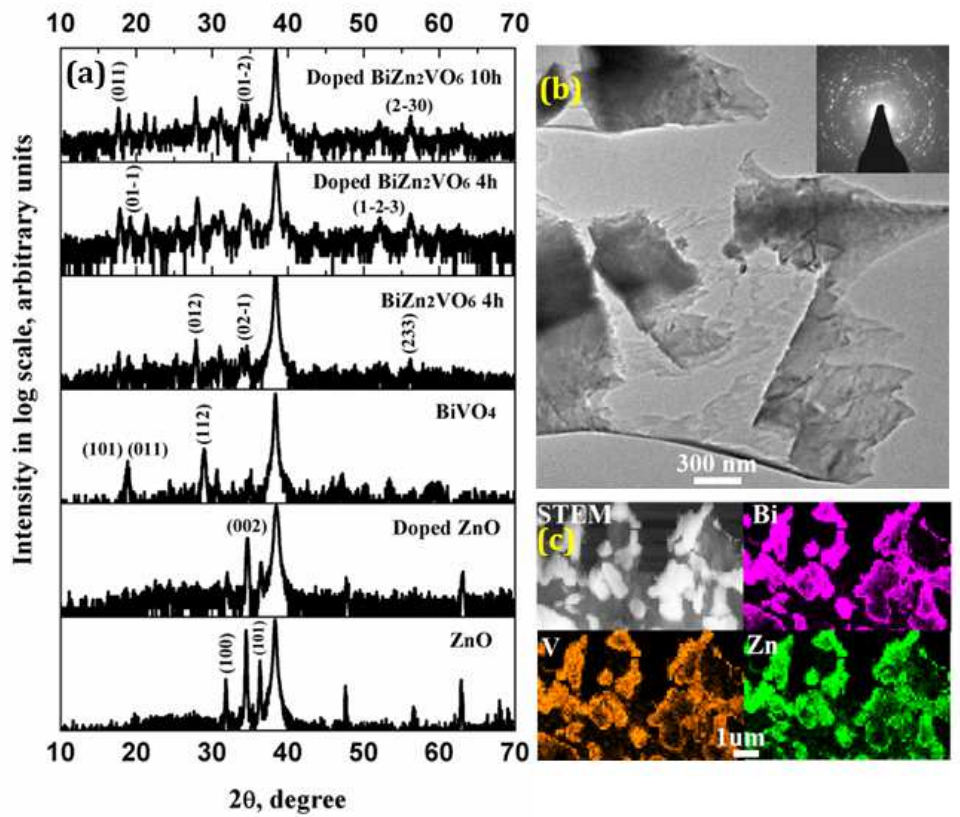

Figure 4. 20: (a) XRD patterns of ZnO NBs, PEG-doped ZnO NBs, BiVO4, and PEG-doped $\mathrm{BiZn}_{2} \mathrm{VO}_{6} \mathrm{NCs}$ grown by the low-temperature aqueous solutions hydrothermal synthesis for 4 and 10h, (b) TEM image of a $\mathrm{BiZn}_{2} \mathrm{VO}_{6}$ and the inset shows the corresponding SAED pattern and (c) EDX mapping. ${ }^{106}$

confirmed by comparing the experimental data with the literature data (JCPDS NO 361451). The XRD patterns of $\mathrm{BiVO}_{4}$ agrees well with the characteristic pattern arising from a monoclinic scheelite phase of $\mathrm{BiVO}_{4}$ (JCPDS NO 74-4894). However, the XRD patterns of the $\mathrm{BiZn}_{2} \mathrm{VO}_{6} \mathrm{NCs}$ samples exhibited orthorhombic unit cells that is usually observed for mixed metal oxides. ${ }^{87}$ One can also note that the XRD patterns for the $\mathrm{BiZn}_{2} \mathrm{VO}_{6}$ and the PEG-doped $\mathrm{BiZn}_{2} \mathrm{VO}_{6}$ grown for $4 \mathrm{~h}$ and $10 \mathrm{~h}$ are identical. Thus $4 \mathrm{~h}$ is a suitable growth time for the $\mathrm{BiZn}_{2} \mathrm{VO}_{6} \mathrm{NCs}$, which is an improvement compared to previous published results on the growth of $\mathrm{BiM}_{2} \mathrm{AO}_{6}$ by solid-state reactions using high-temperature and relatively longer growth durations ( $\geq 700{ }^{\circ} \mathrm{C}$, up to $\left.30 \mathrm{~h}\right) .84,85,87$ and 155 Furthermore, the existence of a mixed metal oxide $\left(\mathrm{BiZn}_{2} \mathrm{VO}_{6}\right)$ was confirmed by a TEM as is shown in Figure $4.20 \mathrm{~b}$ and c. Figure $4.20 \mathrm{~b}$ represents the selective area electron diffraction (SAED) pattern that shows the polycrystalline nature of the product. Figure 4.20c shows the energy dispersive X-ray spectroscopy (EDX) mapping and demonstrates that all the $\mathrm{Zn}, \mathrm{Bi}$ and $\mathrm{V}$ has an equal distribution. 

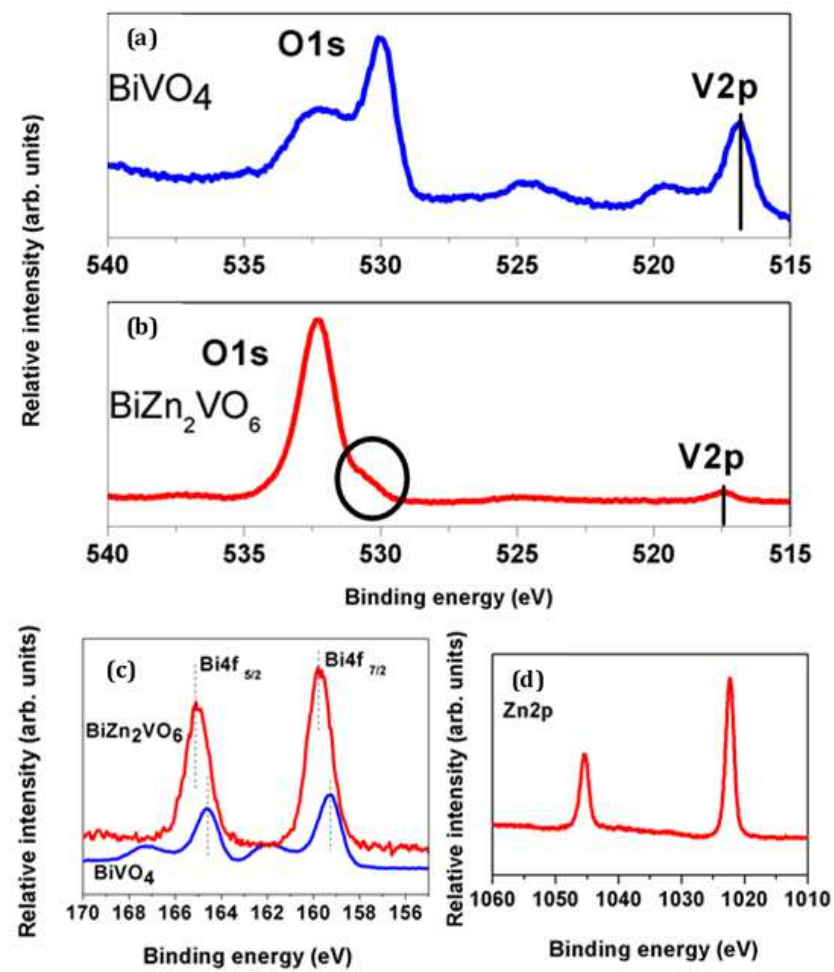

Figure 4. 21: XPS spectra of (a) and (b) 01s and V2p of the as grown $\mathrm{BiVO}_{4}$ and $\mathrm{BiZn}_{2} \mathrm{VO}_{6}$ $\mathrm{NCs}$ on Au coated glass, respectively, (c) Bi4f for both the $\mathrm{BiVO}_{4}$ and the $\mathrm{BiZn}_{2} \mathrm{VO}_{6}$ and (d) Zn 2p spectrum for $\mathrm{BiZn}_{2} \mathrm{VO}_{6}$ NCs. ${ }^{106}$

The XPS was also used to analyze the $\mathrm{BiVO}_{4}$ control sample and the PEG-doped $\mathrm{BiZn}_{2} \mathrm{VO}_{6}$ sample. The XPS peaks at $\sim 530 \mathrm{eV}$ and $\sim 516.8 \mathrm{eV}$ in Figure 4.21a correspond to oxygen species in the metal oxide and vanadium oxide phase, respectively. ${ }^{156}$ The hydroxyl group from adsorbed water has appeared as a shoulder at $\sim 532 \mathrm{eV}$ for the $\mathrm{BiVO}_{4}$. While for doped BiZn2 $\mathrm{VO}_{6} \mathrm{NCs}$ in Figure 4.21b, the hydroxyl group and adsorbed water at $\sim 532 \mathrm{eV}$ is the dominant feature and the feature related to 01s spectrum now appears as a tail in the lower binding energy (marked by a circle in Figure 4.21b).

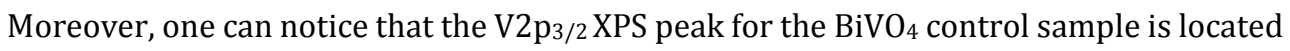
at around $\sim 517 \mathrm{eV}$ and for doped the $\mathrm{BiZn}_{2} \mathrm{VO}_{6} \mathrm{NCs}$ is located at around $\sim 517.5 \mathrm{eV}$ i.e. shifts slightly to a higher binding energy. The same scenario is true for the peak positions of Bi4 can be noticed in Figure 4.21c. According to the literature, the unit cell of the monoclinic $\mathrm{BiVO}_{4}$ has $\mathrm{a} \sim 7.2 \AA$, $\mathrm{b} \sim 11.7 \AA$ and $\mathrm{c} \sim 5.1 \AA$, 157 while for mixed metal oxides 
( $\mathrm{BiM}_{2} \mathrm{AO}_{6}$ ) which is orthorhombic and possesses a unit cell with $\mathrm{a} \sim 11.5 \AA$, $\mathrm{b} \sim 5.5 \AA$ and c $\sim 8.5 \AA .87$ Thus, this shift in the binding energies can be attributed to the incorporation of $\mathrm{ZnO}$ element into the $\mathrm{BiVO}_{4}$ structure because the bonding length and the band structure is expected to be different for $\mathrm{BiVO}_{4}$ and $\mathrm{BiZn}_{2} \mathrm{VO}_{6}$. The $\mathrm{Zn} 2 \mathrm{p}$ XPS spectra of the $\mathrm{BiZn}_{2} \mathrm{VO}_{6}$ is shown in Figure 4.21d, where the spin-orbital splitting peaks at $\sim 1022.3 \mathrm{eV}$ and $\sim 1045.4 \mathrm{eV}$ are assigned to the $\mathrm{Zn} 2 \mathrm{p}_{3 / 2}$ and $\mathrm{Zn} 2 \mathrm{p}_{1 / 2}$, respectively. ${ }^{106}$

Moreover, UV-Vis. spectroscopy indicates an optical band gap at around $2.57 \mathrm{eV}$ as shown in Figure 4.22a. This is larger than previously reported data ${ }^{85}$ by $0.17 \mathrm{eV}$. However, it is still a narrow band gap that can be used for visible light-based applications. The room temperature PL spectra in Figure 4.22b shows the UV peak that is originate form free excitonic emission and the so-called green-yellow band that is caused by deep level emissions. As can be seen that the PEG has a crucial role in quenching the PL emission. This role comes from the fact that the PEG has many hydrogen bonds which can modulate the PL characteristic as reported elsewhere. ${ }^{158}$ This decrease in the PL intensity can be refereed as lower recombination rate which corresponds to higher PEC activity and vice versa. ${ }^{159}$ Therefore, the PEC activity for the PEG-doped $\mathrm{BiZn}_{2} \mathrm{VO}_{6}$ is investigated. Figure 4.23a shows linear sweep voltammetry for $\mathrm{ZnO} \mathrm{NBs}$, PEG-doped $\mathrm{ZnO} \mathrm{NBs}$, $\mathrm{BiZn}_{2} \mathrm{VO}_{6}$, and the PEG-doped $\mathrm{BiZn}_{2} \mathrm{VO}_{6}$ electrodes under simulated solar light at dark conditions (dashed lines) and under light irradiation (full curves). The observed photocurrent density was $0.35 \mathrm{~mA} \mathrm{~cm}^{-2}$ and $0.59 \mathrm{~mA} \mathrm{~cm}^{-2}$ for the undoped and the PEG-doped ZnO NBs at $1.23 \mathrm{~V}$ (vs $\mathrm{Ag} / \mathrm{AgCl}$ ), respectively. In comparison, the photocurrent density was 1.25 $\mathrm{mA} \mathrm{cm}{ }^{-2}$ at $1.23 \mathrm{~V}$ (vs $\mathrm{Ag} / \mathrm{AgCl}$ ) for the undoped $\mathrm{BiZn}_{2} \mathrm{VO}_{6} \mathrm{NCs}$. Hence, the photocurrent density of the $\mathrm{BiZn}_{2} \mathrm{VO}_{6} \mathrm{NCs}$, when compared with pristine and PEG-doped ZnO NBs, increases significantly, which can be assigned to efficient electro-catalytic surface activity of the $\mathrm{BiZn}_{2} \mathrm{VO}_{6} \mathrm{NCs}$ under visible light irradiation. ${ }^{85} \mathrm{PEG}$-doped $\mathrm{BiZn}_{2} \mathrm{VO}_{6} \mathrm{NCs}$ reached a values of $2 \mathrm{~mA} \mathrm{~cm}^{-2}$ at $1.23 \mathrm{~V}$ vs $\mathrm{Ag} / \mathrm{AgCl}$. Which corresponds to an improvement over $60 \%$ compared to pristine $\mathrm{BiZn}_{2} \mathrm{VO}_{6}$ NCs. This improvement in the charge collection efficiency of the electrode surface is attributed and explained for couple of reasons; firstly, the electron communications processes on the electrode surface were efficient due to the heterogeneous catalysis effect at the $\mathrm{BiZn}_{2} \mathrm{VO}_{6} / \mathrm{ZnO} \mathrm{NBs}$ interfaces. 

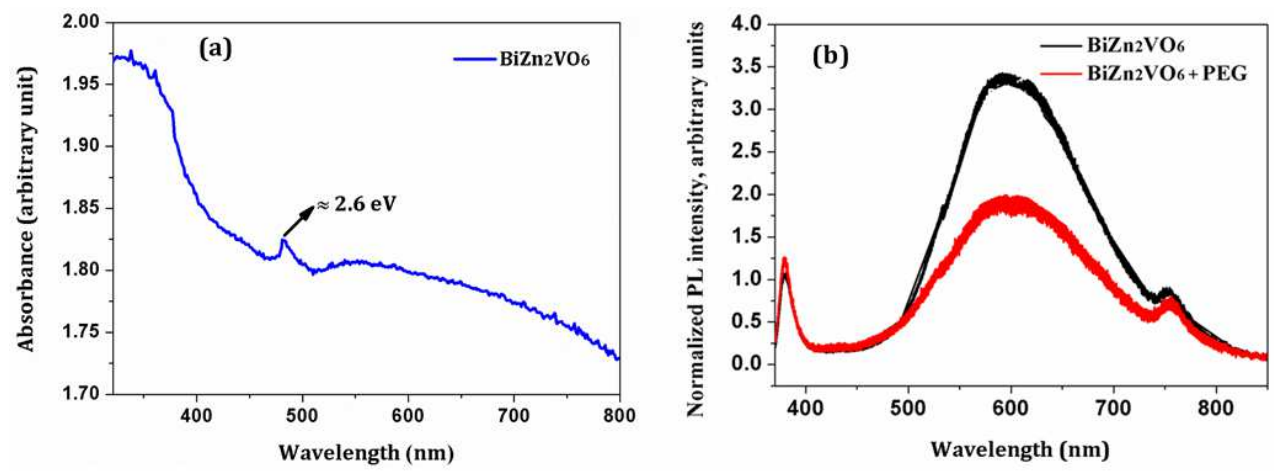

Figure 4. 22: (a) UV-Vis absorption spectrum of the $\mathrm{BiZn}_{2} \mathrm{VO}_{6}$ grown on glass with the same procedure as that used for the Au coated glass (b) PL intensities normalized for the $380 \mathrm{~nm}$ peak of the as-grown $\mathrm{BiZn}_{2} \mathrm{VO}_{6}$ and PEG-doped BiZn $2 \mathrm{VO}_{6}$ NCs. ${ }^{106}$
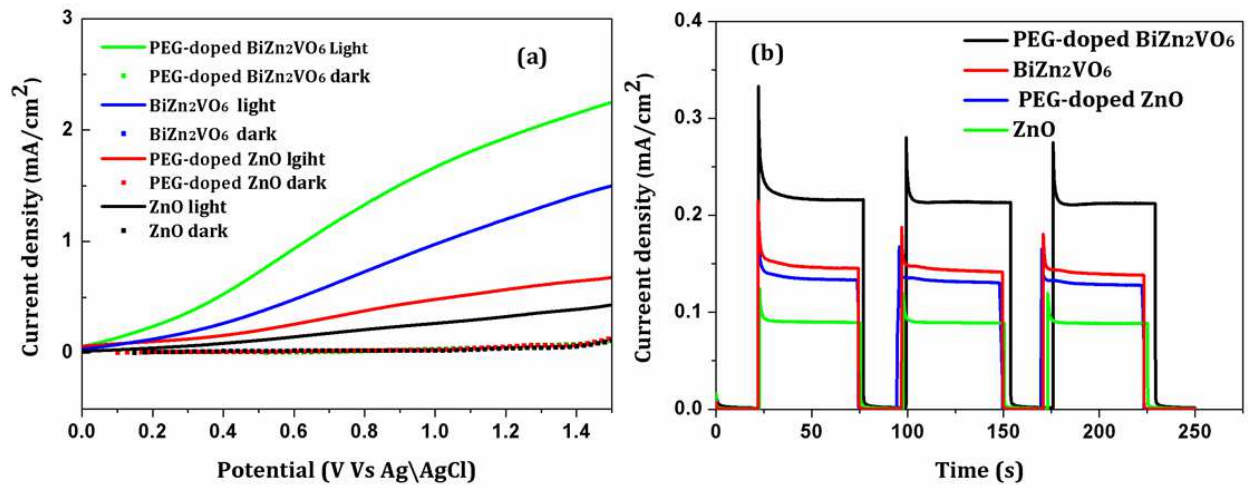

Figure 4. 23: (a) Linear sweep voltammetry of the ZnO NBs, PEG-doped ZnO NBs, $\mathrm{BiZn}_{2} \mathrm{VO}_{6}$ and PEG-doped $\mathrm{BiZn}_{2} \mathrm{VO}_{6}$ NCs electrodes in dark and under solar illumination (AM 1.5G) and (b) Chronoamperometry I-t curves of all electrodes at an applied voltage of $+0.5 \mathrm{~V}$ with $50 \mathrm{~s}$ light on/off cycles. ${ }^{106}$

Secondly, PEG impurities that act as shallow donor and enhance the n-type conductivity as it has been suggested in our previous work. ${ }^{105}$ These results are also consistent with previous published studies, ${ }^{160-162}$ where the authors argued that the doping plays distinct role in enhancing the photoactivity of semiconductor materials. Figure $4.23 \mathrm{~b}$ shows the response time of the pristine and doped electrodes in the dark and under simulated solar light at an applied voltage of $+0.5 \mathrm{~V}$. The stationary photocurrent density was $0.09 \mathrm{~mA} \mathrm{~cm}^{-}$ 2, $0.13 \mathrm{~mA} \mathrm{~cm}^{-2}, 0.14 \mathrm{~mA} \mathrm{~cm}^{-2}$ and $0.2 \mathrm{~mA} \mathrm{~cm}^{-2}$ for the prisitne ZnO NB, PEG-doped ZnO $\mathrm{NB}$, prisitne $\mathrm{BiZn}_{2} \mathrm{VO}_{6}$ and $\mathrm{PEG}$-doped $\mathrm{BiZn}_{2} \mathrm{VO}_{6}$, respectively. These results confirm that the PEG-doped $\mathrm{BiZn}_{2} \mathrm{VO}_{6} \mathrm{NCs}$ based electrode exhibited the highest current density, with a good reproducibility and stability. 


\section{Chapter 5 Conclusion and future prospects}

The presented work is concerned with synthesis of $\mathrm{ZnO}, \mathrm{Co}_{3} \mathrm{O}_{4}$ and $\mathrm{BiZn}_{2} \mathrm{VO}_{6}$ based modified electrodes by the low-temperature wet chemical process and the effects of organic additives on structural, sensing and catalytic properties. Briefly, this research work can be divided into; (1) A potentiometric chemical sensors were used to determine the analytical concentration of dopamine, glucose and glutamate molecules in solution. $\mathrm{ZnO}$ and $\mathrm{Co}_{3} \mathrm{O}_{4}$ nanostructures have been involved in the chemical sensors based CMEs to detect dopamine and glucose molecules. The glutamate molecules have been investigated using $\mathrm{ZnO}$ based CMEs. (2) The $\mathrm{BiZn}_{2} \mathrm{VO}_{6}$ NCs based CMEs were used for visible lightdriven PEC activities.

Dopamine sensor was studied by the potentiometric method using pristine ZnO NRs based CMEs in paper I. In this research work the proposed sensor showed good linearity in a concentration range of $1 \times 10^{-6}$ and up to $1 \times 10^{-1} \mathrm{M}$. However, the concentration of dopamine in biological systems is in the range of $10^{-8}$ to $10^{-6} \mathrm{M}$. In paper II different surfactants (SDS, SDBS, NaPTS, and CTAB) have been used into the growth solution to be acted as the source of impurities and as habit-modifying additives that would yield a desired morphology of the $\mathrm{ZnO}$ nanostructured. The results showed that the surfactant was affecting both the morphology and the photoluminescence characteristics and can tailor the sensing properties. However, no surfactants dependence was observed to modify the crystallographic structure. The findings in this paper indicated the importance of the use of controlled nanostructures morphology for developing efficient functional materials. Furthermore, the effect of different concentrations of urea on the morphology of $\mathrm{Co}_{3} \mathrm{O}_{4}$ nanostructures based CMEs was investigated in paper III. The $\mathrm{Co}_{3} \mathrm{O}_{4}$ nanostructures exhibit morphology of flowers-like and have comprised on nanowires due to the increasing amount of urea. Accordingly, the presented glucose biosensor detected a wide range of glucose concentrations from $1 \times 10^{-6} \mathrm{M}$ to $1 \times 10^{-2} \mathrm{M}$ with a sensitivity of $56.85 \mathrm{mV} /$ decade and indicated a fast response time of less than $10 \mathrm{~s}$. This performance is attributed to the heterogeneous catalysis effect at glucose oxidase enzyme, nano-

flowers, and nanowires interfaces that have enhanced the electron transfer process on the electrode surface. An anionic surfactant, namely sodium dodecylbenzenesulfonate (SDBS), was used to achieve assisted growth procedure. After the successful growth of the 
SDBS-doped $\mathrm{Co}_{3} \mathrm{O}_{4}$ nanowires on $\mathrm{Au}$ coated glass substrates by the ACG method the same polymeric membrane for dopamine molecules used in paper IV. The results also showed that, the morphologies of the $\mathrm{Co}_{3} \mathrm{O}_{4}$ nanostructures were readily tunable by changing the concentration of SDBS as an additive in the growth solution. Furthermore, the proposed SDBS-doped $\mathrm{Co}_{3} \mathrm{O}_{4}$ CMEs based dopamine sensor showed a lower LOD and a wider range of detection ranging from $10^{-9} \mathrm{M}$ and up to $10^{-2} \mathrm{M}$ compared to that previously reported in paper I. Paper V focused on the use of PEG-doped ZnO NRs based modified electrodes to further increase the sensitivity towards Glutamine. PEG was used as the impurity that would yield a desired modulation into the electronic structures and preserving the $\mathrm{ZnO}$ NRs morphology. A slight increase in the carrier concentrations from $\sim 10^{19}$ for pristine ZnO NRs to $10^{20} \mathrm{~cm}^{-3}$ for the ZnO NRs formed with $0.1 \%$ (w/v) of PEG was extracted using the Mott-Schottky analysis at the ZnO NRs/electrolyte interface. Therefore, the enhancement of the sensing properties was attributed to the electro-catalytic properties that was triggered by the PEG addition to the growth procedure along with high surface area-to-volume ratio of the $\mathrm{ZnO} \mathrm{NRs}$.

In paper VI, we demonstrated that for the first time $\mathrm{BiZn}_{2} \mathrm{VO}_{6}$ nano-compounds (NCs) have been prepared by low temperature $\left(80-90{ }^{\circ} \mathrm{C}\right.$ ) by using $\mathrm{BiVO}_{4}$ growth on $\mathrm{ZnO}$ nanobelts (NBs). Then, the NCs were doped with polyethylene glycol (PEG) to tune the electronic structure of the materials. Furthermore, the photo-electrochemical activity of the prepared materials were investigated in $0.1 \mathrm{M}$ lithium perchlorate in carbonate propylene under a simulated solar irradiation (AM1.5G). The results showed that, $4 \mathrm{~h}$ is already a suitable growth time for the $\mathrm{BiZn}_{2} \mathrm{VO}_{6} \mathrm{NCs}$. The $\mathrm{BiZn}_{2} \mathrm{VO}_{6}$ nanostructures exhibit morphology of rice-like grown in $4 \mathrm{~h}$ lying at the top of vertically aligned ordered ZnO NBs. The photocurrent density of the PEG-doped $\mathrm{BiZn}_{2} \mathrm{VO}_{6} \mathrm{NCs}$ were substantially improved. The PEG-doped $\mathrm{BiZn}_{2} \mathrm{VO}_{6} \mathrm{NCs}$ reached a value of $2 \mathrm{~mA} \mathrm{~cm}^{-2}$ at $1.23 \mathrm{~V} \mathrm{vs} \mathrm{Ag} / \mathrm{AgCl}$ which corresponds to an improvement over $60 \%$ compared to pristine $\mathrm{BiZn}_{2} \mathrm{VO}_{6} \mathrm{NCs}$. These results indicate that, the PEG assists the photo-excited electrons and holes to overcome the energy barrier (e.g., the binding energy) and enhances the charge separation/migration processes of the $\mathrm{BiZn}_{2} \mathrm{VO}_{6} \mathrm{NCs}$ electrode. The improved charge collection efficiency of the electrode surface can be attributed to: (1) the heterogeneous catalysis effect at the $\mathrm{BiZn}_{2} \mathrm{VO}_{6} / \mathrm{ZnO}_{\mathrm{NBs}}$ interfaces that was enhanced. Which has led to an efficient electron communications processes at the electrode surface, and (2) the PEG 
impurities that act as shallow donors and enhance the n-type conductivity as it has been suggested in paper $\mathrm{V}$.

Due to the green chemistry aspect and the relatively low cost of the aqueous chemical growth (ACG) method, I plan to continue my research using the ACG approach reported in this thesis to synthesize further other mixed metal oxide nanostructures. I have already started a research project to utilize and avail the grown $\mathrm{BiZn}_{2} \mathrm{VO}_{6}$ for water splitting using sun visible radiation as cheap means to produce efficiently hydrogen as a clean energy source. 


\section{References}

1 N. Taniguchi, Proceedings of the international conference on production engineering, Tokyo, 1974, Part II. Japan Society of Precision Engineering.

2 K. E. Drexler, Engines of creation: The coming era of nanotechnology, Doubleday, 1986.

3 Nanotechnology research directions: IWGN workshop report: vision for nanotechnology in the next decade, Ed. by M. K. Roco, R. S. Williams and P. Alivisatos (Kluwer, Dordrecht, 2000).

4 R. P. Feynman, There's plenty of room at the bottom, Engineering and Science, 1960, $23,22$.

5 Nanoscience and nanotechnologies: opportunities and uncertainties, Royal Society and Royal Academy of Engineering. July 2004, Retrieved 13 May 2011.

6 G. Binnig and H. Rohrer, Scanning tunneling microscopy, IBM Journal of Research and Development, 1986, 30, 355.

7 Press Release: The 1986 Nobel Prize in Physics.

8 Adams, W Wade; Baughman, Ray H, Retrospective: Richard E. Smalley (1943-2005), Science, 2005, 310, 1916.

9 The Nobel Prize in Chemistry 1996.

10 Iijima, Sumio, Helical microtubules of graphitic carbon, Nature, 1991, 354, 56.

11 I. Freestone, N. Meeks, M. Sax and C. Higgitt, The Lycurgus cup- a roman nanotechnology, Gold Bull., 2007, 40, 270.

12 Zsigmondy, R. (1914). Colloids and the ultra-microscope, New York: J.Wiley and Sons. Retrieved 10 May 2011.

13 The Nobel Prize in Chemistry 1925.

14 Clark, L.C. Jr., Monitor and control of blood and tissue $\mathrm{O}_{2}$ tensions, Transactions American Society for Artificial Internal Organs, 1956, 2, 41.

15 Methods in biotechnology, Vol. 17: microbial enzymes and biotransformations, chapter 2, enzyme biosensors, by Steven J. Setford and Jeffrey D. Newman, Edited by: J. L. Barredo (C) Humana Press Inc., Totowa, NJ, 2005, ISBN: 978-1-58829-253-7.

16 Clark, L. C., Jr. and Lyons, C., Electrode system for continuous monitoring in cardiovascular surgery, Ann. NY Acad. Sci. 1962, 102, 29. 
17 A. Hulanicki, S. Glab and F. Ingman, Chemical sensors deffinitions and classification, Pure Appl. Cherm., 1991, 63, 1247.

18 J. Koryta, J. Davorak, and L. Kavan, Principles of electrochemistry. 2nd. England: John Willy \& Sons Ltd., 1993, 6.

19 An introduction to membrane science and technology by Heinrich Strathmann. Wiley-VCH, Weinheim, 2011, 524 E 75.00. ISBN 978- 3527324514

20 J. Janata, Principles of chemical sensors, New York : Plenum Press, 1989.

21 E. Bakker, P. Buhlmann, and E. Pretsch, Polymer membrane ion-selective electrodeswhat are the limits, Electroanalysis, 1999, 11, 915.

22 D. R. Thévenot, K. Toth, R. A. Durst and G. S. Wilson, Electrochemical biosensors: Recommended definitions and classification, Biosens Bioelectron, 2001, 16, 121.

23 N. J. Ronkainen, H. B. Halsall and W. R. Heineman, Electrochemical biosensors, Chem. Soc. Rev., 2010, 39, 1747.

24 W. H. Brattain and J. Bardeen, Surface properties of germanium, Bell Syst. Tech. J. 1952, 32, 1.

25 T. Seiyama, A. Kato, K. Fujiishi and M. Nagatani, A new detector for gaseous components using semiconductor thin film, A. Anal. Chem. 1962, 34, 1502.

26 P. J. Shaver, Activated tungsten oxide gas detectors, Appl. Phys. Lett., 1967, 11, 255.

27 G. G. Guilbault and J. G. Montalvo, A urea-specific enzyme electrode, J. Amer. Chem. Soc. 1969, 91, 2164.

28 R. F. Lane and A. T. Hubbard, Electrochemistry of chemisorbed molecules. I. Reactants connected to electrodes through olefinic substituents, J. Phys. Chem., 1973, $77,1401$.

29 P. R. Moses, L. Wier, and R. W. Murray, Chemically modified tin oxide electrode, Anal. Chem., 1975, 47, 882.

30 R. A. Durst, A. J. Bäumner, R. W. Murry, R. P. Buck and C. P. Andieux, chemically modified electrodes: recommended terminology and definitions, Pure Appl. Chem., $1997,69,1317$.

31 E. Lorenzo, F. Pariente, L. Hernandez, F. Tobalina, M. Darder, Q. WU, M. Maskus and H. D. Abrun, Analytical strategies for amperometric biosensors based on chemically modified electrodes, Biosens Bioelectron, 1998, 13, 319.

32 R. P. Baldwin, K. N. Thomsen, Chemically modified electrodes in liquid chromatography detection: A review, Talanta, 1991, 38, 1. 
33 Ana R. Guadalupe, Hector D. Abruna, Electroanalysis with chemically modified electrodes, Anal. Chem., 1985, 57, 142.

34 R. L, McCreery, The merger of electrochemistry and molecular electronics, Chem Rec. 2012, 12, 149.

35 J. M. Wang, X.W. Sun, and Z Jiao, Application of nanostructures in electrochromic materials and devices: recent progress, Materials, 2010, 3, 5029.

36 P. Bühlmann, H. Aoki, K. P. Xiao, S. Amemiya, K. Tohda, Y. Umezawa, Chemical sensing with chemically modified electrodes that mimic gating at biomembranes incorporating ion-channel receptors, Electroanalysis, 1998, 10, 1149.

37 G. Wang, Y. Ling, H. Wang, L. Xihong, Y. Li, Chemically modified nanostructures for photoelectrochemical water splitting, J. Photochem. Photobio. C: Photochem. Rev., $2014,19,35$.

38 P. W. Davies and F. Brink Jr, Microelectrodes for measuring local oxygen tension in animal tissues, Rev. Sci. Instrum., 1942, 13, 524.

39 M. Fibbioli, W. E. Morf, M. Badertscher, N. F. de Rooij and E. Pretsch, Potential drifts of solid contacted ion-selective electrodes due to zero-current ion fluxes through the sensor membrane, Electroanalysis, 2000, 12, 1286.

40 F. Seker, K. Meeker, T. F. Kuech and A. B. Ellis, Surface chemistry of prototypical bulk II-VI and III-V semiconductors and implications for chemical sensing, Chem. Rev., 2000, 100, 2505.

41 A. Mandelis, Physics, chemistry and technology of solid state gas sensor, New York: Joh Wiley \& Sons, cop., 1993. p. 7.

42 G. E. Brown Jr., V. Henrich, W. Casey, D. Clark, C. Eggleston, A. Felmy, D. W. Goodman, M. Grätzel, G. Maciel, M. I. McCarthy, K. H. Nealson, D. Sverjensky, M. F. Toney and J. M. Zachara, Metal oxide surfaces and their interactions with aqueous solutions and microbial organisms, Chem. Rev., 1999, 99, 77.

43 M. Willander, H. Alnoor, S. Elhag, Z. H. Ibupotob, E. S. Nour and O. Nur, Comparison between different metal oxide nanostructures and nanocomposites for sensing, energy generation and energy harvesting, Proc. SPIE 9749, Oxide-based Materials and Devices VII, 97491L (February 27, 2016).

44 N. Yamazoe, New approaches for improving semiconductor gas sensors, Sensor Actuat. B, 1991, 5, 7. 
45 Y. Cui, Q. Wei, H. Park and C. M. Lieber, Nanowire nanosensors for highly sensitive and selective detection of biological and chemical species, Science, 2001, 293, 1289.

46 C. M. Lieber, One-dimensional nanostructures: chemistry, physics and applications, Solid State Communications, 1998, 107, 607.

47 E. Comini and G. Sberveglieri, Metal oxide nanowires as chemical sensors, Materials today, 2010, 13, 36.

48 R. S. Wagner and W. C. Ellis, Vapor-liquid-solid mechanism of single crystal growth, Appl. Phys. Lett., 1964, 4, 89.

49 S. Diodati, P. Dolcet, M. Casarin and S. Gross, Pursuing the crystallization of monoand polymetallic nanosized crystalline inorganic compounds by low-temperature wet-chemistry and colloidal routes, Chem. Rev., 2015, 115, 11449.

50 L. Vayssieres, N. Beermann, S.-E. Lindquist and A. Hagfeldt, controlled aqueous chemical growth of oriented three-dimensional crystalline nanorod arrays application to iron(III) oxide, Chem. Mater., 2001, 13, 233.

51 S. Elhag, Z. H. Ibupoto, V. Khranovskyy, M. Willander and O. Nur, Habit-modifying additives and their morphological consequences on photoluminescence and glucose sensing properties of $\mathrm{ZnO}$ nanostructures, grown via aqueous chemical synthesis Vacuum, 2015, 116, 21.

52 V. E. Henrich, The surfaces of metal oxides, Rep. Prog. Phys., 1985, 48, 1481.

53 A. N. Mariano and R. E. Hanneman, Crystallographic polarity of ZnO crystals, J. App. Phy., 1963, 34, 384

54 A. Janotti and C. G. Van de Walle, Fundamentals of zinc oxide as a Semiconductor, Rep. Prog. Phys., 2009, 72, 126501.

55 B. G. Wang, E. W. Shi and W. Z. Zhong, Understanding and controlling the morphology of ZnO crystallites under hydrothermal conditions, Cryst. Res. Technol., 1997, 32, 659.

56 A. S. Prasad, Zinc: the biology and therapeutics of an ion, Anna. Inter. Medicine, 1996, 125, 142.

57 Z. Yang and C. Xie, $\mathrm{Zn}^{2+}$ release from zinc and zinc oxide particles in simulated uterine solution, Collo. Surf. B: Biointerf., 2006, 47, 140.

58 J. Zhou, N. Xu and Z. L. Wang, Dissolving behavior and stability of ZnO wires in biofluids: a study on biodegradability and biocompatibility of $\mathrm{ZnO}$ nanostructures, Adv. Mater., 2006, 18, 2432. 
59 C. Jacob, W. Maret and B. L. Vallee, Control of zinc transfer between thionein, metallothionein, and zinc proteins, Proc. Natl. Acad. Sci., 1998, 95, 3489.

60 D. S. Auld, Zinc coordination sphere in biochemical zinc sites, BioMetals, 2000, 14, 271.

61 P. Patnaik, Handbook of inorganic chemicals; The McGraw-Hill Companies: New York, NY, USA, 2003, p. 252.

62 M. Kudo, T. Kosaka, Y. Takahashi, H. Kokusen, N. Sotani and S. Hasegawa, Sensing functions to $\mathrm{NO}$ and $\mathrm{O}_{2}$ of $\mathrm{Nb}_{2} \mathrm{O}_{5}$ - or $\mathrm{Ta}_{2} \mathrm{O}_{5}$-loaded $\mathrm{TiO}_{2}$ and $\mathrm{ZnO}$, Sens. Actu. B, 2000, 69,10 .

63 N. Yamazoe, G. Sakai and K. Shimanoe, Oxide semiconductor gas sensors, Catalysis Surveys from Asia, 2003, 7,63.

64 G. Eranna, B. C. Joshi, D. P. Runthala and R. P. Gupta, Oxide materials for development of integrated gas sensors-a comprehensive review, Cri. Rev. Sol Stat. Mat. Sci., 2004, 29, 111.

65 P. E. Lippens and M. Lannoo, Optical properties of II-VI semiconductor nanocrystals, Semicond. Sci. Technol., 1991, 6, A157.

66 V. A. Fonoberov, K. A. Alim and A. A. Balandin, Photoluminescence investigation of the carrier recombination processes in $\mathrm{ZnO}$ quantum dots and nanocrystals, Phys. Rev. B, 2006, 73, 165317.

67 D. M. Bagnall, Y. F. Chen, Z. Zhu, T. Yao, S. Koyama, M. Y. Shen and T. Goto, Optically pumped lasing of ZnO at room temperature, Appl. Phys. Lett., 1997, 70, 28.

68 A. Degen and M. Kosec, Effect of $\mathrm{pH}$ and impurities on the surface charge of zinc oxide in aqueous solution, J. Eur. Cera. Soc., 2000, 20, 667.

69 E. Topoglidis, A. E.G. Cass, B. O'Regan and J. R. Durrant, Immobilisation and bioelectrochemistry of proteins on nanoporous $\mathrm{TiO}_{2}$ and $\mathrm{ZnO}$ films, J. Electroana. Chem., 2001, 517, 20.

70 F. Zhang, X. Wang, S. Ai, Z. Sun, Q. Wan, Z. Zhub, Y. Xian, L. Jin and K. Yamamoto, Immobilization of uricase on $\mathrm{ZnO}$ nanorods for a reagentless uric acid biosensor, Analytica Chimica Acta, 2004, 519, 155.

71 R. S. Devan, R. A. Patil, J.-H. Lin and Y.-R. Ma, One-dimensional metal-oxide nanostructures: recent developments in synthesis, characterization, and applications, Adv. Funct. Mater., 2012, 22, 3326. 
72 Z. L. Wang, Functional oxide nanobelts materials, properties and potential applications in nanosystems and biotechnology, Annu. Rev. Phys. Chem., 2004, 55,159 .

73 F. Meng, Z. Fang, Z. Li, W. Xu, M. Wang, Y. Liu, J. Zhang, W. Wang, D. Zhao and X. Guo, Porous $\mathrm{Co}_{3} \mathrm{O}_{4}$ materials prepared by solid-state thermolysis of a novel Co-MOF crystal and their superior energy storage performances for supercapacitors, $J$. Mater. Chem. A, 2013, 1, 7235.

74 J. Jansson, A. E. C. Palmqvist, E. Fridell, M. Skoglundh, L. Österlund, P. Thormählen and $\mathrm{V}$. Langer, On the catalytic activity of $\mathrm{Co}_{3} \mathrm{O}_{4}$ in low-temperature $\mathrm{CO}$ oxidation, J. Catal., 2002, 211, 387-397.

75 P. Monk, R. Mortimer, D. Rosseinsky, Electrochromism and electrochromic devices, Cambridge University Press: Cambridge, UK, 2007.

76 G. George, S. Anandhan, Tuning characteristics of $\mathrm{Co}_{3} \mathrm{O}_{4}$ nanofiber mats developed for electrochemical sensing of glucose and $\mathrm{H}_{2} \mathrm{O}_{2}$, Thin Solid Films, 2016, 610, 48.

77 N. Zhang, J. Shi, S. S. Mao and L. Guo, $\mathrm{Co}_{3} \mathrm{O}_{4}$ quantum dots: reverse micelle synthesis and visible-light-driven photocatalytic overall water splitting, Chem. Commun., 2014, 50, 2002.

78 Y. Feng, X. Zheng, Copper ion enhanced synthesis of nanostructured cobalt oxide catalyst for oxidation of methane, ChemCatChem, 2012, 4, 1551.

79 P. S. Patil, L. D. Kadam, C. D. Lokhande, Preparation and characterization of spray pyrolysed cobalt oxide thin films, Thin Solid Films, 1996, 272, 29.

80 W. L. Roth, The magnetic structure of $\mathrm{Co}_{3} \mathrm{O}_{4}$, J. Phys. Chem. Solids, 1964, 25, 1-10.

81 J. Chen and A. Selloni, Electronic states and magnetic structure at the $\mathrm{Co}_{3} \mathrm{O}_{4}(110)$ surface: A first-principles study, Phys. Rev. B, 2012, 85, 085306.

82 C. S. Chua, D. Ansovini, C. J. Jun Lee,Y. T. Teng, L. T. Ong, D. Chi, T. S. A. Hor, R. Raja and Y.-F. Lim, The effect of crystallinity on photocatalytic performance of $\mathrm{Co}_{3} \mathrm{O}_{4}$ water-splitting cocatalysts, Phys.Chem.Chem.Phys., 2016, 18, 5172.

83 S. Kittaka and T. Morimoto, Isoelectric point of metal oxides and binary metal oxides having spinel structure. J. Colloid Interface, 1980, 75, 398.

$84 \mathrm{H}$. Liu, R. Nakamura and Y. Nakato, Bismuth-copper vanadate $\mathrm{BiCu}_{2} \mathrm{VO}_{6}$ as a novel photocatalyst for efficient visible-light-driven oxygen evolution, ChemPhysChem $2005,6,2499$. 
85 Liu, R. Nakamura and Y. Nakato, A visible-light responsive photocatalyst, $\mathrm{BiZn}_{2} \mathrm{VO}_{6}$, for efficient oxygen photoevolution from aqueous particulate suspensions, Electrochem Solid-State Lett. 2006, 9, G187.

86 Z. Ding, Y. Fu, Z. Xie, Z. Li, A polymeric complex method to nanocrystalline $\mathrm{BiCu}_{2} \mathrm{VO}_{6}$ with visible light photocatalytic activity, Materials Letters, 2011, 65, 460.

87 S. E. Nunes, C.-H. Wang, K. So, J. S.O. Evans and I. R. Evans, Bismuth zinc vanadate, BiZn2VO6: New crystal structure type and electronic structure, J. Solid St. Chem., 2015, 222, 12.

88 J. Xu, Z. Chen, J. A. Zapien, C.-S. Lee and W. Zhang, Surface engineering of ZnO nanostructures for semiconductor-sensitized solar cells, Adv. Mater., 2014, 26, 5337.

89 Z-F. Huang, L. Pan, J.-J. Zou, X. Zhang and L. Wang, Nanostructured bismuth vanadate-based materials for solar-energy-driven water oxidation: a review on recent progress, Nanoscale, 2014, 6, 14044.

90 M. J. Rosen, Surfactants and interfacial phenomena, 3rd. Ed., John Wiley \& Sons, Inc. 2004.

91 M. P. Pileni, Reverse micelles as microreactors, J. Phys. Chem., 1993, 97, 6961.

92 A. I. Inamdar, S. H. Mujawar, V. Ganesan and P. S. Patil, Surfactant-mediated growth of nanostructured zinc oxide thin films via electrodeposition and their photoelectrochemical performance, Nanotechnology, 2008, 19, 325706.

93 X.-G. Wang, Q.-S. Wu, W.-Z. Liu and Y.-P. Ding, Simultaneous determination of dinitrophenol isomers with electrochemical method enhanced by surfactant and their mechanisms research, Electrochimica Acta, 2006, 52, 589.

94 Tian, W. Li, K. Pan, Q. Zhang, G. Tian, W. Zhou and H. Fu, One pot synthesis of Ag nanoparticle modified $\mathrm{ZnO}$ microspheres in ethylene glycol medium and their enhanced photocatalytic performance, Journal of Solid State Chemistry, 2010, 183, 2720.

95 L. A. Ghule, B. S. Shirke, K. B. Sapnar, S. D. Dhole, P. P. Hankare and K. M. Garadkar, Preparation of zinc oxide nanorods by microwave assisted technique using ethylene glycol as a stabilizing agent, J Mater Sci: Mater Electron, 2011, 22, 1120.

96 T. Long, X. Dong, X. Liu, J. Liu, S. Yin and T. Sato, Synthesis of ZnO crystals with unique morphologies by a low-temperature solvothermal process and their photocatalytic deNOx properties, Res. Chem. Intermed., 2010, 36, 61. 
97 H. Teterycz, O. Rac, P. S.-Wozniak and D. Oles, The formation mechanism of colloidal spheres of ZnO in ethylene glycol, Digest Journal of Nanomaterials and Biostructures, $2013,8,1157$.

98 Z. H. Ibupoto, K. Khun, J. Lu and M. Willander, The synthesis of CuO nanoleaves, structural characterization, and their glucose sensing application, Appl. Phys. Lett., 2013, 102, 103701.

99 K. Khun, Z.H. Ibupoto, X. Liu, V. Beni and M. Willander, The ethylene glycol template assisted hydrothermal synthesis of $\mathrm{Co}_{3} \mathrm{O}_{4}$ nanowires; structural characterization and their application as glucose non-enzymatic sensor, Materials Science and Engineering B, 2015, 194, 94.

100 S. Rebsdat, D. Mayer, Ethylene glycol, Ullmann's encyclopedia of industrial chemistry, Weinheim: Wiley-VCH, (2005), doi:10.1002/14356007.a10_101.

101 J. Zhang, Z. PengYan Zhang, M. Kai, H. Fang, C. GuoHua and W. XiongHui, Hydrogen bonding interactions between ethylene glycol and water: density, excess molar volume, and spectral study, Sci China Ser B-Chem, 2008, 51, 420.

102 S. Elhag, Z. H. Ibupoto, O. Nur and M. Willander, Incorporating beta-cyclodextrin with $\mathrm{ZnO}$ nanorods: A potentiometric strategy for selectivity and detection of dopamine, Sensors, 2014, 14, 1654.

103 S. Elhag, Z. H. Ibupoto, X. Liu, O. Nur and M. Willander, Dopamine wide range detection sensor based on modified Co304 nanowires electrode, Sensors and Actuators B, 2014, 203, 543.

104 Z. H. Ibupoto, S. Elhag, O. Nur and M. Willander, Effect of urea on the morphology of $\mathrm{Co}_{3} \mathrm{O}_{4}$ nanostructures and their application for potentiometric glucose biosensor, Electroanalysis, 2014, 26, 1773.

105 S. Elhag, K. Khun, V. Khranovskyy, X. Liu, M. Willander and O. Nur, Efficient donor impurities in $\mathrm{ZnO}$ nanorods by polyethylene glycol for enhanced optical and glutamate sensing properties, Sensors 2016, 16, 222.

106 S. Elhag, D. Tordera, T. Deydier, J. Lu, X. Liu, V. Khranovskyy, L. Hultman, M. Willander, M. P. Jonsson and O. Nur, Low-temperature growth of polyethylene glycol-doped $\mathrm{BiZn}_{2} \mathrm{VO}_{6}$ nanocompounds with enhanced photoelectrochemical properties, $J$. Mater. Chem. A, 2017, 5, 1112. 
107 U. Koch, A. Fojtik, H. Weller and A. Henglein, Photochemistry of semiconductor colloids. Preparation of extremely small $\mathrm{ZnO}$ particles, fluorescence phenomena and size quantization effects, Chem. Phys. Lett., 1985, 122, 507.

108 A. Zainelabdin, S. Zaman, G. Amin, O. Nur and M. Willander, Deposition of wellaligned $\mathrm{ZnO}$ nanorods at $50{ }^{\circ} \mathrm{C}$ on metal, semiconducting polymer, and copper oxides substrates and their structural and optical properties, Cryst. Growth Des., 2010, 10, 3250 .

109 C. Pacholski, A. Kornowski and H. Weller, Self-assembly of ZnO: from nanodots to nanorods, Angewandte Chemie International Edition, 2002, 41, 1188.

110 L. Vayssieres, K. Keis, S-E. Lindquist and A Hagfeldt, Purpose-built anisotropic metal oxide material: 3D highly oriented microrod array of ZnO, J. Phys. Chem., B 2001105 3350.

111 B. Postels, H-H. Wehmann, A. Bakin, M. Kreye, D. Fuhrmann, J. Blaesing, A. Hangleiter, A. Krost, and A. Waag, Controlled low-temperature fabrication of ZnO nanopillars with a wet-chemical approach, Nanotechnology, 200718195602.

112 S. Elhag, Z. H. Ibupoto, O. Nur and M. Willander, Synthesis of $\mathrm{Co}_{3} \mathrm{O}_{4}$ cotton-like nanostructures for cholesterol biosensor, Materials, 2015, 8, 149.

113 L. Zhou, W. Wang and H. Xu, Controllable synthesis of three-dimensional welldefined $\mathrm{BiVO}_{4}$ mesocrystals via a facile additive-free aqueous strategy, Cryst. Growth Des., $2008,8,728$.

114 A. Carlsson, The occurrence, distribution and physiological role of catecholamines in the nervous system, Pharmacol. Rev., 1959, 11, 490.

115 K. Jackowska and P. Krysinski, New trends in the electrochemical sensing of dopamine, Anal. Bioanal. Chem., 2013, 405, 3753.

116 J. L. F. C. Lima and M. C. B. S. M. Montenegro, Dopamine ion-selective electrode for potentiometry in pharmaceutical preparations, Mikrochim. Acta, 1999, 131, 187.

117 S. Jinap and P. Hajeb, Glutamate. Its applications in food and contribution to health, Appetite, 2010, 55, 1.

118 Q. R. Smith, Transport of glutamate and other amino acids at the blood-brain barrier, J. Nutr., 2000, 130, 1016S.

119 S. Qin, M. Zeyden, W. H. Oldenziel, T. I. F. H. Cremers and B. H. C. Westerink, Microsensors for in vivo measurement of glutamate in brain tissue. Sensors, 2008, 8, 6860. 
120 S. Yao, D. Liu, K. Ge, K. Chent and L. Nie, A novel glutamine biosensor system based on a conductance-surface acoustic wave frequency response, Enzyme Microb. Technol., 1995, 17, 413.

121 V. K. Pecharsky and P. Y. Zavalij, Fundamentals of powder diffraction and structural characterization of materials, 2009, Springer US, DOI:10.1007/978-0-387-09579-0.

122 Joint committee for powder diffraction standards.

123 http://serc.carleton.edu/research_education/geochemsheets/electroninteractions .html

124 J. Tauc, R. Grigorovici, and A. Vancu, Optical properties and electronic structure of germanium, Phys. Stat. Sol. 1966, 15, 627.

125 L. Fu, Z. Liu, Y. Liu, B. Han, P. Hu, L. Cao and D. Zhu, Beaded cobalt oxide nanoparticles along carbon nanotubes towards more highly integrated electronic devices, $A d v$. Mater., 2005, 17, 217.

126 H. Xia, D. Zhu, Z. Luo, Y. Yu, X. Shi, G. Yuan and J. Xie, Hierarchically structured $\mathrm{Co}_{3} \mathrm{O}_{4}$ $\mathrm{Pt} \mathrm{MnO}_{2}$ nanowire arrays for high-performance supercapacitors, Sci. Rep., 2013, 3, 2978.

127 M. C. Biesingera, B. P. Paynec, A. P. Grosvenord, L. W.M. Laua, A. R. Gerson and R. St. C. Smart, Resolving surface chemical states in XPS analysis of first row transition metals, oxides and hydroxides: Cr, Mn, Fe, Co and Ni, Appl. Sur. Sci., 2001, 257, 2717.

128 W. Huang, P. Jiang C. Wei, D. Zhuang and J. Shi, Low-temperature one-step synthesis of covalently chelated $\mathrm{ZnO} /$ dopamine hybrid nanoparticles and their optical properties, J. Mater. Res., 2008, 23, 1946.

129 S.-M. Lee, S.-N. Cho and J. Cheon, Anisotropic shape control of colloidal inorganic nanocrystals, Advanced Materials, 2003, 15, 441.

130 M. J. Siegfried and K.-S. Choi, Electrochemical crystallization of cuprous oxide with systematic shape evolution, Adv. Materials, 2004; 16: 1743.

131 D. Beneventi, B. Carre and A. Gandini, Role of surfactant structure on surface and foaming Properties, Colloids and Surfaces A: Physicochemical and Engineering Aspects, 2001, 189, 65.

132 X. M. Sun, X. Chen, Z. X. Deng and Y. D. Li, A CTAB-assisted hydrothermal orientation growth of ZnO nanorods, Materials Chemistry and Physics, 2002, 78, 99.

133 R. Wahab, S. G. Ansari, Y. S. Kim, M. Song, H.-S. Shin, The role of pH variation on the growth of zinc oxide nanostructures, Applied Surface Science, 2009, 255, 4891. 
134 A. V. Delgado, Interfacial electrokinetics and electrophoresos, surfactant science series volume, 1062002 Marcel Dekker, Inc. page. 8.

135 V. E. Henrich, Metal-oxide surfaces, Prog. Sur. Sci., 1995, 50, 77.

136 F. Gu, C. Li, Y. Hu and L. Zhang, Synthesis and optical characterization of $\mathrm{Co}_{3} \mathrm{O}_{4}$ nanocrystals, Journal of Crystal Growth, 2007, 304, 369.

137 Y. Wang and N. Herron, Nanometer-sized semiconductor clusters materials synthesis, quantum size effects, and photophysical properties, J. Phys. Chem., 1991, 95, 525 .

138 B. Shouli, C. Liangyuan, L. Dianqin, Y. Wensheng, Y. Pengcheng, L. Zhiyong, C. Aifan and C. C. Liu, Different morphologies of ZnO nanorods and their sensing property, Sens. Actuators B Chem, 2010, 146, 129.

139 O. Lupan, L. Chow, L. K. Ono, B. R. Cuenya, G. Chai, H. Khallaf, S. Park and A. Schulte, Synthesis and characterization of Ag- or Sb-doped $\mathrm{ZnO}$ nanorods by a facile hydrothermal route, J. Phys. Chem. C, 2010, 114, 12401.

140 P. Rai, Y.-S. Kim, H.-M. Song, M.-K. Song, Y.-T. Yu, The role of gold catalyst on the sensing behavior of $\mathrm{ZnO}$ nanorods for $\mathrm{CO}$ and $\mathrm{NO}_{2}$ gases, Sens. Actuators B Chem., 2012, 165, 133.

141 S. Limpijumnong and S. B. Zhang, Resolving hydrogen binding sites by pressure-A first-principles prediction for ZnO. App. Phys. Lett., 2005, 86, 151910.

142 E. V. Lavrov and J. Weber, Effect of uniaxial stress on vibrational modes of hydrogen in ZnO, Phys. Rev. B, 2006, 73, 035208.

143 E. V. Lavrov, F. Börrnert and J. Weber, Photoconductivity and infrared absorption study of hydrogen-related shallow donors in ZnO, Phys. Rev. B 2005, 73, 085212.

144 A. B. Djurisic and Y. H. Leung, Optical properties of ZnO nanostructures, Small, 2006, 2,944 .

145 C. Tsiarapas, D. Girginoudi and N. Georgoulas, Effect of hydrogen on ZnO films and $\mathrm{Au} / Z n O$ schottky contacts. Semicond. Sci. Technol. 2014, 29, 045012.

146 Z. Y. Xia, P. G. Han, J. Xu, D. Y. Chen, D. Y. Wei, Z. Y. Ma, K. J. Chen, L. Xu and X. F. Huang, Hydrogen passivation effect on enhanced luminescence from nanocrystalline Si/SiO 2 multilayers. Chin. Phys. Lett. 2007, 24, 2657.

147 S. Park, Y. Mun, S. An, W. I. Lee and C. Lee, Enhanced photoluminescence of Aufunctionalized ZnO nanorods annealed in a hydrogen atmosphere. J. Lumin., 2014, 147,5 . 
148 I. Lorite, J. Wasik, T. Michalsky, R. Schmidt-Grund and P. Esquinazi, Hydrogen influence on the electrical and optical properties of $\mathrm{ZnO}$ thin films grown under different atmospheres. Thin Solid Films, 2014, 556, 18.

149 C.-W. Chen, K.-H. Chen, C.-H. Shen, A. Ganguly, L.-C. Chen, J.-J. Wu, H.-I. Wen and W.F. Pong, Anomalous blue shift in emission spectra of $\mathrm{ZnO}$ nanorods with sizes beyond quantum confinement regime. Appl. Phys. Lett., 2006, 88, 241905.

150 C. G. Van de Walle, Hydrogen as a cause of doping in zinc oxide. Phys. Rev. Lett. 2000, 85, 1012.

151 K. Rajeshwar, Encyclopedia of Electrochemistry: Semiconductor Electrodes and Photoelectrochemistry; Licht, S., Ed.; Wiley-VCH: Weinheim, Germany, 2002; Ch. 1.

152 U. V. Desnica, Doping limits in II-Vl compounds-challenges, problems and solutions. Prog. Cryst. Growth Charact., 1998, 36, 291.

153 H. Talke and G. E. Schubert, Enzymatic urea determination in the blood and serum in the Warburg optical test. Klinische Wochenschrift, 1965, 43, 174.

154 S. Wachiratianchai, A. Bhumiratana and S. Udomsopagit, Isolation, purification, and characterization of L-glutamate oxidase from streptomyces sp. 18G. Elec. J. Biotec., 2004, 7, 277.

155 Y. Murakami, M. Ikarashi, M. Hashizume, A. Y. Nosaka and Y. Nosaka, Laser ablation of the photocatalytic $\mathrm{BiVO}_{4}$ and $\mathrm{BiZn}_{2} \mathrm{VO}_{6}$ powders in water and their photocurrent properties, Electrochem. Solid-State Lett., 2008, 11, H42.

156 S. Tokunaga, H. Kato and A. Kudo, Selective preparation of monoclinic and tetragonal $\mathrm{BiVO}_{4}$ with scheelite structure and their photocatalytic properties, Chem. Mater., $2001,13,4624$.

157 J. K. Cooper, S. Gul, F. M. Toma, L. Chen, P.-A. Glans, J. Guo, J. W. Ager, J. Yano and I. D. Sharp, Electronic Structure of Monoclinic BiVO 4 Chem. Mater., 2014, 26, 5365

158 P. Yang, J. Zhao, L. Zhang, L. Li, and Z. Zhu, Intramolecular hydrogen bonds quench photoluminescence and enhance photocatalytic activity of carbon nanodots Chem. Eur. J., 2015, 21, 8561.

159 S. J. A. Moniz, J. Zhu and J. Tang, 1D Co-Pi Modifi ed BiVO $4 / Z n O$ Junction Cascade for Effi cient Photoelectrochemical Water Cleavage, Adv. Energy Mater., 2014, 4, 1301590. 
160 L. Chen, F. M. Toma, J. K. Cooper, A. Lyon, Y. Lin, I. D. Sharp and J. W. Ager, Mo-doped $\mathrm{BiVO}_{4}$ photoanodes synthesized by reactive sputtering, ChemSusChem, 2015, 8, 1066.

161 O. Zandi, B. M. Klahr and T. W. Hamann, Highly photoactive Ti-doped a-Fe ${ }_{2} \mathrm{O}_{3}$ thin film electrodes: resurrection of the dead layer, Energy Environ. Sci., 2013, 6, 634.

162 L. Zhang, E. Reisner and J. J. Baumberg, Al-doped ZnO inverse opal networks as efficient electron collectors in $\mathrm{BiVO}_{4}$ photoanodes for solar, Energy Environ. Sci., $2014,7,1402$. 


\section{Papers}

The articles associated with this thesis have been removed for copyright reasons. For more details about these see:

http://urn.kb.se/resolve? urn:nbn:se:liu:diva-134275 